Selecionando candidatos a descritores para agrupamentos hierárquicos de documentos utilizando regras de associação 



\section{Selecionando candidatos a descritores para agrupamentos hierárquicos de documentos utilizando regras de associação}

Fabiano Fernandes dos Santos

Orientadora: Prof ${ }^{a} D r^{a}$ Solange Oliveira Rezende

Dissertação apresentada ao Instituto de Ciências Matemáticas e de Computação - ICMC-USP, como parte dos requisitos para obtenção do título de Mestre em Ciências - Ciências de Computação e Matemática Computacional

USP - São Carlos

Agosto/2010 



\section{Agradecimentos}

Aos meus pais, Vera e Agnaldo, pelo apoio e compreensão nessa jornada tão difícil que é criar um filho para o mundo.

À Rafaela, minha namorada, pelo carinho e atenção mesmo nos momentos mais conturbados deste trabalho.

Aos amigos do LABIC pelas horas de boas risadas e discussões.

Aos "irmãos de orientação" que tornaram possível a realização deste trabalho.

À Veronica, cujas contribuições foram fundamentais para os rumos deste trabalho.

À minha orientadora, Solange, que não desistiu de mim mesmo quando nem mesmo eu acreditava que terminaria este trabalho.

À todos os amigos que direta ou indiretamente contribuíram para a minha formação pessoal e profissional.

À CAPES pelo auxílio financeiro. 



\section{Resumo}

Uma forma de extrair e organizar o conhecimento, que tem recebido muita atenção nos últimos anos, é por meio de uma representação estrutural dividida por tópicos hierarquicamente relacionados. Uma vez construída a estrutura hierárquica, é necessário encontrar descritores para cada um dos grupos obtidos pois a interpretação destes grupos é uma tarefa complexa para o usuário, já que normalmente os algoritmos não apresentam descrições conceituais simples. Os métodos encontrados na literatura consideram cada documento como uma bag-of-words e não exploram explicitamente o relacionamento existente entre os termos dos documento do grupo. No entanto, essas relações podem trazer informações importantes para a decisão dos termos que devem ser escolhidos como descritores dos nós, e poderiam ser representadas por regras de associação. Assim, o objetivo deste trabalho é avaliar a utilização de regras de associação para apoiar a identificação de descritores para agrupamentos hierárquicos. Para isto, foi proposto o método SeCLAR (Selecting Candidate Labels using Association Rules), que explora o uso de regras de associação para a seleção de descritores para agrupamentos hierárquicos de documentos. Este método gera regras de associação baseadas em transações construídas à partir de cada documento da coleção, e utiliza a informação de relacionamento existente entre os grupos do agrupamento hierárquico para selecionar candidatos a descritores. Os resultados da avaliação experimental indicam que é possível obter uma melhora significativa com relação a precisão e a cobertura dos métodos tradicionais. 



\section{Abstract}

One way to organize knowledge, that has received much attention in recent years, is to create a structural representation divided by hierarchically related topics. Once this structure is built, it is necessary to find labels for each of the obtained clusters, since most algorithms do not produce simple descriptions and the interpretation of these clusters is a difficult task for users. The related works consider each document as a bag-of-words and do not explore explicitly the relationship between the terms of the documents. However, these relationships can provide important information to the decision of the terms that must be chosen as descriptors of the nodes, and could be represented by rass. This works aims to evaluate the use of association rules to support the identification of labels for hierarchical document clusters. Thus, this paper presents the SeCLAR (Selecting Candidate Labels using Association Rules) method, which explores the use of association rules for the selection of good candidates for labels of hierarchical clusters of documents. This method generates association rules based on transactions built from each document in the collection, and uses the information relationship between the nodes of hierarchical clustering to select candidates for labels. The experimental results show that it is possible to obtain a significant improvement with respect to precision and recall of traditional methods. 



\section{Sumário}

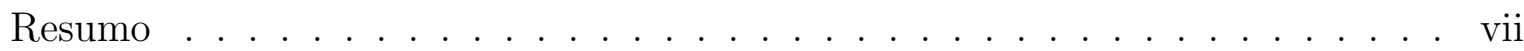

Abstract ....................... ix

Sumário . . . . . . . . . . . . . . . . . . . xii

Lista de Figuras . . . . . . . . . . . . . . . . . . . . . . . . . . xiii

Lista de Tabelas . . . . . . . . . . . . . . . . . . . . . . xv

Lista de Algoritmos . . . . . . . . . . . . . . . . . . . . . . . xvii

1 Introdução 1

2 Mineração de Textos e Regras de Associação 5

2.1 Considerações Iniciais . . . . . . . . . . . . . . . . . . . . . . . . 5

2.2 Mineração de Textos . . . . . . . . . . . . . . . . . . . 5

2.2 .1 Identificação do Problema . . . . . . . . . . . . . . 6

2.2 .2 Pré-processamento . . . . . . . . . . . . . . . 7

2.2 .3 Extração de padrões . . . . . . . . . . . . . . . . . . 9

2.2.4 Pós-processamento . . . . . . . . . . . . . . . . . . 10

2.2.5 Utilização do Conhecimento . . . . . . . . . . . . . . . . . . . . 10

2.3 Regras de Associação . . . . . . . . . . . . . . . . . . . . . . . . . . . 10

2.3.1 Definições e Conceitos . . . . . . . . . . . . . . . 11

2.3.2 Geração de Regras de Associação . . . . . . . . . . . . . . . . . . . 14

2.4 Considerações finais . . . . . . . . . . . . . . . . . . . 17

3 Agrupamento Hierárquico de Documentos $\quad 19$

3.1 Considerações Iniciais . . . . . . . . . . . . . . . . . . . . . . . . . . . . . . 19

3.2 Medidas de proximidade . . . . . . . . . . . . . . . . . . . . . . . 19

3.3 Métodos de Agrupamento . . . . . . . . . . . . . . . . . . 21

3.3.1 Métodos Particionais . . . . . . . . . . . . . . . 21

3.3.2 Métodos Hierárquicos . . . . . . . . . . . . . . . 22

3.4 Considerações finais . . . . . . . . . . . . . . . . . . . 25

4 Seleção de Candidatos a Descritores para Agrupamentos Hierárquicos 27

4.1 Considerações iniciais . . . . . . . . . . . . . . . . . . 27 
4.2 Abordagens para seleção de descritores para agrupamento hierárquico de documentos . . . . . . . . . . . . . . . . . . . . . 28

4.3 Seleção de candidatos a descritores . . . . . . . . . . . . . . . . . . 32

4.4 Método SeCLAR . . . . . . . . . . . . . . . . . . . 34

4.4.1 Gerar as regras de associação para cada nó . . . . . . . . . . . 36

4.4.2 Selecionar os candidatos a descritores . . . . . . . . . . . . . . 38

4.4.3 Remover os nós da hierarquia que ficaram sem descritores . . . . . 39

4.5 Avaliação Experimental . . . . . . . . . . . . . . . . . . . . . . . 39

4.5.1 Critério de avaliação . . . . . . . . . . . . . . . . . 40

4.5.2 Pré-processamento e obtenção das hierarquias . . . . . . . . . . . . 41

4.5.3 Avaliação dos parâmetros do SeCLAR . . . . . . . . . . . . . . . . 42

4.5.4 Avaliação do uso do SeCLAR combinado com os métodos tradicionais 45

4.6 Considerações finais . . . . . . . . . . . . . . . . . . . . . . . . 50

5 Conclusões $\quad 53$

$\begin{array}{ll}\text { Referências } & 61\end{array}$ 


\section{Lista de Figuras}

2.1 Etapas do processo de Mineração de Textos. Fonte: Rezende et al. (2003) . 6

3.1 Análise da Estrutura do Dendrograma. Fonte: Metz (2006) . . . . . . . . . 25

4.1 Processo de seleção candidatos a descritores. . . . . . . . . . . . . . . . . . . . 29

4.2 Processo de seleção candidatos a descritores utilizando o SeCLAR. . . . . . 33

4.3 Exemplo de relação pai-filho $(r)$ processada como uma relação de regra de associação . . . . . . . . . . . . . . . . . . . . . 34

4.4 Etapas da metodologia para seleção de candidatos a descritores utilizando o SeCLAR. . . . . . . . . . . . . . . . . 35

4.5 Exemplo de execução do método Gerar-Regras-Associação. . . . . . . . . . 37

4.6 Visão geral do desenho experimental utilizado neste projeto. . . . . . . . . . 42

4.7 Desenho experimental para a avaliação dos parâmetros do SeCLAR. . . . . 43

4.8 Desenho experimental para a avaliação do método SeCLAR combinado com os métodos de seleção de descritores da literatura. . . . . . . . . . . . . . . 45

4.9 Exemplo do resultado obtido pelo processo de seleção de descritores para a base Biophysics. . . . . . . . . . . . . . . . . . . . . . . . . . . . . . . . . 47

4.10 Exemplo do resultado obtido pelo processo de seleção de descritores para a base Quantum Physics. . . . . . . . . . . . . . . . . . 48 



\section{Lista de Tabelas}

2.1 Padrão de matriz documento termo . . . . . . . . . . . . . . . . . 8

4.1 Visão geral dos métodos de seleção de descritores. . . . . . . . . . . . . . . . 32

4.2 Número de recuperações para cada nó . . . . . . . . . . . . . . . . . . . . 40

4.3 Número de documentos e atributos das bases de textos utilizadas. . . . . . 42

4.4 Valores utilizados para os parâmetros do método proposto. . . . . . . . . . 43

4.5 Melhores médias obtidas para a medida precisão. . . . . . . . . . . . . . . 44

4.6 Melhores médias obtidas para a medida revocação. . . . . . . . . . . . . . 44

4.7 Melhores configurações dos parâmetros de acordo com a medida Precisão. . 45

4.8 Melhores configurações dos parâmetros de acordo com a medida Revocação. 45

4.9 Valores dos parâmetros do método SeCLAR utilizados nesta avaliação. . 46

4.10 Resultados obtidos do uso combinado do método de seleção de descritores e o SeCLAR com configuração igual para as bases . . . . . . . . . . . . . . 46

4.11 Resultados obtidos do uso combinado do método de seleção de descritores e o SeCLAR com configuração igual para as bases (versão detalhada). . . . 49

4.12 Resultados obtidos do uso combinado do método de seleção de descritores e o SeCLAR com configuração otimizada para cada bases . . . . . . . . . . 50

4.13 Resultados obtidos do uso combinado do método de seleção de descritores e o SeCLAR com configuração otimizada para cada bases (versão detalhada). 51 



\section{Lista de Algoritmos}

1 Apriori. Fonte: (Agrawal e Srikant, 1994) . . . . . . . . . . . . . . 15

2 Função apriori-gen. Fonte: (Agrawal e Srikant, 1994) . . . . . . . . . . . 15

3 Gera Regras de Associação. Fonte: (Agrawal e Srikant, 1994) . . . . . . . . 16

$4 \quad$ SeCLAR . . . . . . . . . . . . . . . . . 36

5 Método Gerar-Regras-Associação . . . . . . . . . . . . . . . . . . 37

6 Método selecionar-descritores-candidatos . . . . . . . . . . . . . . . 38

7 Método remover-nós . . . . . . . . . . . . . . . . . . . 39 



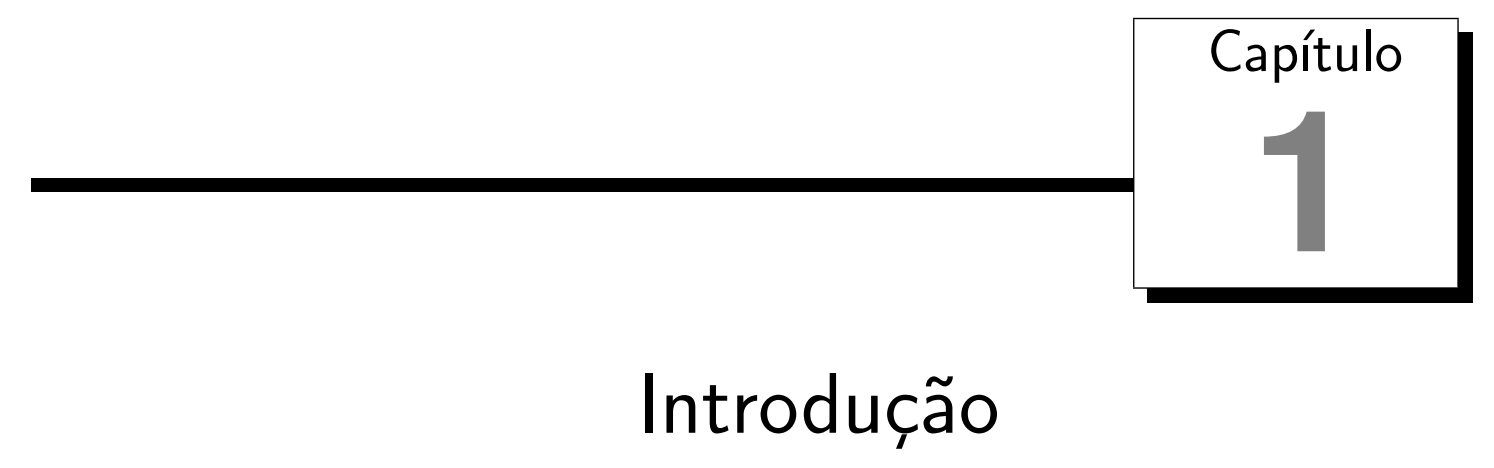

A quantidade de informação disponível em formato digital na rede mundial de computadores tem aumentado incessantemente. De acordo com estimativas realizadas em 2009, somente em 2008 foram adicionado ao universo digital 487 bilhões de gigabytes. A previsão para 2012 é que haverá 5 vezes a quantidades de bits no universo digital em relação a 2008 (Gantz e Reinsel, 2009). Embora seja lógico pressupor que grande parte desses dados não são armazenados, o grande aumento na sua geração sugere que as pessoas estejam armazenando mais dados e informações (Gantz et al., 2007, 2008).

Além disso, estudos ${ }^{1}$ indicam que $80 \%$ da informação das corporações no mundo é representada por dados não estruturados, em que uma parte significativa são documentos textuais. Muitos desses documentos são armazenados em meio eletrônico e lançados diariamente na $W e b$, formando grandes coleções de dados, como relatórios, especificações de produtos, resumos, notas, correspondência eletrônica e toda variedade de publicações eletrônicas textuais - bibliotecas virtuais e acervos documentais variados (Han e Kamber, 2001). Utilizar esses dados de forma inteligente é de grande interesse para as corporações, pois o conhecimento implícito nos textos pode ser valioso para a compreensão de algum processo ou para a obtenção de vantagem competitiva. No entanto, o espantoso volume de dados e informações é tal que extrapola a capacidade humana de, manualmente, analisá-lo e comprendê-lo por completo.

Nesse contexto, as técnicas de mineração de textos vêm auxiliar a transformação desse grande volume de dados não estruturados em conhecimento útil, muitas vezes inovador para as empresas. Assim, com o uso da mineração de textos é possível transformar o conteúdo de coleções textuais em informação e conhecimento a ser analisado e compartilhado pela organização. O futuro aproveitamento desse conhecimento gerado pode se dar em várias aplicações, desde a simples organização e recuperação de informação até sistemas mais complexos de apoio à decisão.

Uma forma de extrair e organizar o conhecimento, que tem recebido muita atenção

\footnotetext{
${ }^{1}$ http://www.delphigroup.com/
} 
nos últimos anos, é por meio de uma representação estrutural dividida por tópicos hierarquicamente relacionados (Moura e Rezende, 2010). Nessa estrutura, o conhecimento mais geral da coleção se encontra nos tópicos de níveis mais altos da hierarquia enquanto o conhecimento mais específico se encontra nos níveis mais baixos. Assim, é possível realizar busca exploratória em diversos níveis de granularidade, localizando a informação de interesse de maneira mais rápida e intuitiva. Ainda, satisfaz à premissa de que se um usuário está interessado em um documento específico pertencente a um tópico pode também estar interessado em outros documentos desse tópico e de seus subtópicos.

A construção de tópicos hierarquicamente relacionados pode ser realizada de forma automática aplicando-se algoritmos de agrupamento hierárquicos ou pode ser construída e mantida por especialistas de domínio, como nos casos dos diretórios online do Yahoo! ou o Open Directory Project (Treeratpituk e Callan, 2006). Uma vez obtida esta estrutura, é importante encontrar descritores para auxiliar a compreensão dos grupos de documentos ao longo da hierarquia. A seleção de descritores para agrupamentos é uma tarefa comum na mineração de texto e na recuperação de informação. Geralmente, os métodos buscam uma lista de termos discriminativos, que são usados para facilitar a recuperação da informação ou uma interpretação de cada grupo (Moura e Rezende, 2010). Em muitos casos, essa lista é construída utilizando apenas os termos existentes nos documentos da coleção. O método mais simples e amplamente utilizado é a seleção daqueles que aparecem mais vezes nos documentos do grupo, ou seja, os termos com maior frequência. Esta lista normalmente revela os tópicos de mais alto nível, mas pode deixar de retratar detalhes específicos do agrupamento (Popescul e Ungar, 2000).

Os métodos de seleção de descritores encontrados na literatura podem ser divididos em métodos baseados em frequência, como no caso do método citado anteriormente, métodos baseados em centróide (Cutting et al., 1992; Larsen e Aone, 1999; Zhang et al., 2009), métodos baseados em modelos probabilísticos ou estatísticos (Glover et al., 2002; Moura e Rezende, 2010; Popescul e Ungar, 2000; Treeratpituk e Callan, 2006) e ainda métodos que adicionam conhecimento externo (Tseng, 2010; Carmel et al., 2009). Estes trabalhos consideram cada documento como uma bag-of-words e não exploram explicitamente o relacionamento existente entre os termos dos documento do grupo. No entanto, essas relações podem trazer informações importantes para a decisão dos termos que devem ser escolhidos como descritores dos nós, e poderiam ser representadas por regras de associação, uma vez que essa técnica carrega um nível semântico intrínseco que não é possível de determinar com uma simples contagem de frequência ou redução da dimensionalidade (Lopes et al., 2007).

O foco desse trabalho é apresentar uma abordagem que visa melhorar a qualidade dos descritores para os agrupamentos. Para isso foi proposto e desenvolvido o método SeCLAR - Selecting Candidate Labels using Association Rules -, que explora o uso de regras de associação para a seleção de descritores para agrupamentos hierárquicos de documentos. Este método gera regras de associação baseadas em transações construídas à partir de cada documento da coleção, e utiliza a informação de relacionamento existente entre os grupos do agrupamento hierárquico para selecionar candidatos a descritores. Uma vez selecionados, estes candidatos são processados por algum método clássico de seleção 
de descritores, obtendo-se o conjunto final de descritores para os nós da hierarquia.

Assim, a principal hipótese é a de que o uso de regras de associação para identificar candidatos a descritores em agrupamentos hierárquicos leva a um melhor resultado no processo de seleção de descritores. Como hipótese secundária, considera-se que é possível obter bons descritores à partir dos termos presentes na coleção de textos.

O objetivo principal deste trabalho é apoiar a identificação de descritores para agrupamentos hierárquicos de documentos. Para isso, são utilizadas as relações embutidas nas regras de associação.

Outro objetivo é avaliar a utilização de regras de associação para apoiar a identificação de descritores para agrupamentos hierárquicos. Experimentos foram realizados para avaliar o método proposto na utilização dos candidatos a descritores para os métodos tradicionais de seleção de descritores. Os resultados indicam que é possível obter uma melhora significativa com relação a precisão e a cobertura dos métodos tradicionais.

Este trabalho está dividido da seguinte forma: no Capítulo 2 é apresentado o processo de Mineração de Textos bem como uma revisão sobre as regras de associação. No Capítulo 3 o problema de obtenção de agrupamento hierárquico de documento é abordado. No Capítulo 4, é apresentado a seleção de candidatos a descritores para agrupamentos hierárquicos com ênfase no método proposto e desenvolvido e nos resultados da avaliação realizada. Finalmente, as conclusões e trabalhos futuros são apresentadas no Capítulo 5. 



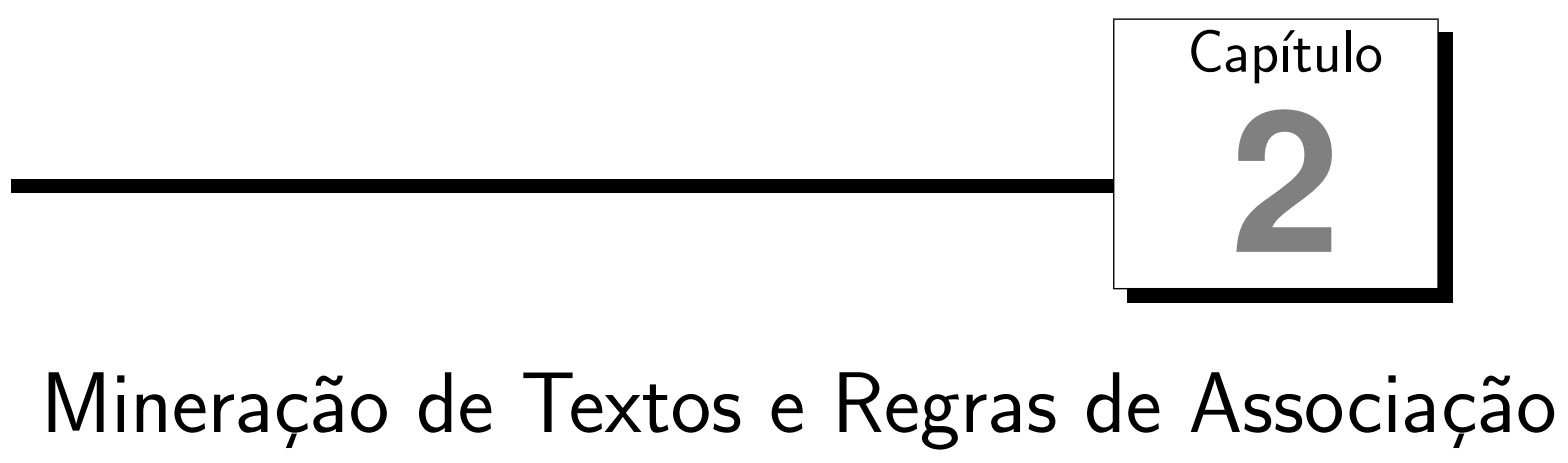

\subsection{Considerações Iniciais}

A mineração de textos é uma área de pesquisa cujo objetivo é a busca por padrões, tendências e regularidades em textos escritos em língua natural e pode ser vista como uma especialização do processo de mineração de dados. Enquanto esta última trabalha sobre bases de dados com estrutura pré-definida, a mineração de textos trabalha sobre dados inerentemente não estruturados (Weiss et al., 2005). Este processo pode ser dividido em uma sequência de etapas genéricas, formando um ciclo no qual, ao final, obtém-se o conhecimento acerca dos textos analisados.

Uma tarefa importante na mineração de dados e textos é a mineração de regras de associação. Esta última tem recebido grande atenção desde que foi proposta por Agrawal et al. (1993). A aplicação direta em problemas de negócios junto com sua compreensibilidade inerente - não só para especialistas em mineração de dados - tornaram essa técnica muito popular (Hipp et al., 2002), não só na identificação de associações entre itens, mas também nas tarefas de análise e mineração de dados como classificação associativa ou agrupamento Han et al. (2007).

Neste capítulo são descritos os principais aspectos da mineração de textos e das regras de associação.

\subsection{Mineração de Textos}

Mineração de Textos é um conjunto de técnicas e processos que descobre conhecimento inovador nos textos. Ela se transformou em um importante aliado às mais diversas corporações, agências de informação e entidades que necessitam gerenciar e extrair conhecimento de grandes coleções de documentos textuais que possam ser úteis para algum processo de tomada de decisão ((Marcacini et al., 2007); (Feldman e Sanger, 2007); (Souza et al., 2006); (Liu et al., 2005)). É um processo no qual há grande iteração por parte do 
usuário e grande incorporação de conhecimento por parte dos especialistas nas etapas, e visa extrair informação útil através da identificação e exploração de padrões interessantes (Feldman e Sanger, 2007).

O processo de mineração de textos pode ser dividido em cinco grandes fases: Identificação do Problema, Pré-processamento, Extração de Padrões, Pós-processamento e Utilização do Conhecimento. O ciclo formado por essas etapas é apresentado na Figura 2.1 .

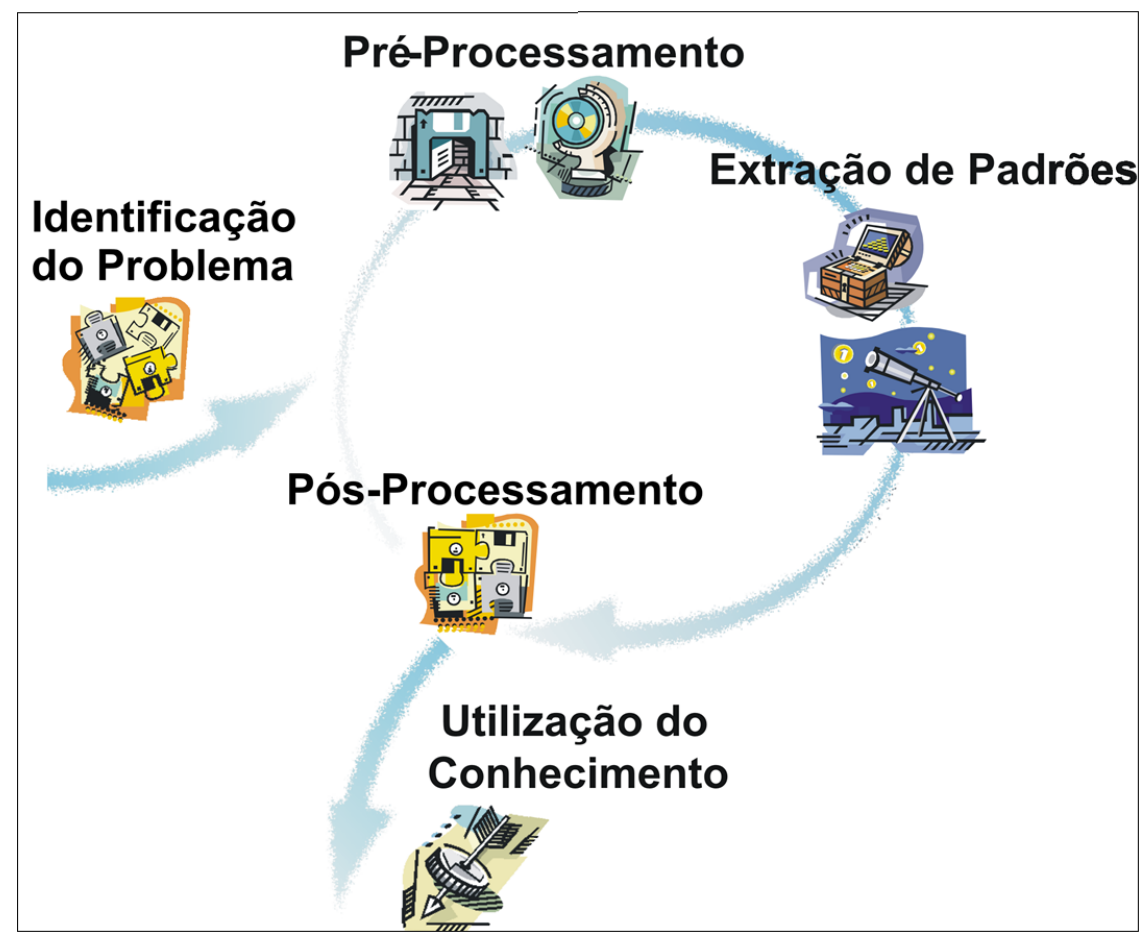

Figura 2.1: Etapas do processo de Mineração de Textos. Fonte: Rezende et al. (2003)

Nas próximas subseções serão detalhadas as etapas do processo de mineração de texto.

\subsubsection{Identificação do Problema}

A Identificação do Problema é uma etapa muito importante, dado que não existe descoberta de conhecimento sem demanda pelo mesmo. Nesta etapa, o especialista do domínio identifica e delimita o problema, o subdomínio do problema, a coleção de textos ${ }^{1}$ a ser analisada ou sua fonte de busca, se existe algum conhecimento prévio de domínio que possa ser utilizado na análise, o que se espera obter e, por fim, como os resultados poderão ser utilizados. É uma etapa que demanda muito esforço tanto do especialista do domínio quanto do especialista em Mineração de Textos, pois a mesma fornece subsídios a todo o processo, permitindo identificar requisitos e possíveis técnicas a serem utilizadas em cada passo (Conrado, 2009). Neste sentido, Rezende et al. (2003) definem quatro questões essenciais a serem respondidas:

- Quais são as principais metas do processo?

- Quais critérios de desempenho são importantes?

\footnotetext{
${ }^{1}$ Neste trabalho, os termos "coleção de textos" e "base de textos" são considerados sinônimos.
} 
- O conhecimento extraído deve ser compreensível a seres humanos ou um modelo do tipo caixa-preta é apropriado?

- Qual deve ser a relação entre simplicidade e precisão do modelo extraído?

As decisões tomadas neste ponto guiarão os passos consecutivos e poderão ter reflexo no desempenho da aplicação. Neste sentido, com o auxílio de especialistas no domínio, uma atividade imprescindível a ser realizada nesta fase é um estudo acerca do domínio do problema para se adquirir um conhecimento inicial, visando o auxílio na tomada de decisão nas etapas subsequentes do processo. Ainda com o auxílio do especialista, é necessário identificar e delimitar a coleção de textos a ser analisada ou sua fonte de busca, se existe algum conhecimento prévio de domínio que possa ser utilizado na análise, o que se espera obter e como os resultados poderão ser utilizados.

\subsubsection{Pré-processamento}

Nesta etapa é encontrada a principal diferença dos processos de Mineração de Textos para os processos de Mineração de Dados: a estruturação dos textos em um formato adequado para a extração de padrões. Para tal, essa etapa compreende atividades de padronização, geração de atributos, estruturação dos documentos e redução da quantidade de atributos gerados (Rezende et al., 2003).

Em um aspecto mais geral, o analista deve verificar neste ponto as características que asseguram a confiabilidade da coleção de textos, bem como sua adequação à tarefa de extração de conhecimento pretendida. Neste sentido, Moura (2009) cita uma série de ações assistidas por especialistas que podem ser tomadas quando necessárias, como:

- Eliminação de repetições de documentos: deve-se verificar se não existem documentos duplicados na base;

- Balanceamento da coleção por reamostragem: é importante que a coleção, quando dividida em classes, esteja balanceada, ou seja, que o número de documentos em cada uma das classes seja igual;

- Redução da quantidade de documentos: caso a quantidade de documentos for muito grande e os objetivos finais assim permitirem, pode-se trabalhar sobre uma amostra da coleção original;

- Verificação da existência de uma estrutura prévia nos documentos: a fim de utilizar essa informação na estruturação final da coleção, como por exemplo, dar um peso maior para a palavra caso ela apareça no título do documento;

- Análise do tamanho dos documentos na coleção: verificar a necessidade de uma normalização dos pesos atribuídos aos termos em função do tamanho dos textos.

Além desses itens, é importante considerar a forma de representação que será utilizada pelos algoritmos de extração de padrões. A representação mais comumente utilizada em Mineração de Textos é baseada no modelo espaço-vetorial (Salton, 1989) dos documentos 
e termos utilizados. Normalmente, essa representação é matricial, e é conhecida como Matriz Documento Termo (Martins, 2003), apresentada na Tabela 2.1, na qual $d_{i}$ corresponde ao $i$-ésimo documento, $t_{j}$ representa o $j$-ésimo atributo (termo) e $a_{i j}$ é a medida que relaciona o $i$-ésimo documento com o $j$-ésimo atributo. Caso os documentos possuam rótulos, ainda haverá uma última coluna que corresponde a classe dos documento $\left(y_{i}\right)$. Essa abordagem para representação estruturada dos documentos é uma abordagem simplista, mas que tem obtido um bom desempenho no resultado final da tarefa de mineração de textos.

\begin{tabular}{c|cccc|c}
\hline & $t_{1}$ & $t_{2}$ & $\ldots$ & $t_{M}$ & $Y$ \\
\hline \hline$d_{1}$ & $a_{11}$ & $a_{12}$ & $\ldots$ & $a_{1 M}$ & $y_{1}$ \\
$d_{2}$ & $a_{21}$ & $a_{22}$ & $\ldots$ & $a_{2 M}$ & $y_{2}$ \\
$\vdots$ & $\vdots$ & $\vdots$ & $\ddots$ & $\vdots$ & $\vdots$ \\
$d_{N}$ & $a_{N 1}$ & $a_{N 2}$ & $\ldots$ & $a_{N M}$ & $y_{N}$ \\
\hline
\end{tabular}

Tabela 2.1: Padrão de matriz documento termo

Neste trabalho, termo, também chamado de característica ou atributo, pode ser uma palavra simples, um conjunto de $n$ palavras ou mesmo um "token". Por exemplo, "inteligência", "inteligência artificial" e "processo de mineração de textos". Geralmente, os termos presentes na Matriz Documento Termo são previamente analisados e tratados. Em um esforço inicial, busca-se desconsiderar aqueles termos dos textos que representam conhecimento pouco relevante, por eliminação de stopwords, ou seja, palavras que não são relevantes na análise dos textos, sendo geralmente constituídas por preposições, pronomes, artigos, interjeições, dentre outras. Posteriormente, busca-se identificar similaridades de significados entre palavras, como em casos de variações morfológicas ou de palavras sinônimas (Ebecken et al., 2003). Para tal, pode-se reduzir uma palavra à sua raiz por meio de processos de stemming, reduzir as palavras ao seu lema (lematização), reduzir a palavra a um substantivo (substantivação) ou mesmo usar dicionários ou thesaurus (Conrado, 2009). Além disso, é possível buscar na coleção a formação de termos compostos, ou n-gramas, que são termos formados por mais de uma palavra, porém apresentando um único significado semântico (Manning e Schütze, 1999; Rahmoun e Elberrichi, 2007; Zhang e Zhu, 2007; Conrado, 2009). A seguir, são descritas as técnicas aqui citadas para redução das palavras:

- stemming: Raiz ou Radical é a parte do verbo ou substantivo que exprime a idéia geral da palavra, ou seja, seu significado mesmo sem o prefixo ou sufixo. É a parte invariável do vocábulo. Exemplo: abert é raiz de abertas e aberto

- lematização: Lema é a forma canônica de uma palavra. Consiste na redução dos radicais das palavras de tal forma a resultar na ausência de flexões. Exemplo: brasileiro é lema de brasileiras e brasileiros

- substantivação: também conhecido como "Nominalização", na qual as palavras passam a exibir um comportamento sintático/semântico semelhante aquele próprio de um nome. Exemplo: passaram é transformada em passagem 
Para calcular os valores das células $a_{i j}$ da Matriz Documento Termo, diversas medidas foram propostas na literatura. Essas medidas podem ser binárias (0 se o elemento não ocorre no documento, e 1 se o elemento ocorre) e baseadas em frequência, como term frequency (tf), inverse document frequency (idf), e a tf-idf (Salton, 1989). Uma vez escolhido o tipo dos pesos, eles servem como base para a extração de diversas medidas estatísticas na extração de padrões, sendo o segundo tipo mais comumente aplicado.

Uma vez formada, a Matriz Documento Termo referente à coleção de documentos é normalmente esparsa e de alta dimensionalidade, o que, por vezes, pode tornar o processo de análise computacionalmente muito custoso ou até mesmo inviável, além de afetar negativamente o resultado de alguns algoritmos de extração de conhecimento. É vital para o processo de análise, portanto, selecionar os termos mais relevantes da coleção de documentos, tornando o conjunto de termos com o qual se trabalha mais conciso, porém não menos representativo em relação ao conjunto original. Este processo é conhecido como seleção de atributos e diversas técnicas são apresentadas em (Yang e Pedersen, 1997; Nogueira et al., 2008).

\subsubsection{Extração de padrões}

Assim que o problema é delimitado e os textos são devidamente representados, o processo avança para a fase de extração de padrões. As tarefas a serem realizadas neste ponto são definidas de acordo com o objetivo final do processo de extração de conhecimento. Assim como na Mineração de Dados, pode-se resumir as principais atividades de extração de padrões em textos em duas grandes tarefas: preditivas e descritivas. As atividades preditivas são aquelas que produzem um modelo descrito pelo conjunto de dados para predizer o valor de uma ou mais variáveis de interesse (rótulos). As atividades descritivas, por sua vez, produzem uma informação nova baseada nos dados disponíveis por meio de padrões que podem ser interpretados por humanos (Kantardzic, 2003).

Para as atividades preditivas são utilizados algoritmos de máquina supervisionados. Esses algoritmos, conhecidos como indutores, exigem um conjunto de exemplos de treinamento para os quais o atributo classe tenha valor conhecido (Mitchell, 1997; Monard e Baranauskas, 2003). Esta classe de algoritmos se divide em duas subclasses principais: os algoritmos de classificação e os algoritmos de regressão. Classificação é referente ao processo em que o atributo classe tem valor categórico, enquanto regressão remete à predição de variáveis com valores numéricos. A aplicação de tarefas preditivas em mineração de textos tem como principal aplicação a categorização automática de documentos.

As atividades descritivas, por sua vez, utilizam algoritmos de aprendizado de máquina não-supervisionados. Esse tipo de atividade consiste na identificação de comportamentos intrínsecos da coleção de dados, sendo que esses dados não possuem rótulos ou são tratados como não rotulados. As principais tarefas deste ramo da mineração de textos são a obtenção de regras de associação, o agrupamento e a sumarização de documentos (Mitchell, 1997; Monard e Baranauskas, 2003).

As regras de associação são relações inferidas entre dados correlacionados de uma ou mais bases de dados, analisados conjuntamente (Agrawal e Srikant, 1994). Essa tarefa 
faz parte do foco deste trabalho e é apresentada em detalhes na Seção 2.3.

O agrupamento de dados, também conhecido como clustering, visa agrupar objetos de forma que os objetos de um mesmo grupo sejam similares (ou relacionados) uns ao outros e diferentes (ou não relacionados) aos objetos de outros grupos. Esta atividade será apresentada em detalhes no Capítulo 3.

\subsubsection{Pós-processamento}

O pós-processamento é a fase de validação das descobertas e da visualização dos resultados encontrados. Nesta fase, o conhecimento extraído é então utilizado seja por ferramentas de visualização ou simplesmente por tabelas de resultados. A análise minuciosa dos resultados obtidos permite que se valide a sua utilidade e até mesmo o próprio processo, determinando a necessidade de retomar passos anteriores, reestruturando-os. Nesta etapa, o especialista do domínio e o de Mineração de Textos devem trabalhar juntos, procurando: representatividade do conhecimento obtido, novidades nos resultados encontrados, diferenças entre o conhecimento obtido e o do especialista, validação dos resultados obtidos, identificação da adequação de procedimentos nas etapas anteriores para tentar melhorar os resultados e, ainda, conhecer os modos com os quais os resultados obtidos devem ser utilizados.

\subsubsection{Utilização do Conhecimento}

Na etapa de utilização do conhecimento supõe-se que os resultados estão validados para poderem ser utilizados como parâmetros para suporte à decisão ou inúmeras outras atividades.

Após ter percorrido todas as etapas do processo, o conhecimento encontra-se apto a ser utilizado pelo usuário. Com o correto desenvolvimento das etapas anteriores, podese garantir que o conhecimento, neste ponto, é válido e potencialmente útil, podendo ser aplicado no apoio à tomada de decisão, considerando os aspectos estabelecidos nos objetivos iniciais do processo.

\subsection{Regras de Associação}

Desde que for proposta por Agrawal et al. (1993) a técnica de regras de associação têm recebido grande atenção. A aplicação direta em problemas de negócios junto com sua compreensibilidade inerente - não só para especialistas em mineração de dados - tornaram essa técnica muito popular (Hipp et al., 2002).

A mineração de regras de associação surgiu da análise de dados de uma cesta de compra, e busca construir regras do tipo "clientes que compram os produtos x1, x2, .., xn também irão comprar o produto y com probabilidade c\%". Apesar da sua ligação com o contexto varejista, as regras geradas apresentam hoje uma ampla gama de aplicações em que são bem sucedidas, como por exemplo na detecção de invasão de redes de computadores (Ping-ping e Qiu-ping, 2002). 
Neste capítulo são abordados os conceitos e definições de regras de associação, a forma de geração de regras e medidas de interesse importantes. Também é apresentada a sintaxe para representar regras de associação utilizada neste trabalho.

\subsubsection{Definições e Conceitos}

Uma regra de associação caracteriza o quanto a presença de um conjunto de itens nos registros de uma Base de Dados implica na presença de algum outro conjunto distinto de itens nos mesmos registros (Agrawal e Srikant, 1994). Desse modo, o objetivo das regras de associação é encontrar tendências que possam ser usadas para entender e explorar padrões de comportamento dos dados. Por exemplo, observando os dados de vendas de um supermercado, sabe-se que $80 \%$ dos clientes que compram o produto $Q$ também adquirem, na mesma ocasião, o produto $W$. Em outras palavras, pode-se dizer que essa regra apresenta confiabilidade de $80 \%$.

O formato de uma regra de associação pode ser representado como uma implicação $L H S \Rightarrow R H S$, em que LHS e RHS são, respectivamente, o lado esquerdo (Left Hand Side) e o lado direito (Right Hand Side) da regra, definidos por conjuntos disjuntos de itens. As regras de associação podem ser definidas como descrito a seguir (Agrawal e Srikant, 1994):

Seja $D$ uma Base de Dados composta por um conjunto de itens $A=\left\{a_{1}, \ldots, a_{m}\right\}$ ordenados lexicograficamente e por um conjunto de transações $T=\left\{t_{1}, \ldots, t_{n}\right\}$, na qual cada transação $t_{i} \in T$ é composta por um conjunto de itens (itemset) tal que $t_{i} \subseteq A$, com $i=1, \ldots, n$.

Em uma Regra de Associação $L H S \Rightarrow R H S$, em que $L H S \subset A, R H S \subset A$ e $L H S \cap R H S=\varnothing$. A regra $L H S \Rightarrow R H S$ ocorre no conjunto de transações $T$ com confiança conf se em conf\% das transações de $T$ em que ocorre $L H S$ ocorre também RHS. A regra $L H S \Rightarrow R H S$ tem suporte sup se em sup\% das transações em $D$ ocorre $L H S \cup R H S$.

O valor do suporte mede a força da associação entre $L H S$ e $R H S$ e não relaciona possíveis dependências de RHS com LHS. Por outro lado, a confiança mede a força da implicação descrita pela regra (Zhang e Zhang, 2002).Essas duas medidas são definidas a seguir:

Suporte: quantifica a incidência de um itemset $X$ ou de uma regra no conjunto de dados, ou seja, indica a frequência com que $X$ ou com que $L H S \cup R H S$ ocorre no conjunto de dados. Da maneira como foi definido, o suporte para um itemset $X$ pode ser representado por:

$$
\sup (X)=\frac{n(X)}{N}
$$

em que $n(X)$ é o número de transações nas quais $X$ ocorre e $N$ é o número total de transações consideradas. Já o suporte de uma regra $L H S \Rightarrow R H S$ pode ser representado por:

$$
\sup (L H S \Rightarrow R H S)=\sup (L H S \cup R H S)=\frac{n(L H S \cup R H S)}{N}
$$


em que $n(L H S \cup R H S)$ é o número de transações nas quais $L H S$ e $R H S$ ocorrem juntos e $N$ é o número total de transações consideradas.

Confiança: indica a frequência com que $L H S$ e $R H S$ ocorrem juntos em relação ao número total de transações em que $L H S$ ocorre. Do modo como foi definida, a confiança de uma regra $L H S \Rightarrow R H S$ pode ser representada por:

$$
\operatorname{conf}(L H S \Rightarrow R H S)=\frac{\sup (L H S \cup R H S)}{\sup (L H S)}=\frac{n(L H S \cup R H S)}{n(L H S)}
$$

em que $n(L H S)$ é o número de transações nas quais $L H S$ ocorre.

Melanda (2004) apresenta uma análise crítica sobre o uso exclusivo das medidas de suporte e confiança para avaliação da qualidade das regras, mostrando assim a necessidade de utilização de outras medidas para avaliação das regras de associação geradas. Carvalho (2007) apresenta diversas medidas que podem ser utilizadas para este fim. Entre elas, podemos destacar a lift (ou interest factor - IF (Brin et al., 1997)), a laplace e a gini index. Abaixo, uma definição destas medidas:

lift: essa medida indica o quanto a frequencia do consequente aumenta na presença do antecedente. Em outras palavras, mede o grau de dependência entre os itens. Regras com lift $=1$ possuem antecedente e consequente independentes, ou seja, a presença do antecedente não leva ao aumento ou à diminuição da ocorrência do conseqüente. No caso de regras com lift $>1$, pode-se dizer que o antecedente influencia positivamente a frequencia do consequente (dependência positiva) e, no caso de lift $<1$, o antecedente e o consequente apresentam dependência negativa.

$$
\text { lift }=\frac{\operatorname{conf}(L H S \Rightarrow R H S)}{\sup (R H S)}
$$

laplace: é uma variação da medida Confiança (Equação 2.3) e penaliza regras muito específicas (regras que cobrem poucas transações). Sua semântica é a mesma daquela apresentada pela Confiança. Na Equação 2.5, $N$ é o número total de transações.

$$
\text { laplace }=\frac{N \times \sup (L H S \cup R H S)+1}{N \times \sup (L H S)+2}
$$

gini index: frequentemente utilizada como critério de seleção na indução de árvores de decisão, ela é utilizada para medir o decréscimo da impureza ou incerteza de uma determinada classe (variável meta), condicionada ao conhecimento do valor de uma determinada variável (variável preditora). Quanto maior o valor da medida, maior será a associação entre as variáveis. No problema de regras de associação, quanto maior o valor para esta medida, mais o antecedente e o consequente estão associados. A Equação 2.6 está definida em função das medidas apresentadas anteriormente e $P(A \mid B)$ é a probabilidade condicional entre os elementos do antecedente e do consequente. Observa-se que $\overline{R H S}$ e $\overline{L H S}$ são os complementos das medidas RHS e LHS. 


$$
\begin{array}{r}
\text { giniindex }= \\
\sup (L H S)\left[P(R H S \mid L H S)^{2}+P(\overline{R H S} \mid L H S)^{2}\right]+ \\
\sup (\overline{L H S})\left[P(R H S \mid \overline{L H S})^{2}+P(\overline{R H S} \mid \overline{L H S})^{2}\right]- \\
\sup (R H S)^{2}-\sup (\overline{R H S})^{2}
\end{array}
$$

Usualmente, valores de suporte e confiança mínimos são definidos pelo usuário antes da mineração das regras de associação. Em geral, a definição de altos valores para esses parâmetros gera apenas regras triviais; já a definição de baixos valores gera, em geral, um grande volume de conhecimento no formato de regras, dificultando a análise do usuário na etapa de Pós-processamento. Uma maneira de superar as dificuldades na análise dessas regras no Pós-processamento é utilizar-se de algoritmos que possibilitam usar taxonomias já durante a etapa de Extração de Padrões.

O problema de obtenção de regras de associação é decomposto em dois sub-problemas (passos) (Agrawal et al., 1993):

1. Encontrar todos os $k$-itemsets (conjunto de $k$ itens) que possuam suporte maior ou igual ao suporte mínimo especificado pelo usuário (sup-min). Os itemsets com suporte igual ou superior a sup-min são definidos como itemsets frequentes, os demais conjuntos são denominados de itemsets não-frequentes;

2. Utilizar todos os $k$-itemsets frequentes, com $k \geq 2$, para gerar as regras de associação. Para cada itemset frequente $l \subseteq A$, encontrar todos os subconjuntos $\tilde{a}$ de itens não vazios de $l$. Para cada subconjunto $\tilde{a} \subseteq l$, gerar uma regra na forma $\tilde{a} \Rightarrow(l-\tilde{a})$ se a razão de $\sup (l)$ por $\sup (\tilde{a})$ é maior ou igual a confiança mínima especificada pelo usuário (conf-min).

Com um conjunto de itemsets frequentes $\{a, b, c, d\}$ e um subconjunto de itemsets frequentes $\{a, b\}$, por exemplo, pode-se gerar uma regra do tipo $a b \Rightarrow c d$, desde que $\operatorname{conf}(a b \Rightarrow c d) \geq$ conf-min, em que, $\operatorname{conf}(a b \Rightarrow c d)=\sup (a, b, c, d) / \sup (a, b)$.

Para que não haja necessidade de se percorrer todo o espaço de busca à procura dos itemsets de fato frequentes, algoritmos modernos para minerar regras de associação utilizam um método que gera e testa itemsets candidatos. Esses algoritmos geram conjuntos de itemsets potencialmente frequentes chamados conjuntos de itemsets candidatos. Utilizam-se da propriedade de linha de fronteira (downward closure) do suporte de um itemset (Agrawal e Srikant, 1994) que determina que todo subconjunto de um itemset frequente deve ser frequente (para remover os itemsets com pelo menos um subconjunto de itens não-frequentes). Então, calcula-se o valor de suporte para cada itemset candidato (não removido) utilizando a base de dados $\mathrm{D}$, removendo-se, na sequência, os itemsets candidatos com suporte inferior ao suporte mínimo (sup-min) definido pelo usuário. O algoritmo inicia uma nova iteração utilizando os itemsets frequentes gerados na última iteração e tem encerrada sua execução quando não houver nenhum itemset potencialmente frequente podendo ser considerado um itemset candidato. 
Existem diversas formas de implementar o processo de geração de regras de associação, que têm um impacto significativo no desempenho final do processo, e a escolha do algoritmo correto depende do objetivo final da aplicação. Para este trabalho foi escolhido o algoritmo Apriori (Agrawal e Srikant, 1994), amplamente utilizado para obtenção de itemsets frequentes. Este algoritmo e também um algoritmo simples para obtenção de regras de associação são apresentados na próxima seção.

\subsubsection{Geração de Regras de Associação}

A obtenção de itemsets frequentes para gerar regras de associação pode ser realizada utilizando diversos algoritmos, como: AIS (Agrawal et al., 1993), Apriori e AprioriTid (Agrawal e Srikant, 1994), SETM (Houtsma e Swami, 1995), Opus (Webb, 1995), Direct Hashing and Prunning (DHP) (Park et al., 1997), Dynamic Set Couting (DIC) (Brin et al., 1997), Closet (Pei et al., 2000) e Charm (Zaki e Hsio, 2002). Dentre eles, o Apriori que é amplamente utilizado (Zhang e Zhang, 2002) será apresentado a seguir.

\section{O Algoritmo Apriori}

O algoritmo Apriori (Algoritmo 1) foi proposto com o objetivo de minerar regras de associação em grandes e complexas bases de dados, e seu grande diferencial está na sua simplicidade original e na versatilidade. Conforme apresentado em Agrawal e Srikant (1994), no primeiro passo o algoritmo simplesmente conta a ocorrência de itens para determinar a largura do conjunto de 1-itemsets (linha 1 do Algoritmo 1). Em seguida, chamado passo $k$, temos duas fases:

1. O itemset $\mathrm{L}_{k-1}$ encontrado no $(k-1)$-ésimo passo é usado para gerar os itemsets candidatos $\mathrm{C}_{k}$ (linha 3 do Algoritmo 1), usando a função apriori-gen (Algoritmo 2).

2. A base de dados é percorrida e o valor de suporte dos candidatos em $\mathrm{C}_{k}$ é contado (linhas 4 a 9 do Algoritmo 1).

A solução final é dada pela união de todos os candidatos $\mathrm{C}_{k}$ com um valor de suporte maior que um valor sup-min definido pelo usuário (linha 10 do Algoritmo 1).

O conjunto de itemsets frequentes encontrado pelo algoritmo 1 é utilizado como entrada para algum algoritmo que gera regras de associação, como por exemplo o Algoritmo 2 .

A seguir é apresentado o algoritmo da função apriori-gen que faz parte do algoritmo apriori. Esta função usa como argumento de entrada o itemset $L_{k-1}$ encontrado pelo Algoritmo 1 e retorna um superconjunto do conjunto de todos os $(k-1)$-itemsets. A função executa inicialmente uma operação de união dos elementos dos itemsets em $L_{k-1}$ com o último elemento de outros itemsets, diferentes do primeiro, em $L_{k-1}$ (linhas 1 a 4 do Algoritmo 2). Em seguida são podados os $k$-itemsets que possuem algum subconjunto de tamanho $(k-1)$ não pertencente a $L_{k-1}$ (linhas 5 a 11 do Algoritmo 2). Essa poda é orientada conforme a propriedade de limite de fronteira de suporte de um itemset, descrita na Seção 2.3.1. 

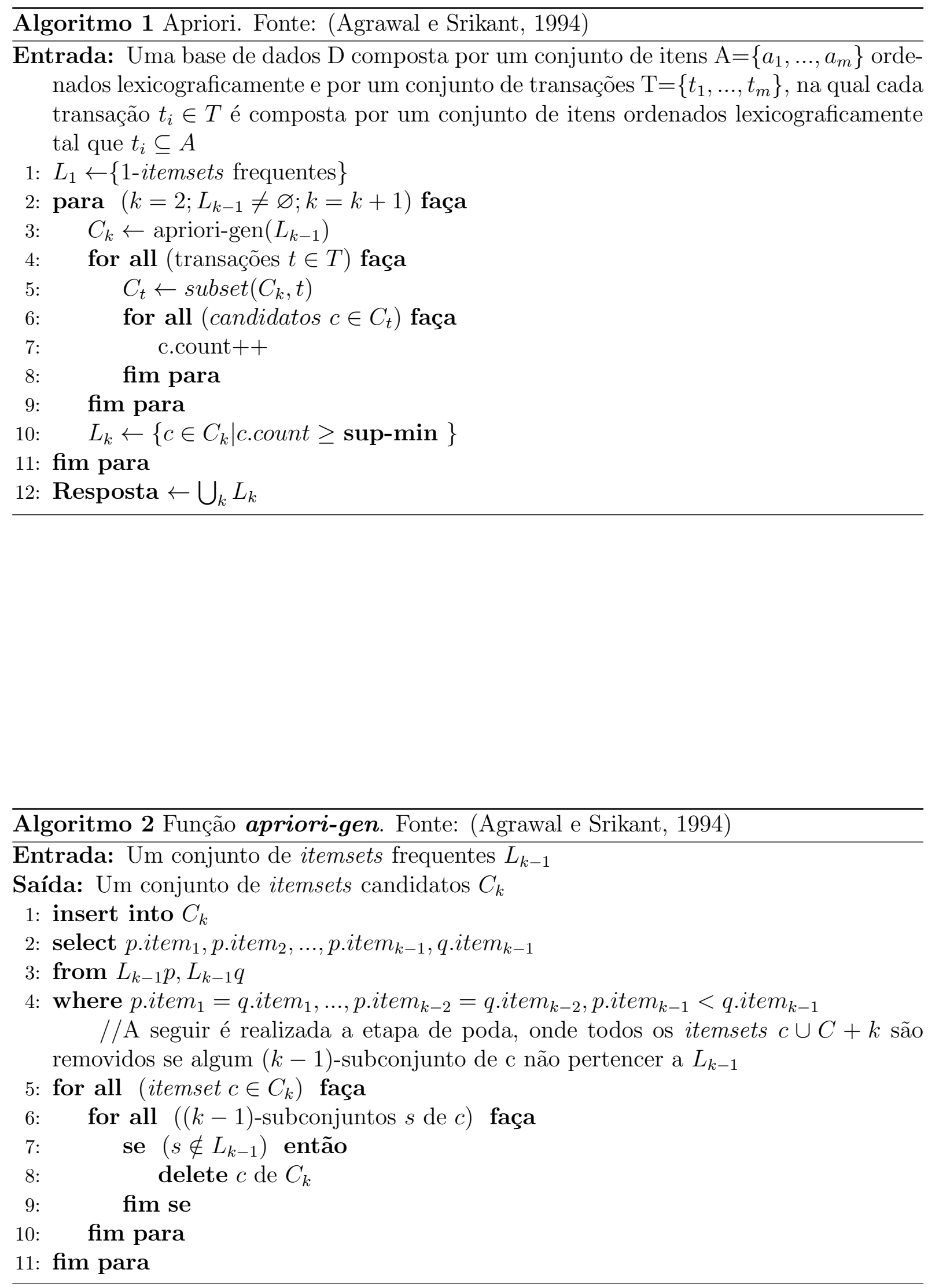
Além da função apriori-gen, outra importante função apresentada no código do algoritmo apriori é a subset. Esta função retorna os $k$-itemsets candidatos que estão contidos em uma dada transação $t_{i}$. Para isso, os itemsets candidatos são armazenados em uma árvore-hash. Cada nó da árvore pode conter uma lista de itemsets ou uma tabela hash (nó folha ou nó intermediário, respectivamente). Partindo do nó raíz, a função encontra todos os itemsets candidatos presentes na transação $t_{i}$. Se um nó folha é atingido e o itemset encontrado está contido na transação $t_{i}$, uma referência é adicionada ao conjunto de resposta. Se um nó intermediário é atingido a partir de um item $a_{j} \in A$, cada item é pesquisado (hash) após $a_{j}$ em $t_{i}$. Isso é possível porque os itens estão em ordem lexográfica. No nó raíz, todos os itens $a_{j}$ em $t_{i}$ são pesquisados.

\section{Algoritmo Simples para Gerar Regras de Associação}

Existem diversos algoritmos que geram regras de associação a partir dos itemsets frequentes obtidos de uma Base de Dados (Domingues, 2004). Um dos algoritmos mais simples foi proposto por Agrawal e Srikant (1994) e é apresentado a seguir.

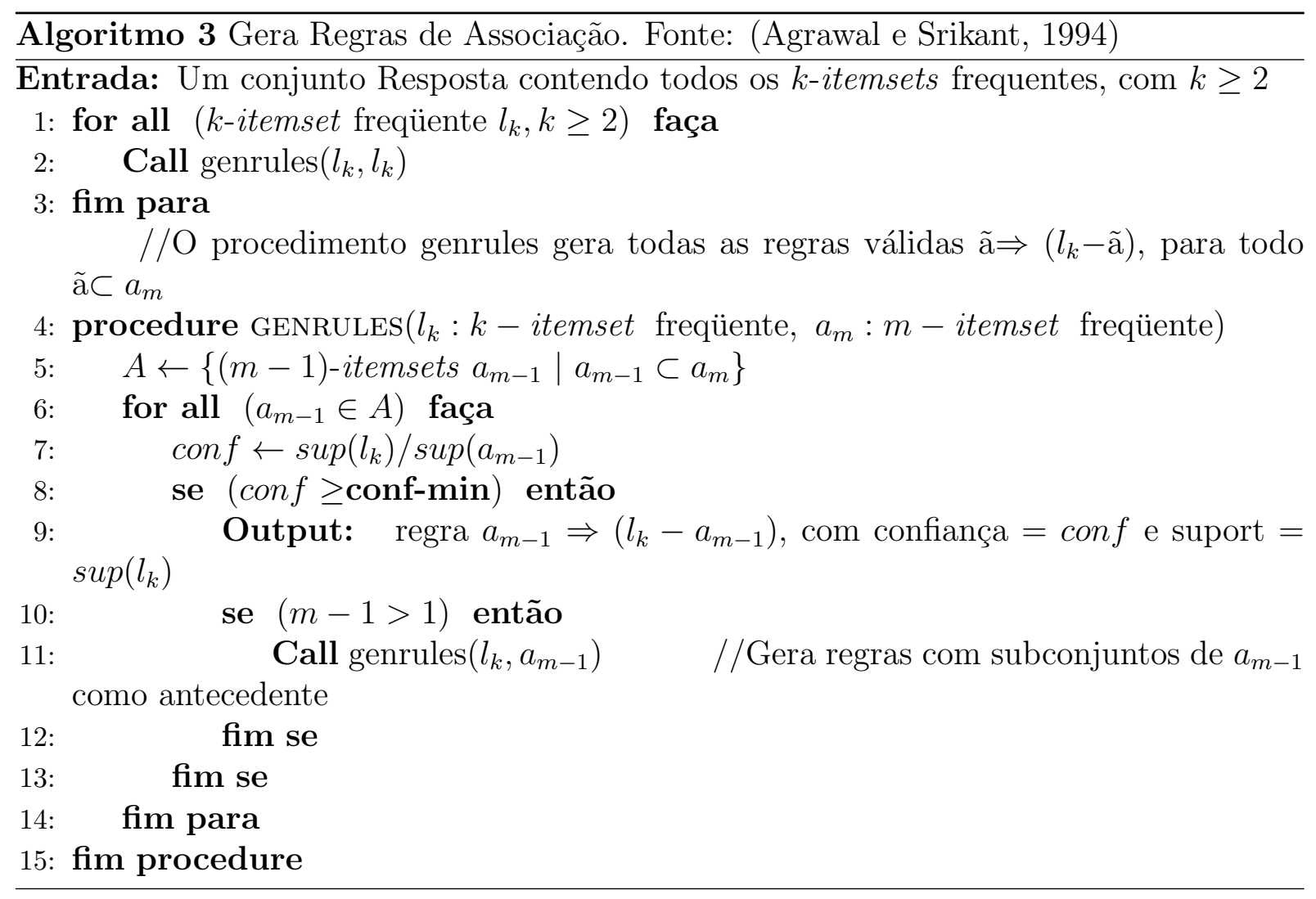

O algoritmo é executado para os k-itemsets frequentes, com $k>2$. Inicialmente são gerados os subconjuntos não vazios de um itemset frequente. Em seguida são geradas regras do tipo $L H S \Rightarrow R H S$ utilizando os subconjuntos definidos, que satisfazem a condição: confiança da regra maior ou igual à confiança mínima especificada pelo usuário (conf-min). 


\subsection{Considerações finais}

Neste capítulo foi apresentado o processo de Mineração de Textos, que é fundamental para organizar, gerenciar e extrair conhecimentos de coleções de documentos textuais. Neste capítulo também foi apresentada a técnica de associação, usada para obter relações entre conjuntos de itens, e que neste trabalho será utilizada para identificar termos candidatos a descritores em agrupamentos hierárquicos de documentos.

No próximo capítulo, o problema de obtenção de agrupamento hierárquico de documento é apresentado, bem como técnicas encontradas na literatura para resolvê-lo. Em seguida é apresentada a metodologia para obtenção de candidatos a descritores para agrupamentos hierárquicos de documentos e o método proposto que utiliza a técnica de regra de associação. 



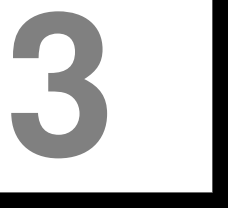

\section{Agrupamento Hierárquico de Documentos}

\subsection{Considerações Iniciais}

Agrupamento de documentos é a organização de um conjunto de documentos em grupos, baseado em uma medida de similaridade, no qual documentos de um mesmo grupo são altamente similares entre si mas dissimilares em relação aos documentos de outros grupos (Manning et al., 2008). Em outras palavras, o agrupamento é baseado no princípio de maximizar a similaridade interna dos grupos (intragrupo) e minimizar a similaridade entre os grupos (intergrupos) (Everitt et al., 2001). A análise de agrupamento também é conhecida como aprendizado por observação ou análise exploratória dos dados, pois a organização dos documentos em grupos é realizada apenas pela observação de regularidades nos dados, sem uso de conhecimento externo. Assim, ao contrário de métodos supervisionados, como algoritmos de classificação, em processos de agrupamento não há classes ou rótulos predefinidos para treinamento de um modelo, ou seja, o aprendizado é realizado de forma não-supervisionada.

O processo de agrupamento depende de dois fatores principais: (1) a medida de proximidade e (2) o método de agrupamento escolhido. As medidas de proximidade determinam como a similaridade entre dois documentos é calculada. Sua escolha influencia a forma como os grupos são induzidos e depende dos tipos de variáveis ou atributos que representam os documentos. Existe uma variedade de medidas de proximidades e as principais medidas utilizadas em dados textuais são discutidas na Seção 3.2. Por fim, na Seção 3.3 são discutidos os métodos de agrupamento, ou seja, as estratégias adotadas para definição dos grupos.

\subsection{Medidas de proximidade}

A escolha da medida de proximidade para calcular o quão similar são dois objetos é fundamental para a análise de agrupamentos. Essa escolha depende das características do 
conjunto de dados, principalmente dos tipos e escala dos dados. Assim, existem medidas de proximidade para dados contínuos, discretos e misturas entre dados contínuos e discretos. As medidas de proximidade podem calcular tanto a similaridade quanto distância (ou dissimilaridade) entre objetos. No entanto, as medidas de similaridades podem ser, geralmente, convertidas para medidas de distância, e vice-versa, por exemplo, calculando-se o complemento entre elas: $\operatorname{sim}\left(x_{i}, x_{j}\right)=1-\operatorname{dist}\left(x_{i}, x_{j}\right)$ (Tan et al., 2005).

No contexto deste trabalho, pode-se citar duas medidas de proximidades comumente utilizadas em dados textuais: cosseno e jaccard, conforme descrito abaixo.

- Cosseno: considera que os documentos estão representados em um espaço mdimensional, no qual cada atributo (termo ou palavra) representa uma dessas dimensões. Assim, considerando os documentos $x_{i}=\left(x_{i 1}, x_{i 2}, \ldots, x_{i m}\right)$ e $x_{j}=$ $\left(x_{j 1}, x_{j 2}, \ldots, x_{j m}\right)$ e um espaço com $m$ atributos, a similaridade cosseno entre $x_{i}$ e $x_{j}$ é calculada pela Equação 3.1 .

$$
d\left(x_{i}, x_{j}\right)=\operatorname{cosine}\left(x_{i}, x_{j}\right)=\frac{x_{i} \bullet x_{j}}{\left|x_{i}\right|\left|x_{j}\right|}=\frac{\sum_{l=1}^{m} x_{i l} x_{j l}}{\sqrt{\sum_{l=1}^{m} x_{i l}^{2}} \sqrt{\sum_{l=1}^{m} x_{j l}^{2}}}
$$

O valor da similaridade representa o cosseno do ângulo formado entre os vetores e é útil quando a magnitude dos dados não é importante. Em documentos textuais, os atributos representam termos (palavras) existentes e os valores podem ser, por exemplo, provenientes da frequência de ocorrência desses termos. Assim, a medida cosseno captura quantos termos são compartilhados por ambos documentos, ponderando-os pelos valores de ocorrência.

- Jaccard: em algumas situações os atributos dos documentos são binários, ou seja, indicam a presença ou ausência de alguma característica. Sejam $x_{i}$ e $x_{j}$ dois documentos com atributos binários, obtém-se as seguintes contagens:

- $f_{00}=$ número de atributos com valor 0 para ambos objetos;

- $f_{11}=$ número de atributos com valor 1 para ambos objetos;

- $f_{01}=$ número de atributos com valor 0 para $x_{i}$ e valor 1 para $x_{j}$; e

- $f_{10}=$ número de atributos com valor 1 para $x_{i}$ e valor 0 para $x_{j}$.

A medida Jaccard define a proximidade entre dois objetos com atributos assimétricos, ou seja, a presença de um efeito é mais importante que sua ausência. O coeficiente de Jaccard é definido na Equação 3.2.

$$
d\left(x_{i}, x_{j}\right)=\frac{f_{11}}{f_{01}+f_{10}+f_{11}}
$$

Uma dúvida pertinente que surge com relação às medidas de proximidade é qual escolher no processo de agrupamento. Não existe uma regra geral para esta escolha. Geralmente, esta decisão é tomada conforme a representação dos dados e é acompanhada de vários testes, seguidos por um processo de validação da qualidade dos grupos obtidos. 


\subsection{Métodos de Agrupamento}

Os métodos de agrupamento podem ser classificados considerando diferentes aspectos. Jain et al. (1999) organizam os métodos de agrupamento de acordo com a estratégia adotada para definir os grupos. Uma análise de diferentes métodos de agrupamento considerando o cenário de Mineração de Dados é apresentada em Berkhin (2006). Muitos desses métodos foram avaliados no contexto de mineração de textos em Zhao et al. (2005).

A seguir, são abordados os métodos de agrupamento particional e hierárquico, discutindo os algoritmos comumente citados na literatura.

\subsubsection{Métodos Particionais}

Os métodos particionais também são conhecidos como métodos de otimização. O objetivo é formar o agrupamento dividindo iterativamente o conjunto de objetos em $k$ grupos, na qual $k$ geralmente é um valor informado previamente pelo usuário. Os grupos são formados otimizando um determinado critério, geralmente uma função baseada na similaridade que busca a compactação e separação entre os grupos (Everitt et al., 2001).

O algoritmo k-means é um dos mais populares dos métodos particionais (Wu et al., 2007). Neste algoritmo, cada grupo possui um representante denominado centroide. O centroide de um grupo é um objeto formado com os valores médios dos atributos dos objetos desse grupo. O k-means, em sua proposta original, só é aplicável em dados que possuam atributos numéricos, na qual a média possa ser calculada. Os passos de execução do algoritmo k-means é exibido a seguir.

1. Perguntar ao usuário em quantos grupos ( $k$ ) o conjunto de documentos será dividido;

2. Selecionar aleatoriamente $k$ documentos como centroides iniciais;

3. Associar cada documento do conjunto ao centroide mais próximo, de acordo com uma medida de proximidade. A partir desta etapa, cada objeto está alocado em um grupo;

4. Atualizar os centroides representantes de cada grupo;

5. Repetir os passos 3 e 4 até um critério de parada, por exemplo, quando a solução convergir ou um determinado número de iterações.

O critério de convergência do $k$-means é determinado pela soma dos erros quadráticos, definido como

$$
E=\sum_{i=1}^{k} \sum_{x \in C_{i}}\left|x-m_{i}\right|^{2}
$$

na qual $E$ é a soma dos erros quadráticos para todos os documentos; $x$ é o vetor de atributos que representa um dado documento; e $m_{i}$ é o centroide do grupo $C_{i}$. Ao minimizar este critério, o $k$-means tenta separar o conjunto de dados em $k$ grupos, otimizando a compactação de cada grupo e a separação entre os grupos. A complexidade do k-means é linear em relação ao número de documentos, o que possibilita sua aplicação eficiente em 
diversos cenários. No entanto, a necessidade de informar com antecedência o número de grupos pode ser visto como uma desvantagem, pois este valor geralmente é desconhecido pelos usuários. Além disso, o método apresenta variabilidade nos resultados, pois a seleção dos centroides iniciais afeta o resultado do agrupamento, inclusive com a possibilidade de que a solução represente um mínimo local. Para minimizar esse efeito, o algoritmo é executado diversas vezes, com várias inicializações diferentes, e o melhor resultado é selecionado.

\subsubsection{Métodos Hierárquicos}

O diferencial desta abordagem é a obtenção de uma organização hierárquica, com grupos e seus subgrupos, representada por um dendrograma, uma estrutura especial de árvore. Os algoritmos de agrupamento hierárquico são utilizados em diversos tipos de problemas, uma vez que não exigem informação inicial a respeito do conjunto de dados, por exemplo, o número de grupos (Manning et al., 2008).

Os algoritmos de agrupamento hierárquico são classificados de acordo com sua estratégia de implementação: Aglomerativos (botton-up) e Divisivos (top-down). Na primeira, cada objeto é considerado um único grupo. Em seguida, pares de objetos são iterativamente agrupados de acordo com um índice de similaridade, até que todos os objetos pertençam a apenas um grupo. Por outro lado, a estratégia divisiva é iniciada com todos os objetos em um único grupo, que é iterativamente bipartido até que cada objeto seja um único grupo.

A maioria dos trabalhos relacionados com agrupamento hierárquico na literatura referenciam as estratégias aglomerativas, mostrando pouco interesse nas estratégias divisivas. Isto pode ser explicado pelo fato de que as estratégias aglomerativas geralmente apresentam complexidade quadrática, ou seja $O\left(N^{2}\right)$, que apesar de relativamente custosa, são muitas vezes aplicáveis. Já a complexidade das estratégias divisivas crescem exponencialmente em relação ao tamanho do conjunto de dados, proibindo sua aplicação em conjuntos de dados grandes (Xu e Wunsch, 2008). No entanto, nos últimos anos foram propostos algoritmos de agrupamento hierárquico divisivos com complexidade semelhante aos aglomerativos, possibilitando sua aplicação em conjuntos de dados maiores, inclusive em coleções textuais (Steinbach et al., 2000).

\section{Estratégias Aglomerativas}

Considerando um conjunto com $N$ documentos, a seguir são descritos os passos executados em um agrupamento hierárquico aglomerativo.

1. Inicialmente, cada documentos é considerado um único grupo, ou seja, existem $N$ grupos unitários. Calcule uma matriz de proximidades entre os $N$ grupos;

2. Encontre a distância mínima $d\left(C_{i}, C_{j}\right)=\min \left(C_{m}, C_{l}\right)$, com $1 \leq m, l \leq N, m \neq l$, e onde $d(\bullet, \bullet)$ é um critério de distância entre grupos discutido adiante. Unir os grupos $C_{i}$ e $C_{j}$ na formação de um novo grupo $C_{i j}$ 
3. Atualize a matriz de proximidades calculando as distâncias entre $C_{i j}$ e os grupos restantes;

4. Repetir os passos 2 e 3 até que um único grupo seja formado.

A diferença entre os algoritmos de agrupamento hierárquico aglomerativos está no critério de distância utilizado para unir os grupos $C_{i}$ e $C_{j}$, na formação de um novo grupo $C_{i j}$ (passo 2). Os algoritmos principais são conhecidos como Single Link, Complete Link e Average Link (Manning et al., 2008).

O Single Link é um dos algoritmos de agrupamento hierárquico mais simples. Esse método utiliza a técnica do vizinho mais próximo (Nearest Neighbor), na qual a distância entre dois grupos é determinada pela distância do par de objetos mais próximos, sendo cada objeto pertencente a um desses grupos. Esse método de união de grupos apresenta um problema conhecido como "efeito da corrente", em que ocorre a união indevida de grupos influenciada pela presença de ruídos na base de dados. O critério de distância entre grupos do Single Link é descrita na Equação 3.4.

$$
D\left(C_{l},\left(C_{i}, C_{j}\right)\right)=\min \left(D\left(C_{l}, C_{i}\right), D\left(C_{l}, C_{j}\right)\right)
$$

Já o Complete Link utiliza uma técnica conhecida como Farthest Neighbor, ou vizinho mais distante. Ao contrário do algoritmo Single Link, esse algoritmo determina a distância entre dois grupos de acordo com a maior distância entre um par de objetos, sendo cada objeto pertencente a um grupo distinto. Esse método dificulta a formação do efeito da corrente, como ocorre no Single Link, e tende a formar grupos mais compactos e em formatos esféricos. O critério de distância entre grupos do Complete Link é definida na Equação 3.5.

$$
D\left(C_{l},\left(C_{i}, C_{j}\right)\right)=\max \left(D\left(C_{l}, C_{i}\right), D\left(C_{l}, C_{j}\right)\right)
$$

O Single Link e Complete Link são opostos em termos do critério utilizado para união dos grupos. Uma abordagem intermediária é o algoritmo Average Link, também conhecido como UPGMA. No algoritmo Average Link, a distância entre dois grupos é definida como a média das distâncias entre todos os pares de objetos em cada grupo, cada par composto por um objeto de cada grupo. Esse método elimina muitos problemas relacionados à dependência do tamanho dos grupos, mantendo a próxima variabilidade interna entre eles. O critério de distância entre grupos do Average Link é definida na Equação 3.6 .

$$
D\left(C_{l},\left(C_{i}, C_{j}\right)\right)=\frac{1}{2}\left(D\left(C_{l}, C_{i}\right)+D\left(C_{l}, C_{j}\right)\right) .
$$

A escolha do critério de união de grupos dos algoritmos aglomerativos depende geralmente do conjunto de dados e dos objetivos da aplicação. Por exemplo, em dados textuais, avaliações experimentais têm mostrado o Average Link como uma boa opção entre os algoritmos que adotam estratégias aglomerativas (Zhao et al., 2005). 


\section{Estratégias Divisivas}

O principal algoritmo de agrupamento hierárquico divisivo adotado em coleções textuais é conhecido como Bi-Secting K-Means (Steinbach et al., 2000) e seu funcionamento será descrito a seguir.

O algoritmo Bi-Secting K-Means é, essencialmente, o uso sucessivo do algoritmo KMeans clássico, de forma a construir um agrupamento hierárquico. No algoritmo K-Means clássico, é necessário informar um número $k$ de grupos desejado e, então, é encontrada a melhor partição (conjunto de grupos não hierárquico) em relação ao $k$.

Com base no K-Means clássico, o algoritmo Bi-Secting K-Means inicia com um único grupo de todos os documentos e executa os seguintes passos:

1. Escolha o grupo para dividir;

2. Encontre dois sub-grupos usando o algoritmo K-Means com $k=2$;

3. Repita os passos 1 e 2 até que cada grupo seja um único documento.

As estratégias divisivas baseada no Bi-Secting K-Means têm se mostrado uma alternativa razoável às estratégias aglomerativas Zhao et al. (2005). No entanto, conforme mencionado anteriormente, este método é sensível à escolha inicial dos centroides na etapa do K-Means. Uma forma de contornar este problema é repetir o processo de divisão do grupo em dois sub-grupos, com o K-Means, diversas vezes e escolher a solução mais promissora.

Tanto as estratégias aglomerativos quanto as divisivas organizam os resultados do agrupamento em uma árvore binária conhecida como dendrograma. Esta representação é uma forma intuitiva de visualizar e descrever a sequência do agrupamento e a similaridade com que os grupos foram formados.

Na Figura 3.1 é apresentado um exemplo de dendrograma. Essa estrutura é uma árvore com $N$ folhas e com altura $N$ - 1, considerando uma coleção de $N$ documentos. Os documentos são dispostos no eixo horizontal, enquanto que o eixo vertical indica similaridade entre os grupos. O topo do dendrograma (primeiro nível) corresponde a um grupo contendo todos os documentos da coleção. O último nível contém os grupos unitários (nós folhas), e cada nó ${ }^{1}$ é um documento da coleção. Os nós intermediários e as uniões entre eles representam a sequência do agrupamento (Metz, 2006).

O dendrograma também possibilita extrair uma partição, ou seja, um conjunto de grupos não hierárquico. Por exemplo, ainda na Figura 3.1, pode-se extrair uma partição com 3 grupos, com distância em torno de 70, representado pela linha do nível 3 na figura. A extração de uma partição é muito comum quando o interesse é obter uma organização flat da coleção.

É possível analisar a qualidade do agrupamento diretamente pelo dendrograma. A altura dos arcos que unem dois subgrupos indicam o grau de compactação do grupo formado por eles. Quanto menor a altura, mais compactos são os grupos. No entanto, também espera-se que os grupos formados sejam distantes entre si, ou seja, que a similaridade de

\footnotetext{
${ }^{1}$ Os termos nó e grupo são utilizados indistintamente neste trabalho.
} 


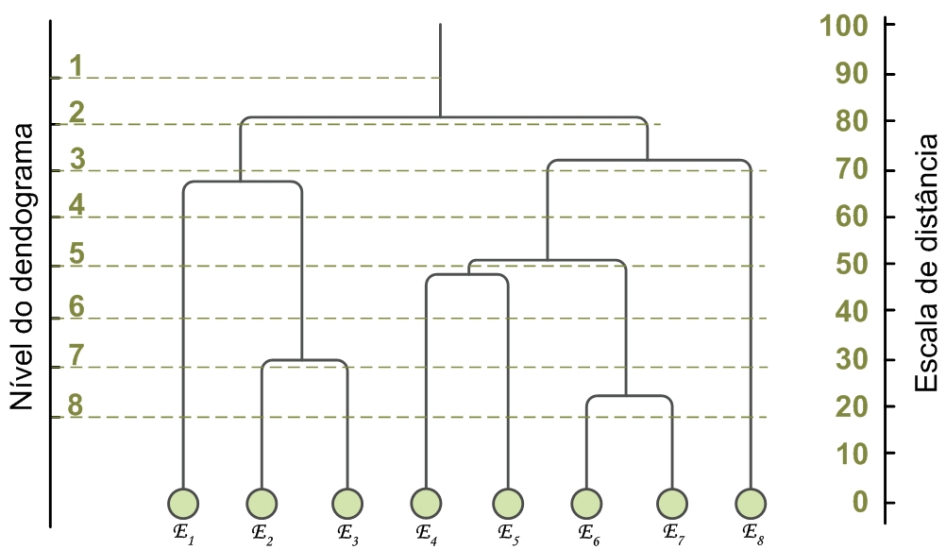

Figura 3.1: Análise da Estrutura do Dendrograma. Fonte: Metz (2006)

documentos em grupos distintos seja a menor possível. Essa característica é representada quando existe uma grande diferença entre a altura de um arco e os arcos formados abaixo dele. Desta forma, a diferença entre os algoritmos de agrupamento hierárquico são expressados diretamente pelo dendrograma.

\subsection{Considerações finais}

O agrupamento de documentos é muito útil em uma grande variedade de aplicações, como na recuperação de informação ou na organização de bibliotecas digitais. O uso de agrupamentos hierárquicos de documentos permite explorar o conhecimento obtido em diferentes níveis de abstração. Entretanto, a interpretação dos grupos obtidos é uma tarefa complexa para o usuário pois os algoritmos não apresentam descrições conceituais simples, mas apenas um conjunto de dados descritos normalmente por meio de valores estatísticos e índices de similaridade (Metz, 2006). Assim, é importante encontrar bons descritores para os grupos que auxiliem o usuário na navegação, busca e compreensão do conhecimento obtido.

Assim, o problema de seleção de descritores para agrupamento hierárquico de documentos é descrito com mais detalhes no Capítulo 4, bem como a metodologia proposta neste trabalho para seleção de candidatos a descritores e o método proposto. 



\section{Capítulo}

\section{4}

\section{Seleção de Candidatos a Descritores para Agrupamentos Hierárquicos}

\subsection{Considerações iniciais}

Uma vez construída a estrutura hierárquica, é necessário encontrar descritores para cada um dos grupos obtidos. A seleção de descritores para agrupamentos é uma tarefa comum na mineração de texto e na recuperação de informação. Geralmente, os métodos buscam uma lista de termos discriminativos, que são usados para facilitar a recuperação da informação ou uma interpretação de cada grupo (Moura e Rezende, 2010).

Existe uma quantidade considerável de pesquisas para melhorar os algoritmos de agrupamento hierárquico e suas aplicações na recuperação de informação. Entretanto, pouca atenção é dada na etapa de seleção de bons descritores. Descritores para os grupos obtidos de forma automática normalmente são pouco compreensíveis ou consistem em uma lista de termos que dão uma idéia muito vaga sobre o tema dos documentos do grupo (Treeratpituk e Callan, 2006; Manning et al., 2008).

A tarefa de seleção de descritores para agrupamentos consiste em obter descrições concisas e significativas para os grupos. Normalmente, os descritores utilizados são aqueles que facilitam interpretação dos dados. No caso de agrupamentos de dados textuais, é preciso encontrar descritores que sejam significativos para o usuário. Um bom descritor deve conter um pequeno número de termos que distingue precisamente cada grupo dos outros (Feldman e Sanger, 2007).

Em muitos problemas, como por exemplo na organização de uma biblioteca digital, o agrupamento hierárquico de documentos já está construído. Nestes casos, é preciso obter um conjunto de descritores para os nós da hierarquia respeitando a organização existente e utilizando a informação contida na própria coleção. Assim, na Seção 4.2 é apresentado o problema de seleção de descritores para agrupamentos hierárquicos de documentos. A metodologia proposta neste trabalho para seleção de descritores é descrita na Seção 4.3. 
Na Seção 4.4, o método proposto é apresentado, e a avaliação e discussão dos resultados são detalhados da Seção 4.5 .

\subsection{Abordagens para seleção de descritores para agrupamento hi- erárquico de documentos}

A maior parte dos trabalhos de agrupamento de documentos considera que documentos em um mesmo grupo apresentam comportamento similar com respeito à relevância da informação desejada pelo usuário (hipótese de agrupamento). Esta hipótese também norteia a maior parte dos trabalhos de seleção de descritores em agrupamento de textos. Manning et al. (2008) descreve duas linhas principais de pesquisa:

- Seleção baseada nas diferenças entre os grupos: A seleção dos descritores é realizada comparando a distribuição dos termos de cada grupo em relação aos outros grupos. Os termos selecionados são aqueles que mais caracterizam o grupo em contraste com os outros grupos;

- Seleção baseada em critérios internos do grupo: A seleção dos descritores depende exclusivamente das informações contidas no grupo. Por exemplo, a lista de descritores de um grupo pode ser formada pelos $K$ termos com maior frequência absoluta entre os documentos deste grupo.

As soluções encontradas para as duas linhas de pesquisa se comportam muito bem em problemas de agrupamento não hierárquico de documentos. No caso de agrupamentos hierárquicos de documentos, algumas dificuldades são encontradas. Além da necessidade de diferenciar aqueles nós internos da hierarquia que estão ligados a um mesmo nó pai, também é preciso diferenciar os nós pais dos nós filhos. Os documentos de um nó, por definição, também são membros do nó pai deste nó. Então, não é possível adotar um método mais simples que apenas seleciona aqueles descritores que diferenciam o nó pai e o nó filho.

Os métodos de seleção de descritores para agrupamento hierárquico de documentos encontrados na literatura podem ser divididos em métodos baseados em frequência, como no caso do método Mais Frequentes (Miiller e Dorre, 1999; Chuang e Chien, 2005), métodos baseados em centroide (Cutting et al., 1992; Larsen e Aone, 1999; Zhang et al., 2009), métodos baseados em modelos probabilísticos ou estatísticos (Glover et al., 2002; Moura e Rezende, 2010; Popescul e Ungar, 2000; Treeratpituk e Callan, 2006) e ainda métodos que adicionam conhecimento externo (Tseng, 2010; Carmel et al., 2009). Além disso, a seleção pode ocorrer de forma embarcada no algoritmo de agrupamento hierárquico, ou seja, durante a obtenção dos grupos os descritores são selecionados, ou podem ocorrer em uma etapa separada, após a aplicação do algoritmo de agrupamento hierárquico.

De forma geral, os métodos de seleção de descritores executam dois passos principais, ilustrados na Figura 4.1. Seja $H$ o agrupamento hierárquico obtido a partir do conjunto $D$ de documentos, $T$ o conjunto de termos que estão presentes nos documentos em $D$ e $N$ o conjunto de nós de $H$. Inicialmente, o método obtém um conjunto de possíveis 
descritores para cada nó de $N$ (Passo 1). Esse conjunto normalmente é obtido a partir dos termos do conjunto $T$. Em seguida, selecionam-se alguns itens desse conjunto para formar a lista de descritores associada ao nó (Passo 2). Esse processo é executado até que todos os nós de $N$ sejam processados.

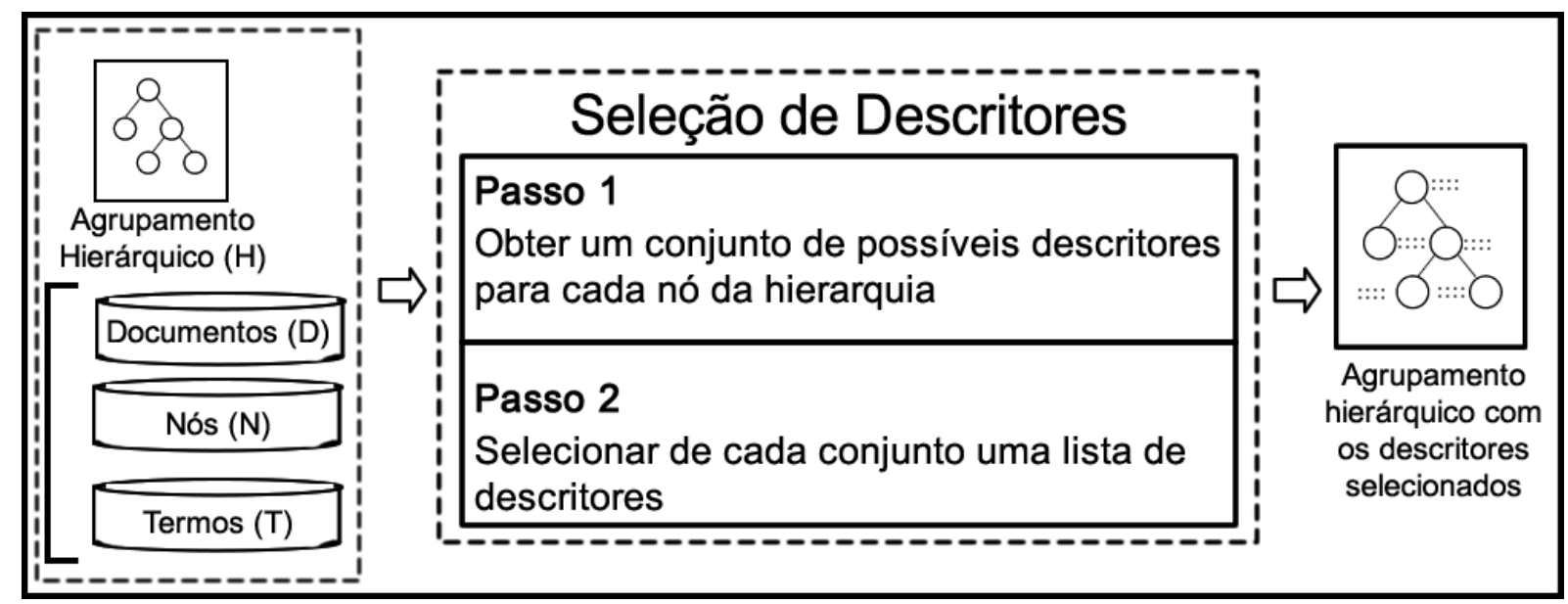

Figura 4.1: Processo de seleção candidatos a descritores.

O método mais simples e amplamente utilizado é a seleção daqueles que aparecem mais vezes nos documentos do grupo, ou seja, os termos com maior frequência. Esta lista normalmente revela os tópicos de mais alto nível, mas pode deixar de retratar detalhes específicos do agrupamento (Popescul e Ungar, 2000). Segundo Moura (2009), esse método apresenta bons resultados para agrupamentos não hierárquicos e disjuntos (flat clusters), porém introduz uma série de repetições desnecessárias de termos ao longo da hierarquia.

Métodos de seleção de descritores baseados em centróides são utilizados principalmente combinados com agrupamentos obtidos pelos métodos $k$-means e $k$-medóide e seus derivados, tanto em suas versões particionais quanto em suas versões hierárquicas. O método de recuperação scatter/gather proposto por Cutting et al. (1992) utiliza a informação do documento mais próximo ao centróide para selecionar a lista de descritores que é apresentada ao usuário. O método é dividido em duas etapas principais. Na primeira fase, a coleção é dividida em um número pequeno de grupos, utilizando algum método particional baseado em centróide. Cada grupo recebe como descritor uma lista de termos extraída do documento mais próximo do centróide deste grupo. O usuário escolhe aquele grupo que parece conter a informação mais próxima daquela desejada. Os documentos do grupo escolhido é então reprocessado como na primeira fase do processo, e cada novo grupo obtido recebe como descritor os termos selecionados do documento mais próximo do centróide. O trabalho de Larsen e Aone (1999) propõe o uso do método $k$-means combinado com as idéias principais do método scatter/gather visando reduzir a complexidade do algoritmo e a necessidade de interação com o usuário. Neste método, o agrupamento hierárquico é produzido pela aplicação recursiva do método $k$-means em cada um dos grupos obtidos, e os descritores são obtidos ao selecionar os termos presentes no documento mais próximo ao centróide.

Trabalhando-se com modelos probabilísticos de agrupamentos há o modelo CAM Cluster Abstraction Model, desenvolvido por Hofmann (1999). Nesse modelo restringe-se a presença do termo no nó da hierarquia como ascendente ao grupo em que o termo é signi- 
ficativo no documento somada à distribuição das palavras condicionadas aos documentos, ou seja, os descritores de um nó são aqueles termos que melhor descrevem o conteúdo dos documentos associados a ele. Para determinar o que é um termo significativo, o autor propõe um modelo probabilístico baseado no teorema de Bayes. Com isto, captura-se a idéia de propagação de termos em uma taxonomia, em que se verifica que um documento é composto por uma mistura de termos que vão dos mais genéricos para os mais específicos. O resultado é bom, embora a forma de se chegar ao mesmo seja muito complexa e envolva o acerto dos critérios de convergência dos métodos empregados, além de ser um método de seleção de descritores dependente do método de agrupamento.

Outra solução, não probabilística e mais simples, é a utilizada no ambiente TaxaMiner (Kashyap et al., 2005), que busca identificar taxonomias de tópicos a partir de agrupamentos hierárquicos em que os documentos são agrupados mediante o cálculo de um fator de coesão dos grupos. A taxa de coesão de cada grupo indica também os atributos mais significativos em cada um deles. Nesse método é realizado um procedimento de pruning da árvore de cluster com base na idéia de propagação de termos em uma taxonomia. A base do procedimento de pruning é que níveis mais específicos da árvore que nada acrescentam aos seus antecedentes podem ser podados; para tomar essa decisão o método utiliza a medida de coesão, nele definida, para maximizar a relação intracluster e também estabelece empiricamente um threshold.

Uma idéia independente de como a hierarquia é obtida e que tenta evitar duplicações desnecessárias das palavras é a apresentada em Popescul e Ungar (2000). Parte-se da raiz para as folhas da árvore, verificando cada um dos nós. Cada nó recebe uma lista de possíveis descritores composta por todos os termos dos documentos associados a este nó, e cada termo é associado a sua frequência total nesta coleção. Para selecionar a lista final de descritores, cada termo com frequência maior que zero nos filhos é avaliada segundo o seu grau de dependência ou associação com este filho. Se a hipótese de independência for aceita, então a palavra pertence ao nó pai e é removida dos nós filhos, caso contrário ela é associada aos nós filhos e removida do nó pai. Um dos problemas desse método é garantir a convergência da distribuição das diferenças dos valores esperados e observados para uma distribuição $\chi^{2}$, utilizada nos testes, quando os valores esperados são muito pequenos (próximos de zero).

Outro método independente do método de agrupamento foi proposto por Glover et al. (2002). Sua proposta é baseada exclusivamente nas frequências observadas para cada palavra em cada agrupamento, ou seja, na estimativa de máxima verossimilhança das suas probabilidades: $p(w \mid c)$ e $p(w)$, com $w$ correspondendo à palavra e $c$ ao grupo (considerado como uma classe). A hipótese é que se $p(w \mid c)$ é muito comum e $p(w)$ é rara então a palavra discrimina bem a classe $c$, ou se tanto $p(w \mid c)$ como $p(w)$ são comuns então a palavra discrimina melhor a classe pai de $c$ e, finalmente, se $p(w \mid c)$ é muito comum e $p(w)$ é relativamente rara na coleção então a palavra discrimina melhor a classe filha de $c$; o que significa muito comum ou muito raro é experimentalmente determinado. Uma modificação foi proposta a esse método, que procura estabelecer um compromisso entre um rótulo simples e uma lista de tópicos, estabelecendo um descriptive score ponderado pela $t f$-idf (Treeratpituk e Callan, 2006). Embora os resultados sejam mais promissores, o 
problema de determinar os critérios de convergência experimentalmente foram ampliados também para os novos cuttoffs necessários ao descriptive score.

Com base na proposta apresentada por Popescul e Ungar (2000), Moura e Rezende (2010) propuseram o RLUM - Robust Lableling Up Method. Ele tanto resolve mais diretamente a questão de repetição dos descritores quanto utiliza um estimador mais robusto para testar as hipóteses de independência ou dissociação das palavras aos grupos. Além disso, o objetivo é distribuir os termos ao longo da hierarquia, evitando repetições desnecessárias nos mesmos ramos, mantendo os termos mais genéricos nos níveis mais altos e os mais específicos nos níveis mais baixos. O RLUM é mais robusto e possui uma complexidade menor que a do método proposto por Popescul e Ungar (2000).

Tseng (2010) utiliza um subconjunto de relações da WordNet (WordNet, 2009) como parte do critério de decisão para seleção de descritores de um nó. Com isso, o autor espera encontrar termos mais genéricos como descritores dos grupos mais próximos a raiz da hierarquia e termos mais específicos nos grupos mais próximos das folhas. A avaliação mostra que o método consegue melhoras significativas, entretanto alguns problemas são encontrados quando termos extraídos da coleção não estão contemplados na Wordnet. Já o método proposto por Carmel et al. (2009) utiliza conhecimento extraído da Wikipedia para selecionar os descritores. Após extrair palavras chaves e frases dos documentos de um grupo, o método procura identificar as páginas da Wikipedia mais semelhantes com estes documentos. A categoria e o título de cada uma das páginas encontradas é considerada como um candidato a descritor para o grupo, bem como as palavras chaves extraídas inicialmente. Estes candidatos são avaliados e os melhores são selecionados. Os resultados obtidos são promissores, entretanto, quando a coleção de documentos se refere a um domínio específico pouco coberto pela Wikipedia, o método não oferece uma melhora significativa. Observa-se que em ambos os casos, o desempenho está fortemente relacionado a quantidade de informação externa disponível.

Na proposta de Lopes et al. (2007), utilizam-se regras de associação como descritores de agrupamentos não-hierárquicos. Segundo os autores, as regras de associação possuem um nível semântico intrínseco que não é possível determinar com uma simples contagem de frequência ou com uma redução do conjunto de termos dos documentos. A própria regra de associação gerada é utilizada como descritor do grupo, e a geração das regras também considera cada documento como uma bag-of-words. Além disso, as regras de associação são facilmente entendidas e interpretadas tanto por um especialista quanto por um usuário comum (Mahgoub et al., 2008).

Um resumo dos métodos de seleção de descritores aqui mencionados é apresentado na Tabela 4.1, destacando-se as principais características dos métodos de acordo com a visão geral ilustrada na Figura 4.1. Alguns dos trabalhos apresentados não abordam exclusivamente a questão da seleção de descritores, e neste caso, focou-se na solução encontrada pelos autores nessa etapa.

\footnotetext{
${ }^{1}$ Palavras com significado mais abrangente
} 


\begin{tabular}{|c|c|c|c|}
\hline Método & Ideia geral & Passo 1 & Passo 2 \\
\hline Mais Frequentes & $\begin{array}{l}\text { Os termos que apa- } \\
\text { recem com maior } \\
\text { frequência na coleção } \\
\text { são mais importantes }\end{array}$ & $\begin{array}{l}\text { Ordenar os termos de acordo com a } \\
\text { frequência acumulada deste termo } \\
\text { nos documentos do nó }\end{array}$ & $\begin{array}{l}\text { Selecionar os } n \text { termos com maior } \\
\text { valor de frequência acumulada }\end{array}$ \\
\hline $\begin{array}{l}\text { scatter/gather (Cut- } \\
\text { ting et al., 1992) } \\
\text { Larsen e Aone (1999) }\end{array}$ & $\begin{array}{l}\text { O documento mais } \\
\text { próximo ao centro } \\
\text { do grupo (centroide) } \\
\text { é aquele que melhor } \\
\text { representa este grupo }\end{array}$ & $\begin{array}{l}\text { Ordenar os termos do documento } \\
\text { mais próximo do centroide de } \\
\text { acordo com sua frequência neste } \\
\text { documento }\end{array}$ & $\begin{array}{l}\text { Selecionar os } n \text { termos com maior } \\
\text { valor de frequência acumulada }\end{array}$ \\
\hline Hofmann (1999) & $\begin{array}{l}\text { Analisar como o apare- } \\
\text { cimento de um termo } \\
\text { influencia na formação } \\
\text { do grupo com base no } \\
\text { teorema de Bayes }\end{array}$ & $\begin{array}{l}\text { Os termos presente nos documen- } \\
\text { tos do grupo são ordenados de } \\
\text { acordo com um peso calculado à } \\
\text { partir de um modelo probabilístico } \\
\text { proposto }\end{array}$ & $\begin{array}{l}\text { Selecionar os } n \text { termos com maior } \\
\text { peso }\end{array}$ \\
\hline $\begin{array}{l}\text { TaxaMiner (Kashyap } \\
\text { et al., 2005) }\end{array}$ & $\begin{array}{l}\text { Os termos mais rela- } \\
\text { cionados ao centro do } \\
\text { grupo (centroide) são } \\
\text { aqueles que melhor re- } \\
\text { presentam o grupo }\end{array}$ & $\begin{array}{l}\text { Avalia a contribuição de cada } \\
\text { termo nos pesos do centroide }\end{array}$ & $\begin{array}{l}\text { Seleciona os } n \text { termos que mais } \\
\text { contribuem no centroide }\end{array}$ \\
\hline $\begin{array}{l}\text { Popescul e Ungar } \\
(2000)\end{array}$ & $\begin{array}{l}\text { Um termo é descritor } \\
\text { se ele depende estatis- } \\
\text { ticamente do nó }\end{array}$ & $\begin{array}{l}\text { Construir uma tabela de contin- } \\
\text { gência para cada termo observando } \\
\text { sua frequência em cada um dos nós } \\
\text { filhos }\end{array}$ & $\begin{array}{l}\text { Aplicar um teste de hipóteses para } \\
\text { cada termo. Se a hipótese de in- } \\
\text { dependência é aceita, o termo é se- } \\
\text { lecionado como descritor do nó e } \\
\text { não deve ser descritor de nenhum } \\
\text { nó descendente }\end{array}$ \\
\hline $\begin{array}{l}\text { Glover et al. (2002) } \\
\text { Treeratpituk e Callan } \\
(2006)\end{array}$ & $\begin{array}{l}\text { Avaliar a distribuição } \\
\text { de frequência do termo } \\
\text { no nó em relação a sua } \\
\text { distribuição na coleção }\end{array}$ & $\begin{array}{l}\text { Para cada termo, calcular a sua } \\
\text { distribuição de frequência no grupo } \\
\text { e sua distribuição de frequência na } \\
\text { coleção }\end{array}$ & $\begin{array}{l}\text { O termo é selecionado se a sua dis- } \\
\text { tribuição de frequência no grupo é } \\
\text { "comum" e a distribuição na cole- } \\
\text { ção é "rara" }\end{array}$ \\
\hline Tseng (2010) & $\begin{array}{l}\text { Descritores mais gené- } \\
\text { ricos são facilmente in- } \\
\text { terpretáveis }\end{array}$ & $\begin{array}{l}\text { (i) Selecionar os termos que estão } \\
\text { presentes em mais de } r \% \text { dos do- } \\
\text { cumentos do grupo (ii) Localizar, } \\
\text { para cada termo, todos os hipe- } \\
\text { rônimos }^{1} \text { mapeados pela WordNet } \\
\text { (iii) Calcular um peso para cada hi- } \\
\text { perônimo com base em sua profun- } \\
\text { didade na WordNet e o número de } \\
\text { vezes que ele ocorre }\end{array}$ & $\begin{array}{l}\text { Selecionar os } n \text { hiperônimos com } \\
\text { maior peso }\end{array}$ \\
\hline Carmel et al. (2009) & $\begin{array}{l}\text { Adicionar conheci- } \\
\text { mento externo na } \\
\text { obtenção do conjunto } \\
\text { de possíveis descritores }\end{array}$ & $\begin{array}{l}\text { (i) Extrair dos documentos do nó } \\
\text { os termos mais importantes (ii) } \\
\text { utilizar estes termos para identifi- } \\
\text { car páginas relacionadas na Wiki- } \\
\text { pedia e extrair o título e as catego- } \\
\text { rias de cada uma (iii) calcular, para } \\
\text { todos os itens obtidos nas etapas i } \\
\text { e ii, um score baseado em diferen- } \\
\text { tes heurísticas }\end{array}$ & $\begin{array}{l}\text { Selecionar os } n \text { descritores com } \\
\text { maior score }\end{array}$ \\
\hline Lopes et al. (2007) & $\begin{array}{l}\text { Utilizar regras de as- } \\
\text { sociação extraídas dos } \\
\text { documentos como des- } \\
\text { critor melhora a com- } \\
\text { preensão dos grupos } \\
\text { obtidos }\end{array}$ & $\begin{array}{l}\text { (i) Selecionar os } k \text { termos com } \\
\text { maior peso calculado pela razão en- } \\
\text { tre a sua frequência no grupo e a } \\
\text { sua frequência na coleção (ii) Obter } \\
\text { regras de associação à partir destes } \\
\text { termos }\end{array}$ & $\begin{array}{l}\text { Selecionar as } n \text { regras de associ- } \\
\text { ação com maior peso acumulado } \\
\text { (soma dos pesos dos termos presen- } \\
\text { tes na regra) }\end{array}$ \\
\hline
\end{tabular}

Tabela 4.1: Visão geral dos métodos de seleção de descritores.

\subsection{Seleção de candidatos a descritores}

Os métodos apresentados na Tabela 4.1 consideram cada documento presente em $D$ como sendo uma bag-of-words e com isso não exploram explicitamente o relacionamento existente entre os termos dos documento. No entanto, essas relações podem trazer informações importantes para a decisão dos termos que devem ser escolhidos como descritores dos nós, e poderiam ser representadas por regras de associação, uma vez que essa técnica carrega um nível semântico intrínseco que não é possível de determinar com uma sim- 
ples contagem de frequência ou redução da dimensionalidade (Lopes et al., 2007). Assim, neste trabalho é proposto o método SeCLAR - Selecting Candidate Labels using Association Rules -, que explora o uso de regras de associação para a seleção de candidatos a descritores para agrupamentos hierárquicos de documentos.

A metodologia adotada neste trabalho trata a etapa de seleção de descritores de forma independente da etapa de agrupamento dos documentos, como ilustrado na Figura 4.1 da Seção 4.2. Segundo Moura (2009), isso permite avaliar diferentes métodos de obtenção da hierarquia e de seleção de descritores separadamente e, além disso, os métodos de seleção de descritores podem ser aplicados a qualquer hierarquia, tenha ela sido obtida de forma automática ou manual. Assim, o método SeCLAR é proposto como uma etapa adicional, conforme apresentado na Figura 4.2. Essa etapa visa selecionar um subconjunto de termos presentes na coleção que sejam relevantes para descrever cada um dos grupos encontrados, aqui chamados de candidatos a descritores. Espera-se, então, contribuir com os métodos clássicos encontrados na literatura, uma vez que estes irão selecionar os descritores de cada grupo de um subconjunto já relevante de termos. Ainda, sendo uma etapa independente das demais, não há necessidade de alterar as soluções já existentes.

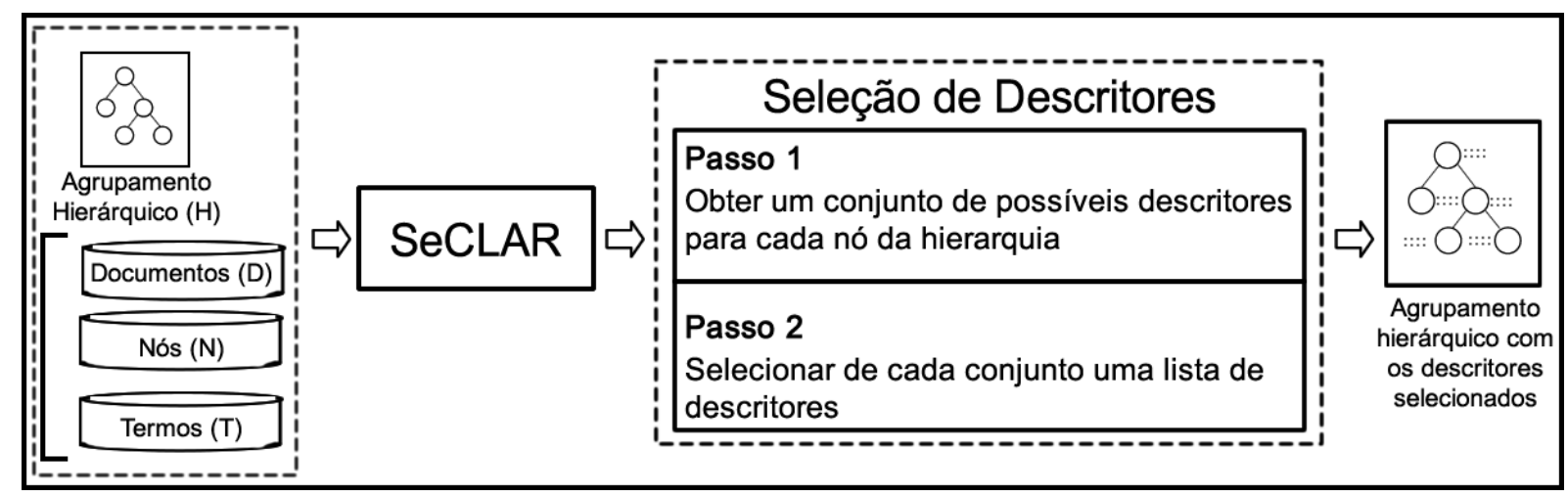

Figura 4.2: Processo de seleção candidatos a descritores utilizando o SeCLAR.

Para cada nó da hierarquia $H$, o método SeCLAR transforma todos os documentos em um conjunto de transações e extrai um conjunto de regras de associação. A transformação realizada neste trabalho difere daquela normalmente adotada na literatura, que considera cada documento como uma única transação. O processo realizado aqui, descrito em detalhes na Seção 4.4.1, percorre cada documento utilizando uma janela deslizante de tamanho fixo. Esse tamanho corresponde ao número de termos consecutivos tratados pela janela. A cada passo, os itens presentes na janela são adicionados ao conjunto de transações, e a janela movimenta para o próximo termo do documento. Ao percorrer o documento dessa maneira, é possível capturar algumas relações presentes na estrutura da escrita do texto. A extração das regras de associação é feita conforme apresentado na Seção 2.3.2. Optou-se por utilizar os mesmos valores de suporte e confiança mínimos para todos os nós.

Uma vez extraídas as regras de associação, a ideia geral do método proposto é considerar cada relação do tipo pai-filho existente entre os nós como do tipo das relações antecedente-consequente utilizadas nas regras de associação. Assume-se, então, que o nó pai influencia cada um dos seus nós filhos, e portanto os descritores selecionados para o 
nó pai devem refletir essa informação, conforme ilustrado na Figura 4.3.

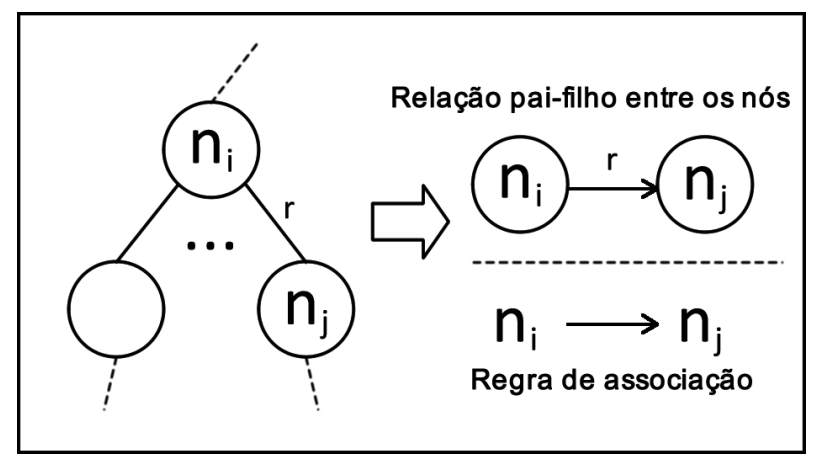

Figura 4.3: Exemplo de relação pai-filho $(r)$ processada como uma relação de regra de associação

Assim, é possível utilizar cada uma das regras de associação extraídas para obter termos candidatos a descritores, associando os termos do antecedente como candidatos a descritor do nó pai e os itens do consequente como candidato a descritor do nó filho. Entretanto, o conjunto de regras de associação extraídas do nó pai não será igual à união dos conjuntos de regras de associação dos seus nós filhos devido a diferença na quantidade de transações em cada grupo. Portanto, deve-se escolher entre utilizar o próprio conjunto de regras do nó ou um conjunto formado pela união das regras geradas nos nós filhos. A segunda estratégia foi utilizada no método SeCLAR uma vez que ela parece captar melhor a informação da estrutura hierárquica.

Além disso, utilizou-se apenas a informação do antecedente da regra de associação como candidatos a descritores do nó pai, descartando a informação do consequente da regra. Isto foi feito pois cada nó filho também possui descendentes que irão fornecer uma lista de possíveis candidatos para este nó. O método SeCLAR é descrito na Seção 4.4, bem como cada uma das etapas propostas.

\subsection{Método SeCLAR}

O método SeCLAR recebe como entrada um agrupamento hierárquico $H$ construído a partir de um conjunto de documentos $D$, o conjunto $N$ de nós associados a $H$ e um conjunto de termos $T$ previamente selecionados do conjunto de termos presentes na coleção, como ilustrado na Figura 4.4. O conjunto $D$ é formado pelos documentos utilizados na formação da hierarquia. Caso haja algum pré-processamento dos documentos, como limpeza, padronizações e remoção de palavras, utiliza-se os arquivos obtidos ao final deste processo. Cada nó do conjunto $N$ possui um conjunto $D^{\prime}$ de documentos associados a este nó tal que $D^{\prime}$ é um subconjunto de $D$. O conjunto $T$ é o conjunto formado por todos os termos presentes nos documentos do conjunto $D$, bem como a informação da relação de cada termo com os documentos em que ele aparece, e uma medida de frequência associada a essa relação, representada normalmente em uma matriz atributo-valor. Essa frequência associada pode ser, por exemplo, a informação da frequência absoluta do termo no documento. O método apresentado no Algoritmo 4 também recebe os seguintes parâmetros como entrada: 
- tamanho_janela é utilizado para ajustar o tamanho da janela para transformar os documentos em um conjunto de transações;

- medida se refere à medida objetiva que será utilizada para selecionar um subconjunto de regras de associação, executado pelo Algoritmo 6;

- $K$ representa o número máximo de regras de associação selecionadas no Algoritmo 6 de acordo com a medida escolhida no parâmetro medida;

- supmin e confmin são os valores de suporte mínimo e confiança mínima, respectivamente, utilizados pelo algoritmo de geração de regras de associação.

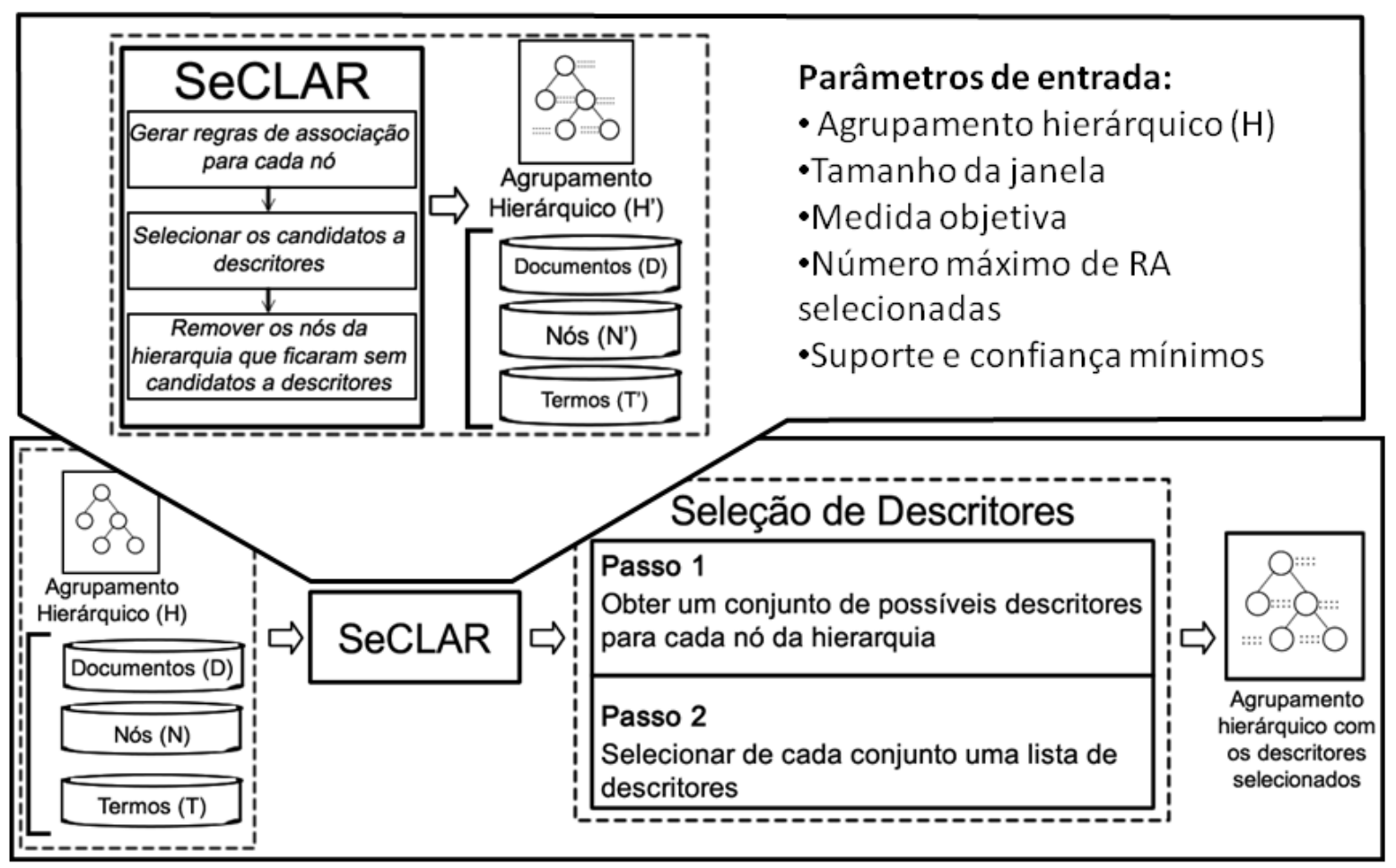

Figura 4.4: Etapas da metodologia para seleção de candidatos a descritores utilizando o SeCLAR.

O processo inicia-se com a geração dos conjuntos de regras de associação associados a cada nó da hierarquia (linhas 1 a 4). Na linha 3, recupera-se o subconjunto de documentos de $D$ que está associado ao nó $n_{i}$ que será processado. O algoritmo auxiliar gerar-regras-associação transforma estes documentos em transações e obtém um conjunto de regras de associação para este nó. Em seguida, é executado o processo de seleção dos candidatos a descritores (linhas 5 a 8). Para realizar o percurso da linha 5, visita-se, a partir da raiz, o nó filho mais à esquerda ainda não visitado. Caso todos os nós filhos já tenham sido visitados, continua a execução processando o nó visitado. Esta estratégia é importante, pois influencia o resultado obtido pela execução do algoritmo selecionardescritores-candidatos. É possível adotar outras estratégias para percorrer a hierarquia, que não foram avaliadas neste trabalho.

Por fim, o algoritmo remover-nós descrito na linha 9 verifica se todos os nós da hierarquia possuem candidatos a descritores. Caso algum nó tenha seu conjunto de candidatos 


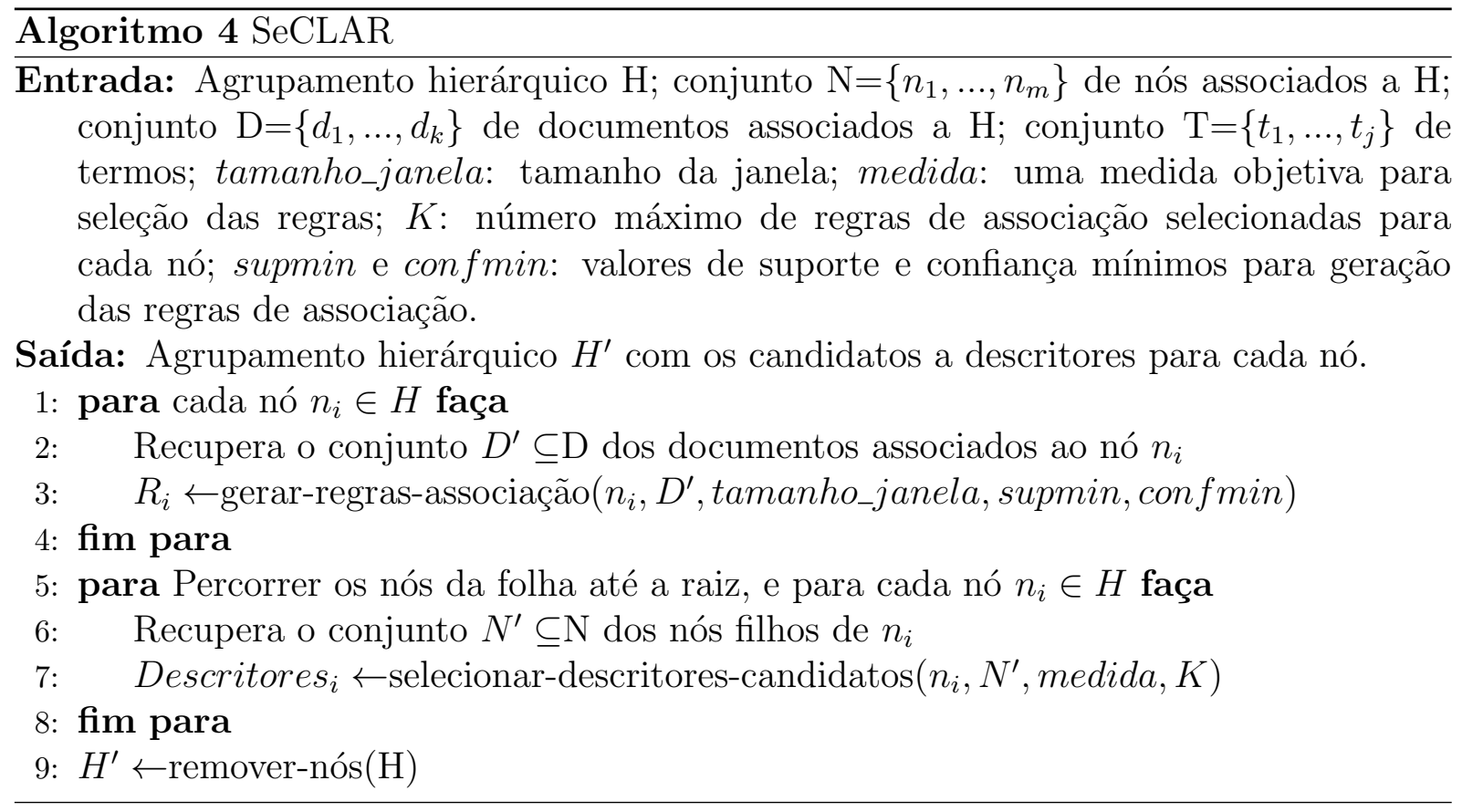

vazio, optou-se por remover este nó da hierarquia e associar seus descendentes ao antecedente direto do nó removido de acordo com o processo. O resultado obtido ao final de todo esse processo é a hierarquia $H^{\prime}$, o conjunto $N^{\prime}$ de nós associados a $H$, o conjunto de termos $T^{\prime}$ e o conjunto $D$ de documentos, conforme apresentado na Figura 4.4. O conjunto $T^{\prime}$ é formado pelos termos em $T$ que foram selecionados como candidatos a descritor. Essa hierarquia é então utilizada como entrada para o método clássico de seleção de descritores.

A seguir, os algoritmos citados nas linhas 3, 7 e 9 são descritos em detalhes.

\subsubsection{Gerar as regras de associação para cada nó}

Para gerar as regras de associação de cada nó do agrupamento é preciso transformar os documentos associados ao nó em um conjunto de transações. Este trabalho assume que, para cada nó $n_{i} \in N$ é possível transformar os documentos associados a este nó em um conjunto de transações e, a partir deste conjunto, gerar as regras de associação. O método descrito no Algoritmo 5 executa essa transformação e obtém o conjunto de regras de associação do nó $n_{i}$.

Neste método, percorre-se os documentos pré-processados (linha 2) e, para cada documento $d_{i}$, obtém-se suas palavras na sequência em que elas aparecem no documento (linha 3). Adiciona-se a i-ésima palavra encontrada ao conjunto que formará uma nova transação. Em seguida, as palavras consecutivas não repetidas são adicionadas ao conjunto que formará a transação. Este processo é repetido até que o conjunto tenha "tamanho_janela" itens ou até que não seja possível obter palavras do documento processado (linhas 4 a 11). A transação formada é adicionada ao conjunto de transações relacionados ao nó $n_{i}$ (linha 12), e o processo é executado até que todos os documentos sejam transformados em transações. Ao final deste processo, o conjunto de transações pertencentes ao nó é processado por um algoritmo de geração de regras de associação (como o Apriori Agrawal e Srikant (1994)), e o conjunto obtido é armazenado (linha 15). 


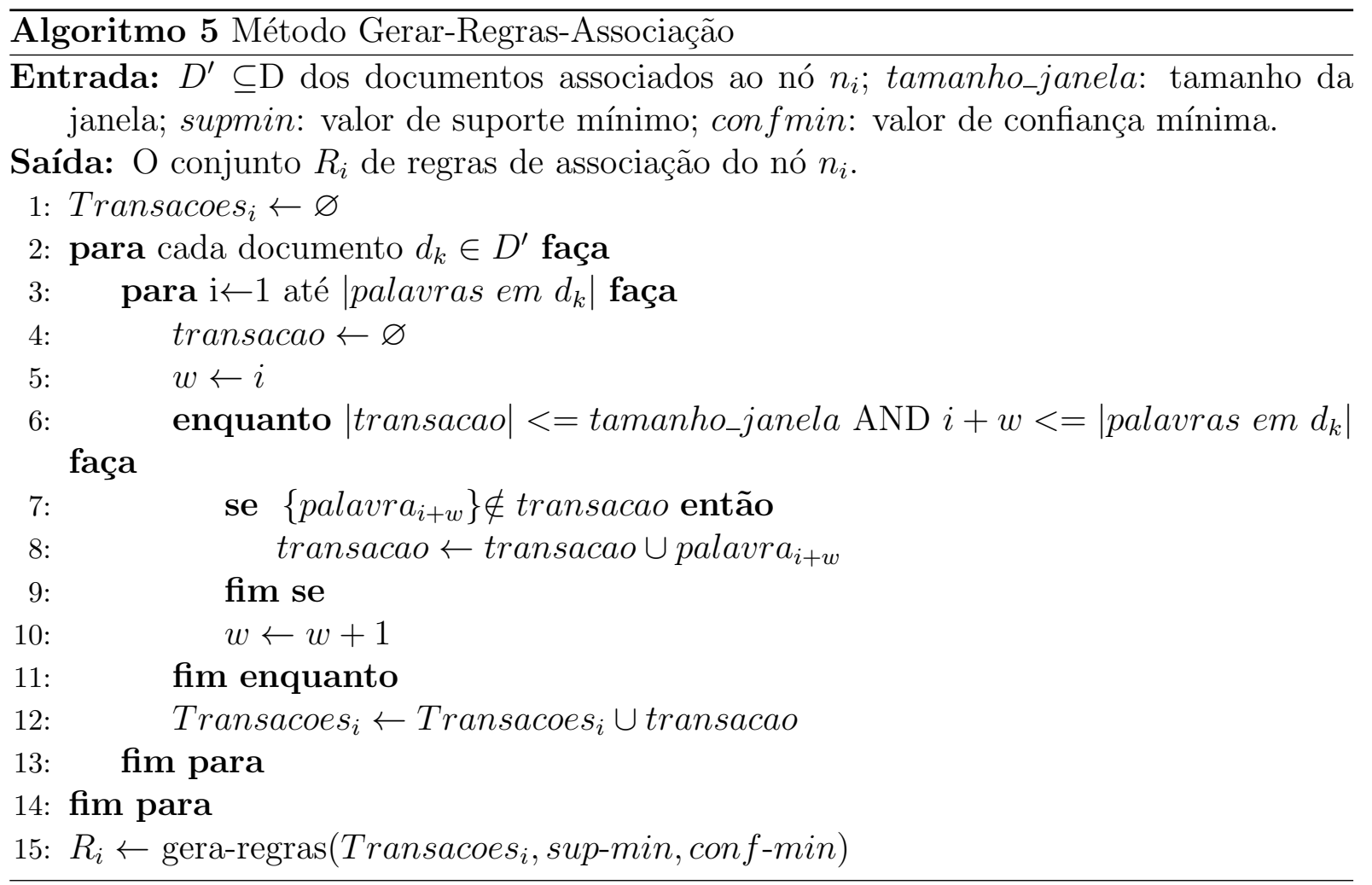

A transformação adotada neste trabalho difere daquela normalmente adotada na literatura, que considera cada documento como uma única transação. No problema tratado aqui, os nós mais próximos aos nós folha da hierarquia possuem poucos documentos associados, o que inviabilizaria a geração de regras de associação, pois o número de transações seria pequeno. Este processo de conversão utilizando janelas torna possível explorar as relações existentes entre as palavras dos documentos com vários níveis de granularidades.

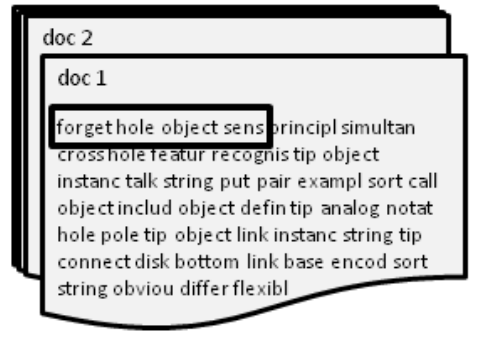

(a)
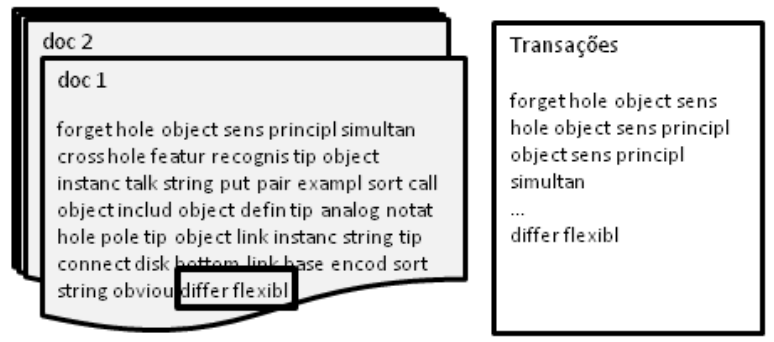

(c)

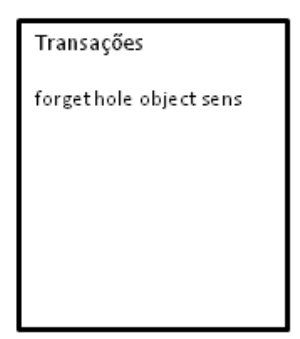

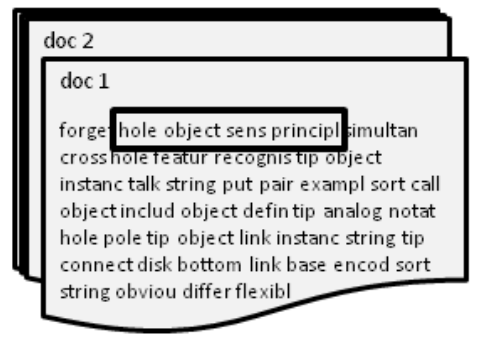

(b)

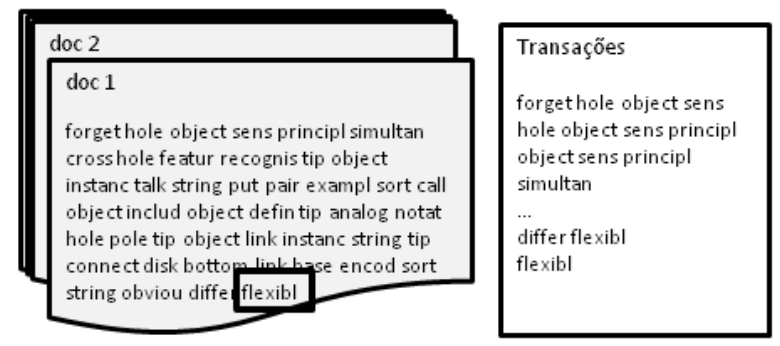

(d)

Figura 4.5: Exemplo de execução do método Gerar-Regras-Associação.

Por exemplo, seja um conjunto de documentos relacionados a um nó da hierarquia e uma janela de tamanho 4 definida pelo usuário. O processo é executado como mostrado 
na Figura 4.5. Cada documento é processado individualmente. A janela é posicionada no início do documento (Figura 4.5 - a), e as palavras da janela são adicionadas a lista de transações do nó. Em seguida, a janela é deslocada para a esquerda de uma palavra, e a sequência encontrada é adicionada a lista de transações (Figura 4.5 - b). Esse processo é executado até o final do documento (Figura 4.5 - c), e a janela vai reduzindo até obter apenas uma palavra (Figura 4.5 - d). Então, o próximo documento é processado da mesma forma. O processo termina quando todos os documentos forem processados. A lista de transações é processada por um algoritmo de geração de regras de associação.

\subsubsection{Selecionar os candidatos a descritores}

Obtido o conjunto de regras de associação para todos os nós, seleciona-se os candidatos a descritores de cada nó $n_{i}$. A proposta é utilizar as regras de associação de cada nó filho de $n_{i}$ conforme descrito no Algoritmo 6.

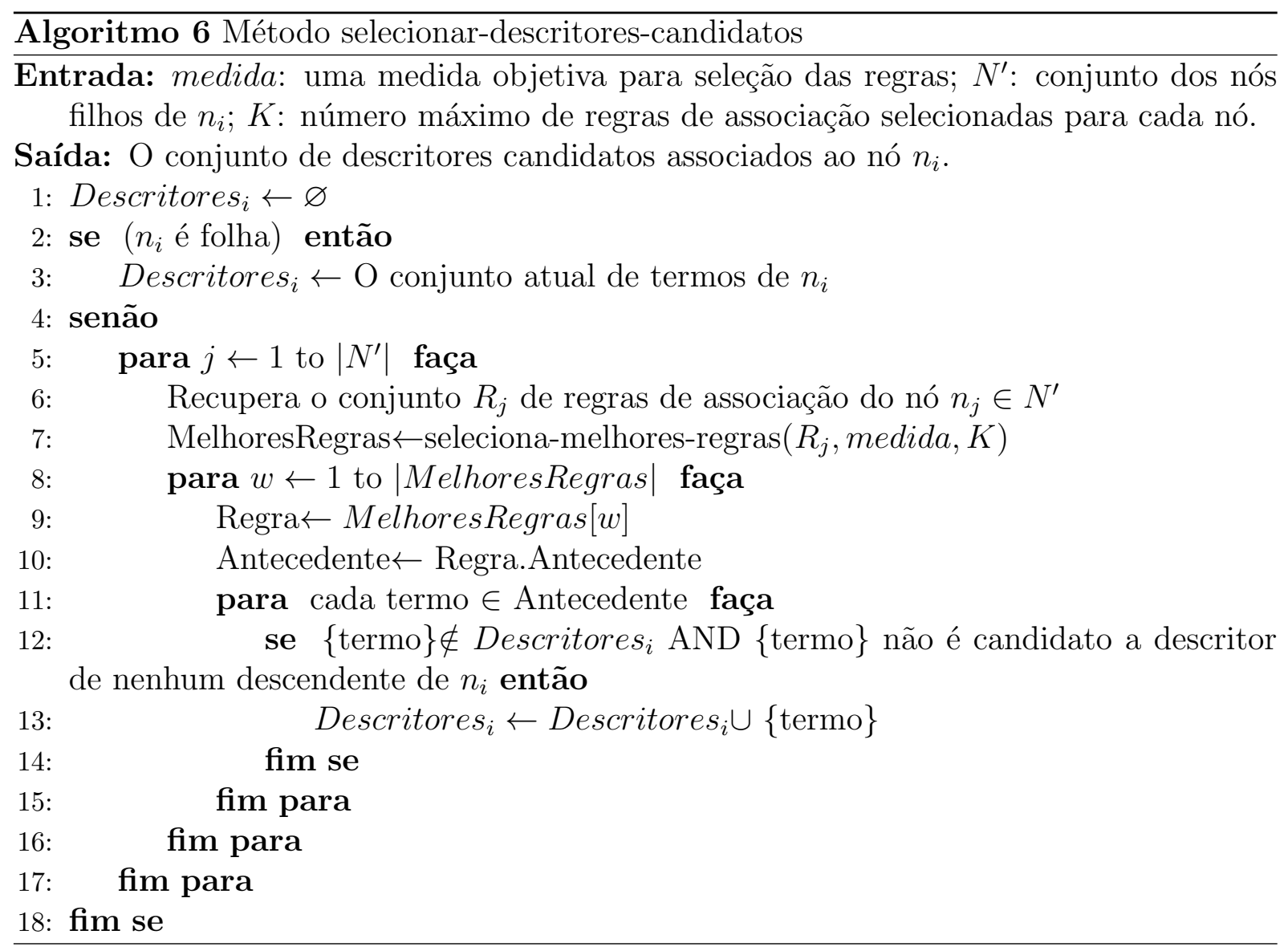

Inicialmente o algoritmo verifica o tipo do nó para decidir qual estratégia será adotada. Não é necessário selecionar nós folhas uma vez que estes não possuem nós filhos. Caso o nó $n_{i}$ avaliado seja um nó folha da hierarquia, todos os termos são adicionados a lista de possíveis candidatos.

Se o nó não é folha, o método seleciona-melhores-regras apresentado na linha 7 recupera as $K$ melhores regras de associação para cada um dos conjuntos de regras dos nós filhos de $n_{i}$. A partir deste subconjunto, seleciona-se os itens do antecedente de cada uma das regras e adiciona-se em um conjunto de possíveis descritores do nó $n_{i}$ (linhas 8 a 17). As $K$ melhores regras de associação, para este trabalho, são aquelas que possuem os maiores valores para a medida objetiva avaliada. 
O método proposto utiliza os itens do antecedente das regras de associação dos nós filhos, conforme discutido na Seção 4.3. Cada item presente no antecedente da regra é um termo presente na coleção, e caso seja possível, será selecionado como candidato a descritor do nó processado. O método não permite que um nó tenha como candidato a descritor um termo que já foi utilizado em um nó descendente não folha e, consequentemente, os termos não são repetidos ao longo da hierarquia (linha 12). Portanto, é possível que um ou mais nós estejam com sua lista de candidatos a descritores vazia ao final do processo. Esta restrição não evita que um mesmo descritor seja utilizado em nós de um mesmo nível, ou que estejam em ramos diferentes da hierarquia.

\subsubsection{Remover os nós da hierarquia que ficaram sem descritores}

Após a aplicação do método apresentado no Algoritmo 6 em todos os nós da hierarquia, é possível que alguns nós tenham ficado com seu o conjunto de descritores vazio. Neste caso, o nó é removido da hierarquia, e seus descendentes são associados ao nó pai do nó removido.

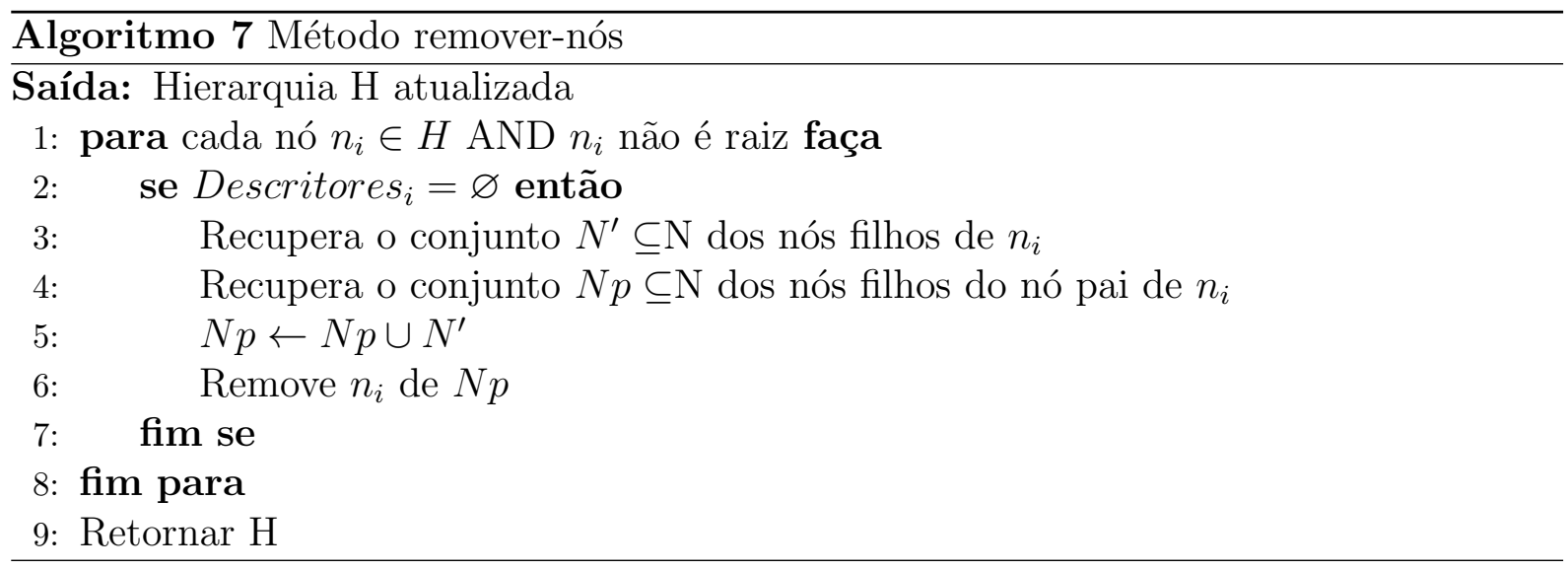

O Algoritmo 7 recebe como entrada uma hierarquia completa e processada. Então, ele visita cada nó verificando se o conjunto de descritores deste está vazio (linha 2). Se o conjunto de candidatos a descritores do nó $n_{i}$ estiver vazio, as ligações existentes entre este nó e seus nós filhos são removidas e cada nó filho é ligado ao nó pai de $n_{i}$ (linha 3-5). Por fim, o nó $n_{i}$ é removido da hierarquia (linha 6).

A remoção aplicada é importante uma vez que o SeCLAR será combinado com um método clássico de seleção de descritores. Isso porque a maior parte dos métodos encontrados não efetuam uma verificação para encontrar nós sem descritores, e o resultado final seria uma hierarquia com vários nós sem descritores.

\subsection{Avaliação Experimental}

Não existe um procedimento padrão para avaliar hierarquias, embora algumas tentativas tenham sido feitas. A avaliação é difícil mesmo quando um grupo de voluntários está disposto a participar, e depende da tarefa para a qual a hierarquia foi designada (Bast et al., 2005). A metodologia proposta em Moura e Rezende (2010) e descrita aqui na Seção 4.5.1 foi utilizada para comparar os resultados obtidos ao aplicar o método SeCLAR 
combinado com alguns métodos clássicos de seleção de descritores apresentados na Seção 4.2 .

O método proposto possui alguns parâmetros que precisam ser ajustados, e por isso a avaliação foi dividida em duas etapas. Na primeira, avaliam-se diferentes configurações para o SeCLAR (Seção 4.5.3). Nesta etapa, foram utilizadas 6 bases de textos construídas a partir de documentos científicos como artigos e dissertações. A segunda etapa avalia o impacto do uso do SeCLAR em conjunto com os métodos da literatura (Seção 4.5.4). Para isso, foram utilizadas 10 bases de textos construídas de maneira similar à descrita anteriormente.

Foi utilizado o mesmo processo de geração do agrupamento hierárquico para todas as bases, conforme apresentado na Seção 4.5.2.

\subsubsection{Critério de avaliação}

O processo para avaliar as hierarquias foi aplicado como proposto em Moura e Rezende (2010), utilizando um processo particular de recuperação de informação. Utilizam-se todos os descritores do nó em uma expressão de busca, conectando os termos com o operador "and". Por exemplo, se o conjunto de descritores de um nó é "\{artificial,intelligence\}", então a expressão de busca será "artificial $\wedge$ intelligence". Como a organização dos documentos é hierárquica, considera-se como o conjunto final de descritores de cada nó os seus descritores e os descritores de todos os seus ancestrais diretos até a raiz. Por exemplo, se a raiz possui em seu conjunto de descritores os termos "\{artificial,intelligence $\}$ " e um de seus filhos possui seu conjunto como sendo "\{data,mining $\}$ ", então a expressão de busca utilizada para avaliar esse nó filho será "artificial $\wedge$ intelligence $\wedge$ data $\wedge$ mining".

Um documento associado ao nó é recuperado quando todos os termos da expressão de busca estão presentes neste. Após o processo de recuperação, são obtidos os valores apresentados na Tabela 4.2 para cada nó da hierarquia $\left(t_{p}\right.$ : documentos recuperados corretamente; $f_{p}$ : documentos recuperados incorretamente; $f_{n}$ : documentos do nó não recuperados; $t_{n}$ : documentos corretamente não recuperados; $r_{d}$ : é o total de documentos recuperados; $d_{i}$ : é o total de documentos que estão associados ao nó; $x$ : é o total de documentos da coleção).

\begin{tabular}{|c|c|c|c|}
\hline & recuperados & !recuperados & total \\
\hline$n_{i}$ & $t_{p}$ & $f_{n}$ & $\left|d_{i}\right|$ \\
\hline$! n_{i}$ & $f_{p}$ & $t_{n}$ & $x-\left|d_{i}\right|$ \\
\hline & $r_{d}$ & $! r_{d}$ & $x$ \\
\hline
\end{tabular}

Tabela 4.2: Número de recuperações para cada nó

Com base na Tabela 4.2, calcula-se os valores de precisão e revocação para cada nó da hierarquia, conforme as equações apresentadas a seguir:

- Precisão: $\operatorname{prec}=t_{p} / r_{d}$

proporção de documentos corretamente recuperados em relação ao total de documentos recuperados; 
- Revocação: $r e c=t_{p} /\left|d_{i}\right|$

proporção dos documentos associados ao nó $n_{i}$ que foi recuperada.

A fim de realizar uma avaliação do método proposto, ajusta-se um modelo linear (detalhes em (Searle, 1971)) generalizado para analisar a variância e obter estimativas para a precisão e a revocação, em cada hierarquia. O modelo considera o efeito do nó e do método de seleção de descritores aplicado, além da média geral, conforme apresentado a seguir:

$$
\hat{m}_{e}=\hat{\mu}+\hat{n_{i}}+\hat{l_{m}}+\hat{e}
$$

no qual:

- $\hat{m}_{e}$ : estimativa da média final da medida de avaliação após o ajuste;

- $\hat{\mu}$ : média geral do modelo, sem qualquer outro efeito;

- $\hat{n}_{i}$ : estimativa do efeito do nó $n_{i}$, que é quanto a medida $\hat{m}_{e}$ desvia-se da média geral devido a esse efeito;

- $\hat{l_{m}}$ : estimativa do efeito do método de seleção de descritores, que é o quanto a medida $\hat{m}_{e}$ desvia-se da média geral devido à aplicação de um dado método;

- $\hat{e}$ : efeito aleatório associado a cada estimativa.

Para que todas as hierarquias sejam avaliadas de forma semelhante, são considerados neste cálculo apenas os nós que são comuns a todos os agrupamentos avaliados. Isso é possível mantendo-se uma identificação única para cada nó.

Segundo Moura e Rezende (2010), comparações estatisticamente mais confiáveis são obtidas ao utilizar um estimador $\hat{m}_{e}$ para cada método avaliado. Neste trabalho, utilizouse o teste estatístico SNK (Student-Newman-Keuls) para analizar a variância e a comparação múltipla das médias ao nível de $5 \%$ de significância. O teste SNK foi escolhido devido a sua força e sua característica de sempre mostrar a real diferença entre as médias analizadas (Snedecor e Cochran, 1967).

\subsubsection{Pré-processamento e obtenção das hierarquias}

Todas as bases de textos ${ }^{1}$ foram pré-processadas utilizando o mesmo método. Os termos foram obtidos pela redução das palavras ao seu stem aplicando-se o algoritmo de Porter (Porter, 1997). Em seguida os termos foram selecionados utilizando a medida de Salton (Salton e Buckley, 1987), que sugere o uso de termos que possuam a frequência de ocorrência na coleção (DF - document frequency) entre um e dez porcento do total de documentos. Como os documentos são submetidos a um processo de agrupamento aglomerativo, optou-se por utilizar o valor mínimo de 2 para a DF. Na Tabela 4.3 é apresentada uma descrição das bases utilizadas. A quantidade inicial de termos da base se refere aos stems obtidos após a aplicação do algoritmo de Porter e a remoção de

\footnotetext{
${ }^{1}$ Estas coleções podem ser acessadas em www.icmc.usp.br/ fabianof/seclar .
} 
stopwords. Os valores da última coluna indicam o número de stems após a seleção de atributos utilizando Salton, ou seja, a cardinalidade final de cada conjunto de documentos utilizado para avaliação. Neste trabalho foi considerada apenas a geração de termos simples, também chamados unigramas.

\begin{tabular}{|c|c|c|c|c|}
\hline Base & \# docs & \# termos & Filtro de Salton DF & card(A) \\
\hline Computer Hardware & 83 & 11159 & $2 \leq D F \leq 10$ & 3076 \\
\hline A.I. & 69 & 10225 & $2 \leq D F \leq 9$ & 2614 \\
\hline Biophysics & 72 & 13804 & $2 \leq D F \leq 9$ & 3898 \\
\hline Mechanics (Physics) & 103 & 13372 & $2 \leq D F \leq 12$ & 3668 \\
\hline Quantum Physics & 70 & 9874 & $2 \leq D F \leq 12$ & 3003 \\
\hline ifm-wp01 & 80 & 10591 & $2 \leq D F \leq 8$ & 4602 \\
\hline ifm-wp02 & 63 & 12126 & $2 \leq D F \leq 8$ & 4854 \\
\hline ifm-wp04 & 47 & 14302 & $2 \leq D F \leq 7$ & 5488 \\
\hline Inorganic Chemistry & 74 & 18705 & $2 \leq D F \leq 9$ & 5888 \\
\hline Polymer Science & 73 & 11810 & $2 \leq D F \leq 9$ & 3343 \\
\hline
\end{tabular}

Tabela 4.3: Número de documentos e atributos das bases de textos utilizadas.

Aplicou-se nas bases pré-processadas o algoritmo de agrupamento hierárquico average linkage, utilizando a medida cosseno. Cada nó recebe uma identificação única de forma que seja possível identificá-los mesmo após o processamento realizado pelos métodos de seleção de descritores. Estes agrupamentos serão utilizados nas avaliações descritas nas Seções 4.5.3 e 4.5.4. Uma visão geral do desenho experimental proposto para avaliar o método SeCLAR é apresentada na Figura 4.6.

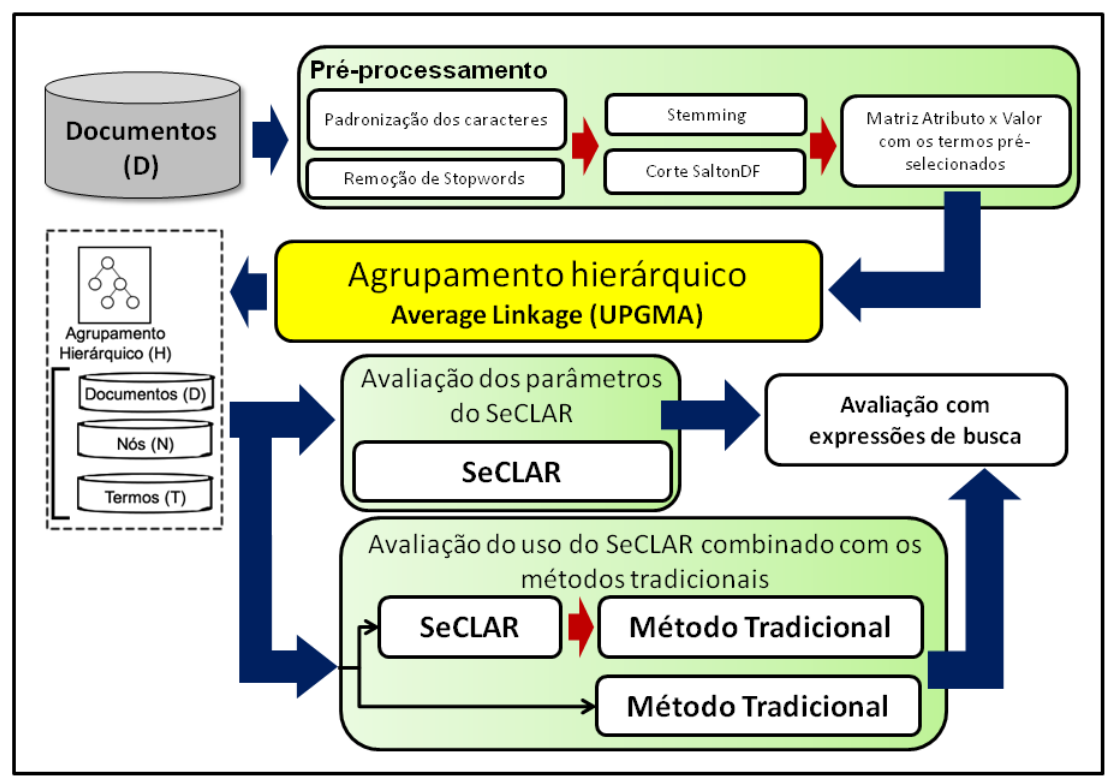

Figura 4.6: Visão geral do desenho experimental utilizado neste projeto.

\subsubsection{Avaliação dos parâmetros do SeCLAR}

Para avaliar o impacto dos parâmetros do método SeCLAR, foram utilizadas todas as combinações das configurações descritas na Tabela 4.4, totalizando 48 combinações para cada base avaliada, como ilustrado na Figura 4.7. Para todos os casos, foram utilizados os valores de suporte e confiança mínimos fixados em 10\%. Aplicou-se uma versão adaptada do Apriori que seleciona regras de associação com um item no consequente. Nesta etapa, foram considerados os 14 descritores mais frequentes para cada nó conforme sugerido em 


\begin{tabular}{|c|c|c|c|c|}
\hline tamanho_janela & 30 & 40 & \multicolumn{2}{|c|}{50} \\
\hline K & 10 & 50 & 100 & 200 \\
\hline medidas & confiança (conf) & lift (lift) & laplace (lapl) & gini index (gini) \\
\hline \multicolumn{2}{|c|}{ supmin and confmin } & \multicolumn{3}{|c|}{$10 \%$} \\
\hline
\end{tabular}

Tabela 4.4: Valores utilizados para os parâmetros do método proposto.

Moura (2009). Isso é feito para que cada nó tenha a mesma quantidade de descritores para avaliação.

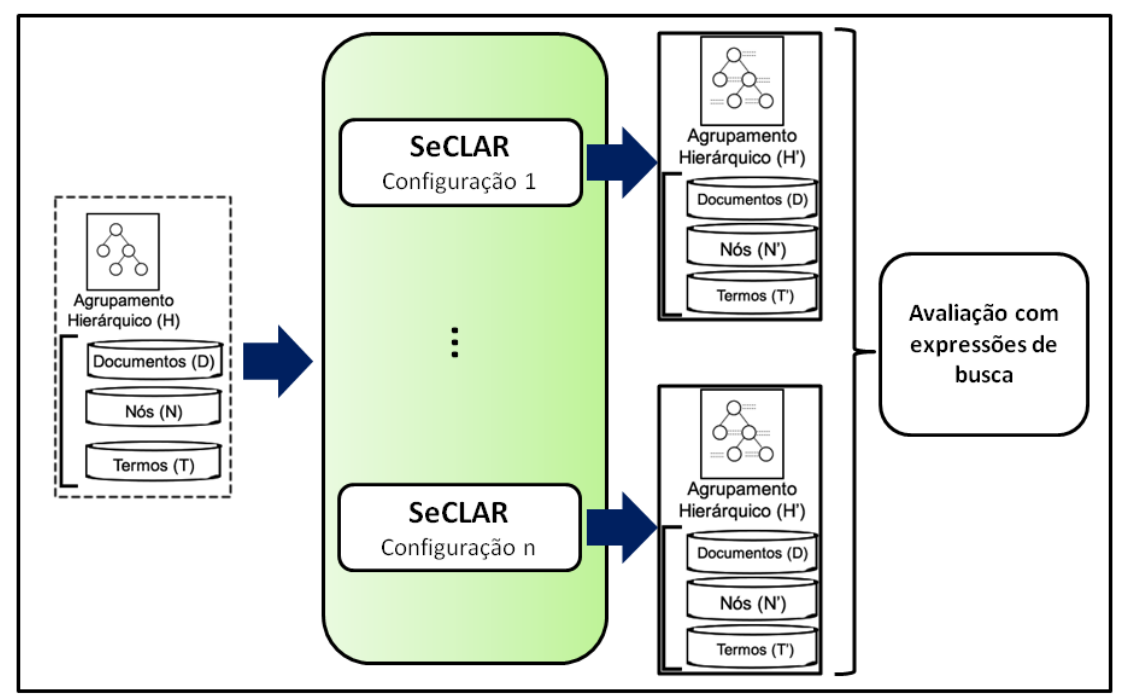

Figura 4.7: Desenho experimental para a avaliação dos parâmetros do SeCLAR.

As configurações utilizadas nesta Seção foram escolhidos empiricamente, pois o objetivo era avaliar o comportamento do método proposto conforme a variação de seus parâmetros. Os valores utilizados para o parâmetro tamanho_janela foram escolhidos para que as transações obtidas pela transformação fossem de tamanho semelhante ao de uma sentença. Para o parâmetro $K$, esperava-se verificar se o aumento no número de regras de associação utilizadas poderia contribuir para um aumento da qualidade dos candidatos a descritores selecionados. As medidas objetivas confiança e lift foram escolhidas por sua ampla utilização na área, bem como pela sua simplicidade de obtenção. As medidas Laplace e gini index foram selecionadas por estarem muito relacionadas a trabalhos em outras áreas do conhecimento envolvendo estruturas de árvore, em específico a obtenção de árvores de decisão. As medidas objetivas utilizadas para avaliar o método são apresentadas na Seção 2.3.1.

Para cada valor de tamanho de janela, obtiveram-se as 16 possíveis combinações e avaliou-se conforme a metodologia descrita anteriormente. Os melhores valores de precisão e revocação calculados para cada base são apresentados, respectivamente, nas Tabelas 4.5 e 4.6 .

Nas Tabelas 4.5 e 4.6 são apresentados os resultados desta avaliação agrupados de acordo com o tamanho da janela.

Após os experimentos, observou-se que o parâmetro correspondente ao tamanho da janela é o que mais influencia na etapa de remoção de nós. Este parâmetro determina a quantidade de transações que serão obtidas pela transformação dos documentos. Seu valor não deve ser muito grande, pois o número de transações gerados seria muito pequeno, inviabilizando o uso de regras de associação para esta base. Valores muito pequenos também 


\begin{tabular}{|c|c|c|c|c|c|c|}
\hline \multicolumn{7}{|c|}{ Precisão } \\
\hline & \multicolumn{6}{|c|}{ tamanho da janela } \\
\hline Base & \multicolumn{2}{|c|}{30} & \multicolumn{2}{|c|}{40} & \multicolumn{2}{|c|}{50} \\
\hline \multirow{2}{*}{ Computer Hardware } & configuração & $\hat{m}_{e}=$ prec & configuração & $\hat{m}_{e}=$ prec & configuração & $\hat{m}_{e}=$ prec \\
\hline & gini $\mathrm{k}=50$ & 0,025253 & lapl $\mathrm{k}=50$ & 0,135626 & conf $\mathrm{k}=200$ & 0,027778 \\
\hline A.I. & lapl $\mathrm{k}=10$ & 0,223886 & lapl $\mathrm{k}=50$ & 0,245405 & lapl $\mathrm{k}=10$ & 0,183361 \\
\hline Biophysics & lapl $\mathrm{k}=10$ & 0,134401 & lapl $\mathrm{k}=10$ & 0,191065 & lapl $\mathrm{k}=50$ & 0,185637 \\
\hline ifm-wp02 & lapl $\mathrm{k}=10$ & 0,049123 & lapl $\mathrm{k}=50$ & 0,04533 & lapl $\mathrm{k}=10$ & 0,200101 \\
\hline ifm-wp04 & lapl $\mathrm{k}=10$ & 0,297434 & lift $\mathrm{k}=200$ & 0,260606 & lapl $\mathrm{k}=10$ & 0,295956 \\
\hline Inorganic Chemistry & lapl $\mathrm{k}=10$ & 0,079458 & lapl $\mathrm{k}=10$ & 0,056525 & lapl $\mathrm{k}=10$ & 0,197809 \\
\hline
\end{tabular}

Tabela 4.5: Melhores médias obtidas para a medida precisão.

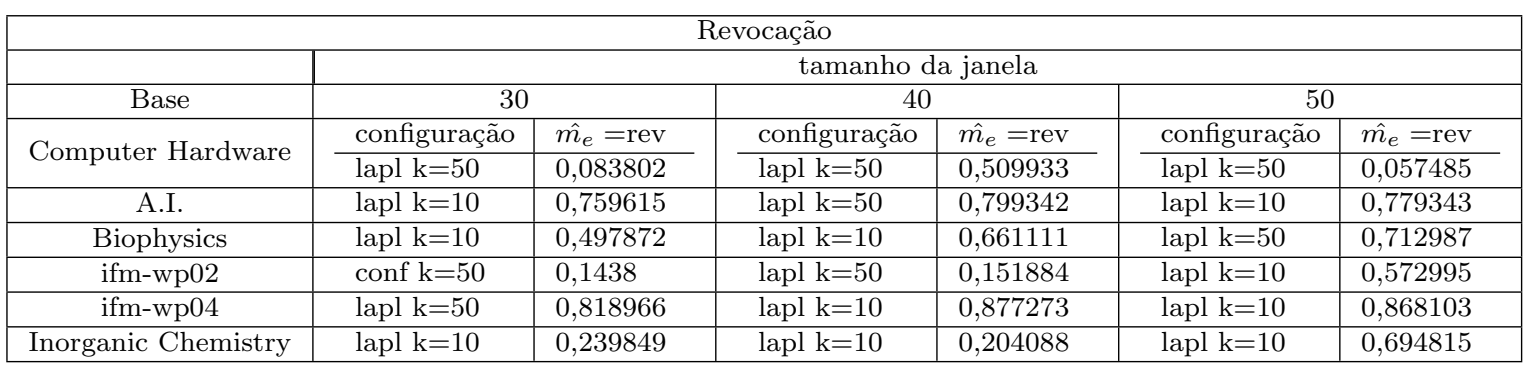

Tabela 4.6: Melhores médias obtidas para a medida revocação.

não devem ser utilizados pois, para gerar uma regra de associação, o valor do parâmetro supmin seria muito próximo de zero, tornando o uso metodologia proposta impraticável. Nesta avaliação, os valores 40 e 50 tiveram melhores resultados se comparados com as médias obtidas utilizando a janela de tamanho 30. As configurações utilizando o valor 30 foram melhores apenas para 1 base ifm-wp04 para a medida de precisão.

Observando os resultados das Tabelas 4.5 e 4.6, verificou-se que a medida objetiva de Laplace foi dominante em todos os casos. Ela foi melhor em 13 dos 16 resultados apresentados para a medida de precisão e em 15 dos 16 resultados apresentados para a revocação. A medida Laplace é uma correção à medida confiança, penalizando o cálculo de forma a favorecer aquelas regras que possam representar a maior porção possível da base de dados analisada. Neste caso, ela parece se adequar bem à seleção de descritores, que visa encontrar o subconjunto de termos que melhor descreve os documentos de cada grupo. Em particular, ela reflete a característica hierárquica do agrupamento obtido, dando indícios de que os relacionamentos do tipo pai-filho podem ser considerados como um relacionamento do tipo antecedente-consequente, no contexto de agrupamento hierárquico de documentos.

O parâmetro $K$, que indica o total das melhores regras de associação que serão selecionadas, foi predominantemente melhor para os valores mais baixos (10 e 50). Isto indica que mesmo com um aumento significativo do número de regras selecionadas, apenas um pequeno conjunto delas contém o subconjunto de termos mais interessantes para serem utilizados como descritores. Os valores 10 e 50 foram melhores em todos os resultados para a revocação, e em 14 dos 16 resultados apresentados para a precisão.

Efetuou-se uma análise dos resultados apresentados nas Tabelas 4.5 e 4.6 para encontrar a melhor configuração para cada uma das bases de textos avaliadas. Estas configurações são apresentadas nas Tabelas 4.7 e 4.8. Em ambos os casos, a medida objetiva Laplace parece ser a mais adequada, entre as medidas avaliadas, para o problema de seleção de candidatos a descritores. Percebe-se também que o método SeCLAR obtém os melhores resultados para a precisão e a revocação utilizando configurações iguais ou 
semelhantes, ou seja, a configuração que melhora os resultados para uma medida também melhora os resultados para a outra. Com isso, espera-se que ao contribuir com a melhora de uma medida, o método não irá afetar a qualidade dos dados, podendo até apresentar resultados melhores para as duas medidas.

\begin{tabular}{|c|c|c|c|c|c|c|}
\hline & ifm1-wp02 & ifm1-wp04 & Comp. Hard. & A.I. & Ino. Chem. & Biop. \\
\hline Medida & Laplace & Laplace & Laplace & Laplace & Laplace & Laplace \\
\hline K & 10 & 10 & 50 & 50 & 10 & 10 \\
\hline tamanho_janela & 50 & 30 & 40 & 40 & 50 & 40 \\
\hline
\end{tabular}

Tabela 4.7: Melhores configurações dos parâmetros de acordo com a medida Precisão.

\begin{tabular}{|c|c|c|c|c|c|c|}
\hline & ifm1-wp02 & ifm1-wp04 & Comp. Hard. & A.I. & Ino. Chem. & Biop. \\
\hline Medida & Laplace & Laplace & Laplace & Laplace & Laplace & Laplace \\
\hline K & 10 & 10 & 50 & 50 & 10 & 50 \\
\hline tamanho_janela & 50 & 40 & 40 & 40 & 50 & 50 \\
\hline
\end{tabular}

Tabela 4.8: Melhores configurações dos parâmetros de acordo com a medida Revocação.

\subsubsection{Avaliação do uso do SeCLAR combinado com os métodos tradicionais}

Para verificar o impacto do uso do SeCLAR combinado com os métodos tradicionais de seleção de descritores foi realizado o experimento conforme descrito nesta seção. Os agrupamentos obtidos como descrito na Seção 4.5.2 são processados como descrito a seguir:

1. Cada agrupamento obtido é processado pelos métodos de seleção de descritores Mais Frequentes, Popescul\&Ungar e o RLUM;

2. Cada agrupamento obtido é processado pelo SeCLAR, e em seguida processado pelos métodos Mais Frequentes, Popescul\&Ungar e o RLUM.

Para os métodos que não definem um valor máximo de descritores, foram considerados os 14 descritores mais frequentes para cada nó conforme sugerido em Moura (2009). Isso é feito para que cada nó tenha a mesma quantidade de descritores para avaliação. Na Figura 4.8 é apresentado o desenho experimental para a avaliação do uso do método SeCLAR combinado com os métodos da literatura.

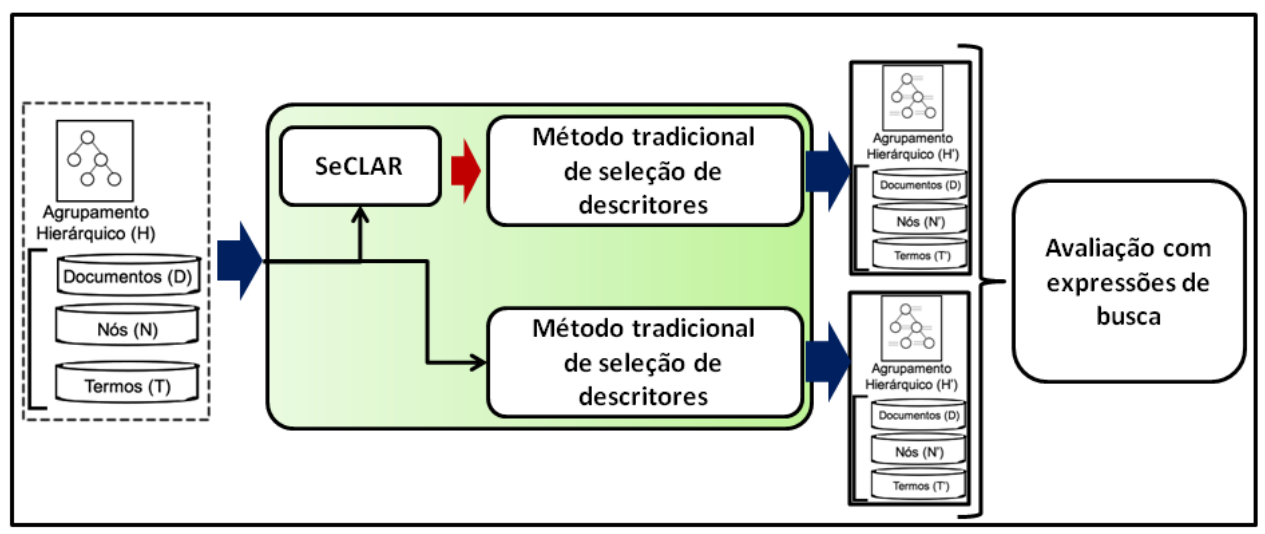

Figura 4.8: Desenho experimental para a avaliação do método SeCLAR combinado com os métodos de seleção de descritores da literatura. 
Esta avaliação foi dividida em duas partes. Na primeira, avaliou-se o uso do SeCLAR com uma mesma configuração de parâmetros utilizando 10 coleções de texto. Em seguida, o SeCLAR foi executado utilizando um conjunto de configurações considerado ótimo para cada uma das 6 bases avaliadas. Os resultados da aplicação do teste estatístico (descrito na Seção 4.5) são apresentados nas Tabelas 4.11 e 4.13. Nestas tabelas, $n$ indica a quantidade de nós avaliados para cada hierarquia e grupo indica o resultado do teste. Se os resultados estão em grupos diferentes, então há diferença estatística significativa entre as médias.

\section{SeCLAR com parâmetro único}

Uma vez que os resultados apresentados nas Tabelas 4.7 e 4.8 parecem indicar uma tendência quanto ao comportamento do método, avaliou-se a utilização de uma mesma configuração para o SeCLAR em todas as bases, como apresentado na Tabela 4.9. Para o parâmetro $K$, optou-se pelo valor 50, pois o conjunto das 50 melhores regras tem como subconjunto aquele das 10 melhores regras geradas. Como esses foram os 2 melhores valores avaliados, optou-se pelo melhor deles. Já para o parâmetro do tamanho da janela, optou-se por escolher o valor 40 pois ele é o menor daqueles que se destacaram, e assim, a quantidade de transações que podem ser obtidas pelo SeCLAR é maior.

\begin{tabular}{|c|c|}
\hline Medida & Laplace \\
\hline K & 50 \\
\hline tamanho_janela & 40 \\
\hline
\end{tabular}

Tabela 4.9: Valores dos parâmetros do método SeCLAR utilizados nesta avaliação.

Os resultados são apresentados na Tabela 4.10. Uma versão detalhada dos resultados é apresentada na Tabela 4.11 .

\begin{tabular}{|c|c|c|c|c|c|c|}
\hline & \multicolumn{2}{|c|}{ Most Frequent } & \multicolumn{2}{|c|}{ Popescul\&Ungar } & \multicolumn{2}{|c|}{ RLUM } \\
\hline Base & prec & rec & prec & rec & prec & rec \\
\hline Computer Hardware & $\Delta$ & $\Delta$ & $\Delta$ & $\Delta$ & - & - \\
\hline A.I. & $\bullet$ & - & $\bullet$ & $\bullet$ & • & 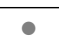 \\
\hline Biophysics & $\Delta$ & $\Delta$ & $\Delta$ & $\Delta$ & $\cdot$ & $\cdot$ \\
\hline ifm-wp02 & $\bullet$ & $\bullet$ & $\bullet$ & $\bullet$ & $\bullet$ & $\bullet$ \\
\hline ifm-wp04 & $\cdot$ & $\cdot$ & $\cdot$ & $\cdot$ & $\cdot$ & $\boldsymbol{\nabla}$ \\
\hline Inorganic Chemistry & $\bullet$ & $\bullet$ & $\cdot$ & $\bullet$ & $\Delta$ & $\bullet$ \\
\hline Mechanics (Physics) & - & $\Delta$ & $\bullet$ & $\Delta$ & $\bullet$ & $\nabla$ \\
\hline Quantum Physics & $\boldsymbol{\nabla}$ & $\boldsymbol{\nabla}$ & $\cdot$ & $\boldsymbol{\nabla}$ & 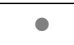 & $\Delta$ \\
\hline ifm-wp01 & $\cdot$ & $\Delta$ & - & $\Delta$ & $\nabla$ & - \\
\hline Polymer Science & $\cdot$ & - & $\cdot$ & - & $\cdot$ & - \\
\hline
\end{tabular}

Tabela 4.10: Resultados obtidos do uso combinado do método de seleção de descritores e o SeCLAR com configuração igual para as bases

\begin{tabular}{cr}
\hline $\boldsymbol{\Delta}$ & O uso do SeCLAR é estatisticamente melhor \\
\hline $\boldsymbol{\nabla}$ & O uso do método tradicional é estatisticamente melhor \\
\hline$\bullet$ & Não há diferença estatística entre os resultados \\
\hline
\end{tabular}

Em linhas gerais, o método parece não contribuir significativamente em relação aos métodos clássicos avaliados. Entretanto, é importante observar que não foi realizada uma otimização dos parâmetros e, ainda assim, o SeCLAR contribuiu em 14 casos. Pelos resultados, há indícios que uma inicialização utilizando a configuração proposta aqui seja 
capaz de já contribuir para a melhoria do método. Um exemplo dos resultados obtidos é apresentado na Figura 4.9, que apresenta um trecho da hierarquia para a base Biophysics processada pelo método $\mathrm{P} \& \mathrm{U}$. Destaca-se um nó folha e seu nó pai, para o qual os descritores do nó pai refletem melhor a informação contida nos documentos que estão abaixo dele de forma um pouco mais genérica e concisa.

Somente o método Popescul\&Ungar.

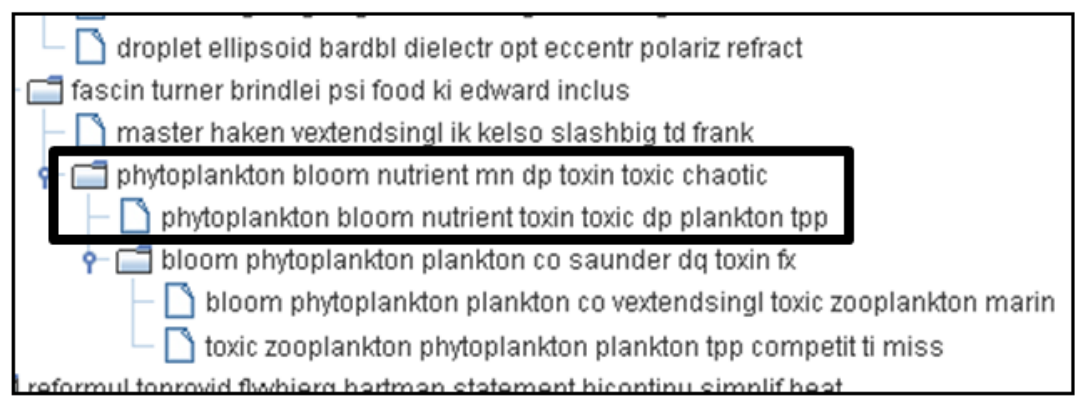

O método Popescul\&Ungar combinado com o SeCLAR

$\square$ magnet grid gi stomach regress intestin squid
bardbl magnet grid gi stomach regress omega intestin
ki master haken ik kelso td frank $\mathrm{nt}$
$\square$ toxic zooplankton phytoplankton plankton tpp competit ti miss

Figura 4.9: Exemplo do resultado obtido pelo processo de seleção de descritores para a base Biophysics.

Os valores utilizados nesta etapa já eram aqueles considerados ótimos para as bases Computer Hardware e A.I. (os valores ótimos são discutidos a seguir, na subseção "SeCLAR com parâmetros ótimos"). Para as bases de texto utilizadas no experimento da Seção 4.5.3, a base ifm-wp04 foi a única que apresentou uma melhora estatística significativa com o uso do SeCLAR combinado com o método RLUM para a medida de revocação. Além disso, as bases cujo valor ótimo de $K$ é 10 (ifm-wp02,ifm-wp04,Inorganic Chemistry) parecem ter sido mais afetadas pela não otimização dos parâmetros.

Considerando as bases utilizadas apenas neste experimento (Mechanics (Physics),Quantum Physics,ifm-wp01,Polymer Science), os resultados parecem mais promissores. Mesmo sem conhecer os valores ótimos, o SeCLAR contribuiu significativamente em 3 das 4 bases, sempre para a revocação. A base Quantum Physics se destaca pelo baixo desempenho para os métodos MF e P\&U, mas o SeCLAR foi capaz de melhorar o desempenho do RLUM neste caso. Entretanto, pode-se observar na Figura 4.10 que a qualidade dos descritores melhora com o uso combinado do método P\&U com o SeCLAR para esta base. Isso é uma característica desejada em tarefas onde o especialista faz uma exploração manual dos grupos obtidos, pois os descritores são mais significativos.

O método SeCLAR parece também ser robusto à inicialização dos parâmetros, quando utilizada a medida de Laplace. Também observa-se para as duas avaliações que o SeCLAR contribui de maneira similar para os métodos MF e P\&U, ou seja, quando há melhora na 
Somente o método Popescul\&Ungar.

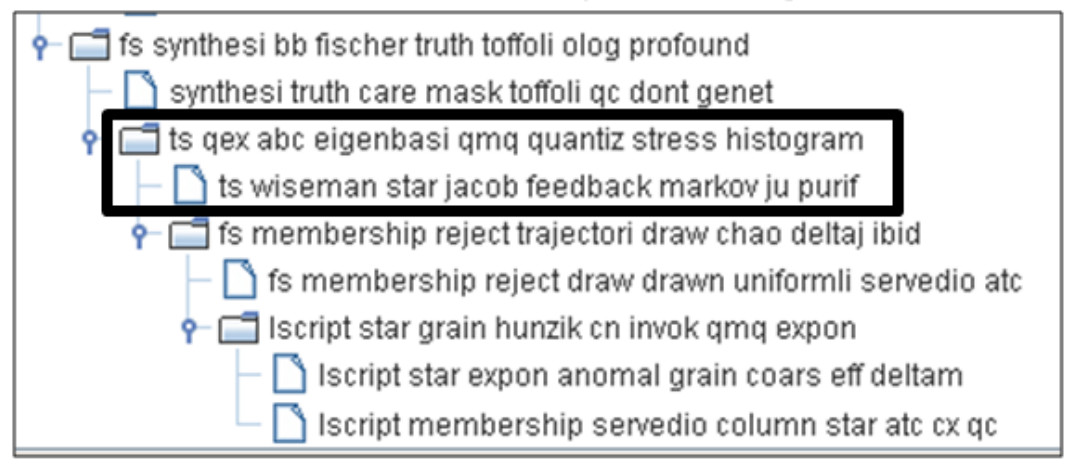

O método Popescul\&Ungar combinado com o SeCLAR

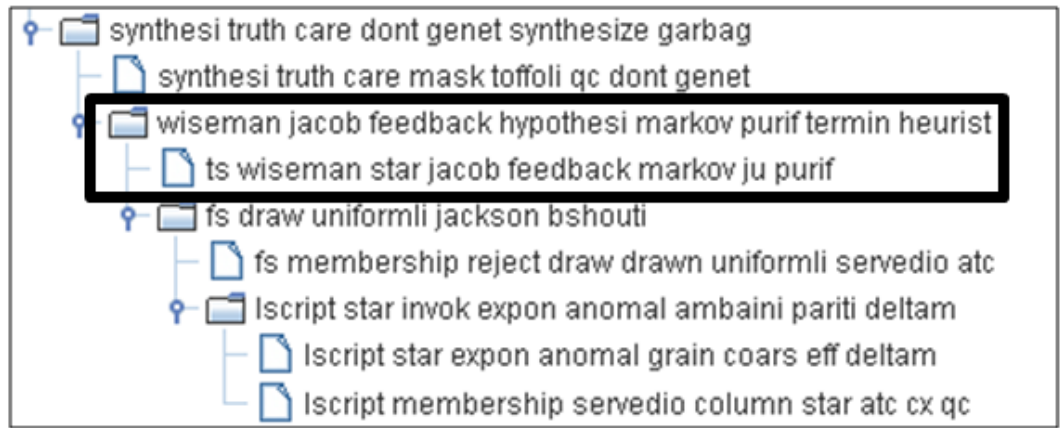

Figura 4.10: Exemplo do resultado obtido pelo processo de seleção de descritores para a base Quantum Physics.

medida para um, também há para o outro.

\section{SeCLAR com parâmetros ótimos}

Para encontrar os valores ótimos de parâmetros em cada base, foi utilizado o processo de avaliação descrito na Seção 4.5.3 buscando aquelas configurações que obtém melhor resultado para a medida de revocação, pois geralmente o uso de organização hierárquica de documentos está relacionado a questões de recuperação de informação. Assim, os parâmetros considerados ótimos para o SeCLAR, em cada base, são aqueles apresentados na Tabela 4.8 .

Os resultados desse procedimento são apresentados na Tabela 4.12. Uma versão detalhada dos resultados é apresentada na Tabela 4.13.

O uso do método SeCLAR contribuiu significativamente para a melhoria dos resultados obtidos pelos métodos Popescul\&Ungar e Mais Frequentes. Para a precisão, o SeCLAR melhorou estatisticamente a média em 6 casos, e não obteve uma melhora estatística em 6 casos (4 para o MF e 2 para o Popescul\&Ungar). Acredita-se que os resultados para o caso do método MF estejam relacionados a sua simplicidade. Para a revocação, houve diferença estatística em 9 avaliações, e 3 empates (2 para o MF e 1 para o Popescul\&Ungar). Portanto, o SeCLAR foi capaz de melhorar a cobertura destes métodos de forma significativa, sem que isto prejudicasse a precisão dos métodos.

Para os casos das bases ifm-wp04 e Inorganic Chemistry, o comportamento dos métodos foi exatamente igual, ou seja, as médias do método Mais Frequentes são idênticas as do Popescul\&Ungar (Tabela 4.13). Estes métodos geralmente obtém resultados similares Moura e Rezende (2010). Uma avaliação visual dos resultados indicou que devido à sele- 


\begin{tabular}{|c|c|c|c|c|c|c|c|c|c|}
\hline Base & & & & & esultad & & & & \\
\hline & Método & & pre & & & & revo & ção & \\
\hline & & configuração & $\bar{n}$ & $\hat{m}_{e}=$ prec & grupo & configuração & $\bar{n}$ & $\hat{m}_{e}=\mathrm{rev}$ & grupo \\
\hline & $\mathrm{MF}$ & SeCLAR & 147 & 0,0889326 & $\mathrm{a}$ & SeCLAR & 147 & 0,171345 & $\mathrm{a}$ \\
\hline Computer & & Tradicional & 148 & 0,037162 & $\mathrm{~b}$ & Tradicional & 148 & 0,025115 & $\mathrm{~b}$ \\
\hline Hardware & DeUt & SeCLAR & 147 & 0,085018 & $\mathrm{a}$ & SeCLAR & 147 & 0,181266 & $\mathrm{a}$ \\
\hline & $P \& U$ & Tradicional & 148 & 0,036036 & $\mathrm{~b}$ & Tradicional & 148 & 0,029443 & $\mathrm{~b}$ \\
\hline & BIJUM & SeCLAR & 117 & 0,267990 & $\mathrm{a}$ & SeCLAR & 117 & 1,000000 & $a$ \\
\hline & RLUM & Tradicional & 117 & 0,262530 & $\mathrm{a}$ & Tradicional & 117 & 0,974359 & $\mathrm{a}$ \\
\hline & (N) & SeCLAR & 122 & 0,032787 & $\mathrm{a}$ & SeCLAR & 122 & 0,044345 & $\mathrm{a}$ \\
\hline & $\mathrm{MF}$ & Tradicional & 122 & 0,030738 & $\mathrm{a}$ & Tradicional & 122 & 0,043092 & $\mathrm{a}$ \\
\hline $\mathrm{I}$ & $\mathrm{D} \ell_{-U}$ & SeCLAR & 122 & 0,032787 & $\mathrm{a}$ & SeCLAR & 122 & 0,044345 & $\mathrm{a}$ \\
\hline A.1. & $P \& U$ & Tradicional & 122 & 0,0330738 & $\mathrm{a}$ & Tradicional & 122 & 0,043092 & $\mathrm{a}$ \\
\hline & PI JUM & Tradicional & 98 & 0,322250 & $\mathrm{a}$ & SeCLAR & 98 & 1,000000 & $\mathrm{a}$ \\
\hline & RLUN1 & SeCLAR & 98 & 0,314963 & $\mathrm{a}$ & Tradicional & 98 & 0,981293 & $\mathrm{a}$ \\
\hline & & SeCLAR & 2123 & 0,155049 & $\overline{\mathrm{a}}$ & SeCLAR & 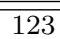 & $0,0,403571$ & 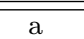 \\
\hline & $\mathrm{MF}$ & Tradicional & 124 & 0,032258 & $\mathrm{~b}$ & Tradicional & 124 & 0,030018 & $\mathrm{~b}$ \\
\hline & & SeCLAR & 123 & 0,151949 & $\bar{a}$ & SeCLAR & 123 & 0,395441 & $\mathrm{a}$ \\
\hline Biophysics & $P \& U$ & Tradicional & 124 & 0,044355 & $\mathrm{~b}$ & Tradicional & 124 & 0,029410 & $\mathrm{~b}$ \\
\hline & RIUUM & SeCLAR & 105 & 0,281128 & $\mathrm{a}$ & SeCLAR & 105 & 0,965873 & $\mathrm{a}$ \\
\hline & KLUM & Tradicional & 105 & 0,267372 & $\mathrm{a}$ & Tradicional & 105 & 0,965873 & $\mathrm{a}$ \\
\hline & $M F$ & Tradicional & 186 & 0,037634 & $\bar{a}$ & SeCLAR & 186 & 0,071118 & $\bar{a}$ \\
\hline & $M F$ & SeCLAR & 186 & 0,035618 & $\mathrm{a}$ & Tradicional & 186 & 0,021518 & $\mathrm{~b}$ \\
\hline Mechanics & $\mathrm{D} \ell_{-U}$ & Tradicional & 186 & 0,037634 & $\mathrm{a}$ & SeCLAR & 186 & 0,071118 & $\mathrm{a}$ \\
\hline (Physics) & $P \& U$ & SeCLAR & 186 & 0,35618 & $\mathrm{a}$ & Tradicional & 186 & 0,21518 & $\mathrm{~b}$ \\
\hline & DUEY & SeCLAR & 146 & 0,217178 & $\mathrm{a}$ & Tradicional & 146 & 0,987443 & $\mathrm{a}$ \\
\hline & RLUM & Tradicional & 146 & 0,211947 & $\mathrm{a}$ & SeCLAR & 146 & 0,964041 & $\mathrm{~b}$ \\
\hline & $M F$ & Tradicional & 127 & 0,047244 & $\mathrm{a}$ & Tradicional & 127 & 0,120079 & $\mathrm{a}$ \\
\hline & MF & SeCLAR & 127 & 0,029528 & $\mathrm{~b}$ & SeCLAR & 127 & 0,038781 & $\mathrm{~b}$ \\
\hline Quantum & & Tradicional & 127 & 0,047244 & $\mathrm{a}$ & Tradicional & 127 & 0,120079 & $\mathrm{a}$ \\
\hline Physics & $P \& U$ & SeCLAR & 127 & 0,034121 & $\mathrm{a}$ & SeCLAR & 127 & 0,031905 & $\mathrm{~b}$ \\
\hline & DUE & SeCLAR & 101 & 0,250112 & $\mathrm{a}$ & SeCLAR & 101 & 0,940594 & $\mathrm{a}$ \\
\hline & RLUN1 & Tradicional & 101 & 0,238101 & $\mathrm{a}$ & Tradicional & 101 & 0,894389 & $\mathrm{~b}$ \\
\hline & $M F$ & "SeCLAR & $\overline{120}$ & $\overline{00,031725}$ & $\bar{a}$ & SeCLAR & 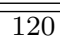 & 0,246605 & $\bar{a}$ \\
\hline & $\mathrm{MF}$ & Tradicional & 121 & 0,025543 & $\mathrm{a}$ & Tradicional & 121 & 0,160167 & $\mathrm{~b}$ \\
\hline iff-wn 01 & $\mathrm{P} \& \mathrm{U}$ & SeCLAR & 120 & 0,030750 & $a$ & SeCLAR & 120 & 0,238272 & $\mathrm{a}$ \\
\hline $1 \mathrm{fm}$-wpul & $P \& U$ & Tradicional & 121 & 0,024073 & $\mathrm{a}$ & Tradicional & 121 & 0,160167 & $\mathrm{~b}$ \\
\hline & PIUUM & Tradicional & 104 & 0,101952 & $\mathrm{a}$ & Tradicional & 104 & 1,000000 & $\mathrm{a}$ \\
\hline & RLUM & SeCLAR & 104 & 0,098684 & $\mathrm{~b}$ & SeCLAR & 104 & 1,000000 & $\mathrm{a}$ \\
\hline & $M F$ & $\overline{\text { SeCLAR }}$ & 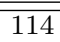 & 0,065789 & $\overline{\mathrm{a}}$ & 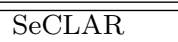 & 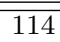 & 0,054052 & $\overline{\mathrm{a}}$ \\
\hline & $\mathrm{MF}^{\prime}$ & Tradicional & 114 & 0,041667 & $\mathrm{a}$ & Tradicional & 114 & 0,035587 & $\mathrm{a}$ \\
\hline$\therefore$ & D D & SeCLAR & 114 & 0,061404 & $\mathrm{a}$ & SeCLAR & 114 & 0,040836 & $\mathrm{a}$ \\
\hline ifm-wp02 & $P \& U$ & Tradicional & 114 & 0,049708 & $\mathrm{a}$ & Tradicional & 114 & 0,031201 & $\bar{a}$ \\
\hline & DU UU & SeCLAR & 85 & 0,311134 & $\mathrm{a}$ & SeCLAR & 85 & 0,956863 & $\mathrm{a}$ \\
\hline & RLUM & Tradicional & 85 & 0,291559 & $\mathrm{a}$ & Tradicional & 85 & 0,956863 & $\mathrm{a}$ \\
\hline & (N) & Tradicional & 87 & 0.091954 & $\bar{a}$ & Tradicional & 87 & 0.050181 & $\bar{a}$ \\
\hline & $\mathrm{MF}^{\prime}$ & SeCLAR & 87 & 0.049808 & $\mathrm{a}$ & SeCLAR & 87 & 0.028158 & $\mathrm{a}$ \\
\hline if $\mathrm{m}$ & $\mathrm{P} \ell_{-} \mathrm{U}$ & Tradicional & 87 & 0.091954 & $\mathrm{a}$ & Tradicional & 87 & 0.050181 & $\mathrm{a}$ \\
\hline lfm-wpu4 & $P \& U$ & SeCLAR & 87 & 0.0517224 & $\mathrm{a}$ & SeCLAR & 87 & 0.028158 & $\mathrm{a}$ \\
\hline & BLUM & Tradicional & 70 & 0.340991 & $\mathrm{a}$ & Tradicional & 70 & 1,000000 & $\mathrm{a}$ \\
\hline & & SeCLAR & 70 & 0.335051 & $\mathrm{a}$ & SeCLAR & 70 & 0,886190 & $\mathrm{~b}$ \\
\hline & $M F$ & Tradicional & 135 & 0.0555556 & $\mathrm{a}$ & SeCLAR & 135 & 0.072667 & $\mathrm{a}$ \\
\hline & MF & SeCLAR & 135 & 0.035803 & $\mathrm{a}$ & Tradicional & 135 & 0.034661 & $\mathrm{a}$ \\
\hline Inorganic & $\mathrm{P} \ell_{-} \mathrm{U}$ & Tradicional & 135 & 0.0555556 & $\mathrm{a}$ & SeCLAR & 135 & 0.072667 & $\mathrm{a}$ \\
\hline try & $P \& 0$ & SeCLAR & 135 & 0.035803 & $\mathrm{a}$ & Tradicional & 135 & 0.034661 & $\mathrm{a}$ \\
\hline & BIUUM & SeCLAR & 108 & 0.320566 & $\mathrm{a}$ & Tradicional & 108 & 1.000000 & $\mathrm{a}$ \\
\hline & RLUM & Tradicional & 108 & 0.296239 & $\mathrm{~b}$ & SeCLAR & 108 & 0.983796 & $\mathrm{a}$ \\
\hline & 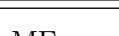 & "Tradicional & 129 & 0,058140 & $\bar{a}$ & SeCLAR & 128 & 0,033344 & $\bar{a}$ \\
\hline & $\mathrm{MF}$ & SeCLAR & 128 & 0,035156 & $\mathrm{a}$ & Tradicional & 129 & 0,030269 & $\mathrm{a}$ \\
\hline Polymer & De & Tradicional & 129 & 0,058140 & $\mathrm{a}$ & Tradicional & 128 & 0,033344 & $\mathrm{a}$ \\
\hline Science & $P \& U$ & SeCLAR & 128 & 0,034505 & $\mathrm{a}$ & SeCLAR & 129 & 0,030269 & $\mathrm{a}$ \\
\hline & Pl $>$ & SeCLAR & 106 & 0,260571 & $\mathrm{a}$ & Tradicional & 106 & 1,000000 & $\mathrm{a}$ \\
\hline & RLUM & Tradicional & 106 & 0,258453 & $\mathrm{a}$ & SeCLAR & 106 & 0,983491 & $\mathrm{a}$ \\
\hline
\end{tabular}

Tabela 4.11: Resultados obtidos do uso combinado do método de seleção de descritores e o SeCLAR com configuração igual para as bases (versão detalhada).

ção realizada pelo SeCLAR, o comportamento dos dois métodos foi idêntico em todos os nós, gerando assim, conjunto de descritores idênticos para os dois casos.

Pode-se perceber que para o método RLUM o SeCLAR contribuiu para o aumento do 


\begin{tabular}{|c||c|c||c|c||c|c|}
\hline \multicolumn{1}{|c||}{} & \multicolumn{2}{c||}{ Most Frequent } & \multicolumn{2}{c||}{ Popescul\&Ungar } & \multicolumn{2}{c|}{ RLUM } \\
\hline Base & prec & rec & prec & rec & prec & rec \\
\hline Computer Hardware & $\Delta$ & $\Delta$ & $\Delta$ & $\Delta$ & $\bullet$ & $\bullet$ \\
\hline A.I. & $\bullet$ & $\bullet$ & $\bullet$ & $\bullet$ & $\bullet$ & $\bullet$ \\
\hline Biophysics & $\bullet$ & $\Delta$ & $\Delta$ & $\Delta$ & $\bullet$ & $\bullet$ \\
\hline ifm-wp02 & $\bullet$ & $\bullet$ & $\Delta$ & $\Delta$ & $\bullet$ & $\bullet$ \\
\hline ifm-wp04 & $\bullet$ & $\Delta$ & $\bullet$ & $\Delta$ & $\bullet$ & $\bullet$ \\
\hline Inorganic Chemistry & $\Delta$ & $\Delta$ & $\Delta$ & $\Delta$ & $\bullet$ & $\bullet$ \\
\hline
\end{tabular}

Tabela 4.12: Resultados obtidos do uso combinado do método de seleção de descritores e o SeCLAR com configuração otimizada para cada bases

\begin{tabular}{cc}
\hline $\boldsymbol{\Delta}$ & O uso do SeCLAR é estatisticamente melhor \\
\hline $\boldsymbol{\nabla}$ & O uso do método tradicional é estatisticamente melhor \\
\hline$\bullet$ & Não há diferença estatística entre os resultados \\
\hline
\end{tabular}

valor de precisão do método como pode ser observado nas linhas referentes ao RLUM na Tabela 4.13 apesar de não ser uma diferença estatisticamente significante. Este método naturalmente obtém ótimos valores para a medida de revocação, quase sempre próximo de 1, e uma melhora nessa medida seria muito difícil, sendo que não foi encontrada diferença estatística para nenhum dos casos desta medida, mas observa-se que o SeCLAR contribuiu para o aumento do valor médio para as medidas (Tabela 4.13).

\subsection{Considerações finais}

Neste capítulo foi apresentado o método SeCLAR, proposto aqui como uma etapa para apoiar o processo de seleção de descritores. A ideia geral do método é explorar as relações existentes nos termos dos documentos utilizando regras de associação, combinando essa análise com a estrutura hierárquica do agrupamento para obter melhores candidatos a descritores.

O método proposto foi avaliado conforme a proposta de Moura e Rezende (2010), e os resultados indicam que o uso de regras de associação para selecionar candidatos a descritores contribui de forma significativa para o processo de seleção de descritores. 


\begin{tabular}{|c|c|c|c|c|c|c|c|c|c|}
\hline Base & & & & & esultad & & & & \\
\hline \multirow{8}{*}{$\begin{array}{l}\text { Computer } \\
\text { Hardware }\end{array}$} & Método & \multicolumn{4}{|c|}{ precisão } & \multicolumn{4}{|c|}{ revocação } \\
\hline & \multirow{3}{*}{ MF } & configuração & $\mathrm{n}$ & $\hat{m}_{e}=$ prec & grupo & configuração & $\mathrm{n}$ & $\hat{m}_{e}=\mathrm{rev}$ & $\begin{array}{l}\text { grupo } \\
\end{array}$ \\
\hline & & SeCLAR & 147 & 0,0889326 & $\mathrm{a}$ & SeCLAR & 147 & 0,171345 & $\mathrm{a}$ \\
\hline & & Tradicional & 148 & 0,037162 & $\mathrm{~b}$ & Tradicional & 148 & 0,025115 & $\mathrm{~b}$ \\
\hline & \multirow{2}{*}{$\mathrm{P} \& \mathrm{U}$} & SeCLAR & 147 & 0,085018 & $\mathrm{a}$ & SeCLAR & 147 & 0,181266 & $\mathrm{a}$ \\
\hline & & Tradicional & 148 & 0,036036 & $\mathrm{~b}$ & Tradicional & 148 & 0,029443 & $\mathrm{~b}$ \\
\hline & \multirow{2}{*}{ RLUM } & SeCLAR & 117 & 0,267990 & $\mathrm{a}$ & SeCLAR & 117 & 1,000000 & $\mathrm{a}$ \\
\hline & & Tradicional & 117 & 0,262530 & $\mathrm{a}$ & Tradicional & 117 & 0,974359 & $\mathrm{a}$ \\
\hline \multirow{6}{*}{ A.I. } & \multirow{2}{*}{$\mathrm{MF}$} & SeCLAR & 122 & 0,032787 & $\mathrm{a}$ & SeCLAR & 122 & 0,044345 & $\mathrm{a}$ \\
\hline & & Tradicional & 122 & 0,030738 & $\mathrm{a}$ & Tradicional & 122 & 0,043092 & $\mathrm{a}$ \\
\hline & \multirow{2}{*}{$\mathrm{P} \& \mathrm{U}$} & SeCLAR & 122 & 0,032787 & $\mathrm{a}$ & SeCLAR & 122 & 0,044345 & $\mathrm{a}$ \\
\hline & & Tradicional & 122 & 0,0330738 & $\mathrm{a}$ & Tradicional & 122 & 0,043092 & $\mathrm{a}$ \\
\hline & \multirow{2}{*}{ RLUM } & Tradicional & 98 & 0,322250 & $\mathrm{a}$ & SeCLAR & 98 & 1,000000 & $\mathrm{a}$ \\
\hline & & SeCLAR & 98 & 0,314963 & $\mathrm{a}$ & Tradicional & 98 & 0,981293 & $\mathrm{a}$ \\
\hline \multirow{6}{*}{ Biophysics } & \multirow{2}{*}{$\mathrm{MF}$} & SeCLAR & 108 & 0,092196 & $\mathrm{a}$ & SeCLAR & 108 & 0,178858 & $\mathrm{a}$ \\
\hline & & Tradicional & 109 & 0,045872 & $\mathrm{a}$ & Tradicional & 109 & 0,031265 & $\mathrm{~b}$ \\
\hline & \multirow{2}{*}{$\mathrm{P} \& \mathrm{U}$} & SeCLAR & 108 & 0,092196 & $\mathrm{a}$ & SeCLAR & 108 & 0,178858 & $\mathrm{a}$ \\
\hline & & Tradicional & 109 & 0,045872 & $\mathrm{~b}$ & Tradicional & 109 & 0,031164 & $\mathrm{~b}$ \\
\hline & \multirow{2}{*}{ RLUM } & SeCLAR & 82 & 0,255062 & $\mathrm{a}$ & SeCLAR & 82 & 1,000000 & $\mathrm{a}$ \\
\hline & & Tradicional & 82 & 0,233793 & $\mathrm{a}$ & Tradicional & 82 & 0,971545 & $\mathrm{a}$ \\
\hline \multirow{6}{*}{ ifm-wp02 } & \multirow{2}{*}{$\mathrm{MF}$} & SeCLAR & 125 & 0,100000 & $\mathrm{a}$ & SeCLAR & 125 & 0,036404 & $\mathrm{a}$ \\
\hline & & Tradicional & 125 & 0,096000 & $\mathrm{a}$ & Tradicional & 125 & 0,032404 & $\mathrm{a}$ \\
\hline & \multirow{2}{*}{$\mathrm{P} \& \mathrm{U}$} & SeCLAR & 92 & 0,184912 & $\mathrm{a}$ & SeCLAR & 92 & 0,451141 & $\mathrm{a}$ \\
\hline & & Tradicional & 93 & 0,064516 & $\mathrm{~b}$ & Tradicional & 93 & 0,038526 & $\mathrm{~b}$ \\
\hline & \multirow{2}{*}{ RLUM } & SeCLAR & 73 & 0,283447 & $\mathrm{a}$ & SeCLAR & 73 & 1,000000 & $\mathrm{a}$ \\
\hline & & Tradicional & 73 & 0,262310 & $\mathrm{a}$ & Tradicional & 73 & 0,956621 & $\mathrm{a}$ \\
\hline \multirow{6}{*}{ ifm-wp04 } & \multirow{2}{*}{$\mathrm{MF}$} & Tradicional & 83 & 0.090361 & $\mathrm{a}$ & SeCLAR & 83 & 0.121600 & $\mathrm{a}$ \\
\hline & & SeCLAR & 83 & 0.062249 & $\mathrm{a}$ & Tradicional & 83 & 0.051299 & $\mathrm{~b}$ \\
\hline & \multirow{2}{*}{$P \& U$} & Tradicional & 83 & 0.090361 & $\mathrm{a}$ & SeCLAR & 83 & 0.121600 & $\mathrm{a}$ \\
\hline & & SeCLAR & 83 & 0.062249 & $\mathrm{a}$ & Tradicional & 83 & 0.051299 & $\mathrm{~b}$ \\
\hline & \multirow{2}{*}{ RLUM } & SeCLAR & 66 & 0.341360 & $\mathrm{a}$ & Tradicional & 66 & 1,000000 & $\mathrm{a}$ \\
\hline & & Tradicional & 66 & 0.322601 & $\mathrm{a}$ & SeCLAR & 66 & 1,000000 & $\mathrm{a}$ \\
\hline \multirow{6}{*}{$\begin{array}{l}\text { Inorganic } \\
\text { Chemis- } \\
\text { try }\end{array}$} & \multirow{2}{*}{$\mathrm{MF}$} & SeCLAR & 118 & 0.133660 & $\mathrm{a}$ & SeCLAR & 118 & 0.326762 & $\mathrm{a}$ \\
\hline & & Tradicional & 119 & 0.046218 & $\mathrm{~b}$ & Tradicional & 119 & 0.033771 & $\mathrm{~b}$ \\
\hline & \multirow{2}{*}{$\mathrm{P} \& \mathrm{U}$} & SeCLAR & 118 & 0.133660 & $\mathrm{a}$ & SeCLAR & 118 & 0.326762 & $\mathrm{a}$ \\
\hline & & Tradicional & 119 & 0.046218 & $\mathrm{~b}$ & Tradicional & 119 & 0.033771 & $\mathrm{~b}$ \\
\hline & BI II & SeCLAR & 94 & 0.285809 & $\mathrm{a}$ & Tradicional & 94 & 1.000000 & $\mathrm{a}$ \\
\hline & KLUM & Tradicional & 94 & 0.277041 & $\mathrm{a}$ & SeCLAR & 94 & 0.960993 & $\mathrm{a}$ \\
\hline
\end{tabular}

Tabela 4.13: Resultados obtidos do uso combinado do método de seleção de descritores e o SeCLAR com configuração otimizada para cada bases (versão detalhada). 



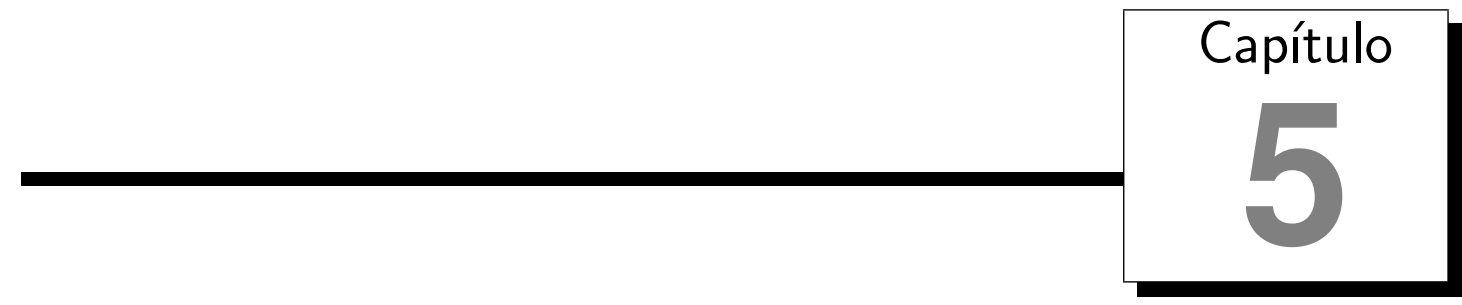

\section{Conclusões}

Neste trabalho foi proposto um método para apoiar a seleção de candidatos a descritores de agrupamentos hierárquicos. O método SeCLAR explora mais explicitamente os relacionamentos diretos existentes na organização hierárquica, observando cada relação do tipo pai-filho de forma similar àquela relação existente no caso das regras de associação. Além disso, ele também explora relações diretas existentes entre os termos dos documentos, uma vez que ele não considera cada documento como uma bag-of-words. Nesta proposta, o SeCLAR pode ser utilizado independentemente do método de seleção de descritores que de fato será escolhido, adicionando características interessantes sem que seja necessário rever a implementação deste último.

Os resultados obtidos pelo uso do SeCLAR indicam que seu uso contribuiu significativamente na seleção de descritores. Em particular, o SeCLAR contribui para a melhora da medida de precisão em muitos casos, sem reduzir a cobertura do método (medida pela revocação). A partir destes resultados, pode-se dizer que o uso de regras de associação para selecionar candidatos a descritores pode contribuir com a melhora dos resultados.

Outro resultado importante é que a medida Laplace parece ser adequada ao problema como proposto aqui. Apesar de sua simplicidade, a medida obteve os melhores resultados para todos os casos avaliados. Também foi possível detectar que o aumento na quantidade de regras de associação selecionadas não contribui para a melhoria dos resultados.

A avaliação do método proposto indica que não é necessário conhecer os melhores valores para cada parâmetro para obter bons resultados. Os valores indicados neste trabalho parecem ser suficientes para uma análise exploratória inicial. Entretanto, métodos mais refinados como o RLUM podem exigir um refinamento maior para obter de fato alguma vantagem em relação às medidas avaliadas.

O método SeCLAR também pode ser utilizado como método de seleção de descritores independente, e seus resultados se aproximam dos obtidos pela sua combinação com o método Mais Frequentes.

Como principais contribuições pode-se destacar: 
- Desenvolvimento de um método para selecionar candidatos a descritores utilizando regras de associação.

- Proposta alternativa para obtenção de transações a partir de coleções de documentos.

Como resultado deste mestrado, foram publicados dois artigos (Santos et al., 2010; Santos e Rezende, 2010). Como resultado indireto, houve a participação no trabalho de Moura et al. (2008) com contribuições em trabalhos relacionados ao problema aqui tratado.

Visando complementar o trabalho relatado nesta dissertação e trazer novas contribuições para a seleção de descritores, como trabalhos futuros pretende-se expandir a avaliação para outras medidas objetivas de regras de associação e avaliar, com apoio de especialistas do domínio, o impacto do SeCLAR para a seleção de descritores de agrupamentos hierárquicos. Também espera-se, como trabalhos futuros, explorar o impacto do uso do método SeCLAR juntamente com o RLUM para a construção de descritores comparando com os outros métodos da literatura. 


\section{Referências Bibliográficas}

Agrawal, R., Imielinski, T., e Swami, A. N. (1993). Mining association rules between sets of items in large databases. Em Buneman, P. e Jajodia, S., editores, Proceedings of the 1993 ACM SIGMOD International Conference on Management of Data, páginas 207-216, Washington, D.C. Citado nas páginas 5, 10, 13, e 14.

Agrawal, R. e Srikant, R. (1994). Fast algorithms for mining association rules in large databases. Em VLDB '94: Proceedings of the 20th International Conference on Very Large Data Bases, páginas 487-499, San Francisco, CA, USA. Morgan Kaufmann Publishers Inc. Citado nas páginas xvii, 9, 11, 13, 14, 15, 16, e 36.

Bast, H., Dupret, G., Majumdar, D., e Piwowarski, B. (2005). Discovering a term taxonomy from term similarities using principal component analysis. Em Ackermann, M., Berendt, B., Grobelnik, M., Hotho, A., Mladenic, D., Semeraro, G., Spiliopoulou, M., Stumme, G., Svátek, V., e van Someren, M., editores, EWMF/KDO, volume 4289 of Lecture Notes in Computer Science, páginas 103-120. Springer. Citado na página 39.

Berkhin, P. (2006). A survey of clustering data mining techniques. Em Kogan, J., Nicholas, C., e Teboulle, M., editores, Grouping Multidimensional Data, capítulo 2, páginas 2571. Springer-Verlag, Berlin, Heidelberg. Citado na página 21.

Brin, S., Motwani, R., Ullman, J. D., e Tsur, S. (1997). Dynamic itemset counting and implication rules for market basket data. Em SIGMOD '97: Proceedings of the 1997 ACM SIGMOD international conference on Management of data, páginas 255-264, New York, NY, USA. ACM. Citado nas páginas 12 e 14.

Carmel, D., Roitman, H., e Zwerdling, N. (2009). Enhancing cluster labeling using wikipedia. Em SIGIR '09: Proceedings of the 32nd international ACM SIGIR conference on Research and development in information retrieval, páginas 139-146, New York, NY, USA. ACM. Citado nas páginas 2, 28, 31, e 32.

Carvalho, V. O. (2007). Generalização de regras de associação utilizando conhecimento de domínio e avaliação do conhecimento generalizado. Doutorado em ciências da computação e matemática computacional, USP - São Carlos, São Carlos, SP, Brasil. Citado na página 12. 
Chuang, S.-L. e Chien, L.-F. (2005). Taxonomy generation for text segments: A practical web-based approach. ACM Trans. Inf. Syst., 23(4):363-396. Citado na página 28.

Conrado, M. S. (2009). O efeito do uso de diferentes formas de extração de termos na compreensibilidade e representatividade dos termos em coleções textuais na língua portuguesa. Mestrado em ciências da computação e matemática computacional, USP São Carlos, São Carlos, SP, Brasil. Citado nas páginas 6 e 8.

Cutting, D. R., Karger, D. R., Pedersen, J. O., e Tukey, J. W. (1992). Scatter/gather: a cluster-based approach to browsing large document collections. Em SIGIR '92: Proceedings of the 15th annual international ACM SIGIR conference on Research and development in information retrieval, páginas 318-329, New York, NY, USA. ACM. Citado nas páginas 2, 28, 29, e 32 .

Domingues, M. A. (2004). Generalização de regras de associação. Mestrado em ciências da computação e matemática computacional, USP - São Carlos, São Carlos, SP, Brasil. Citado na página 16.

Ebecken, N. F. F., Lopes, M. C. S., e de Aragão Costa, M. C. (2003). Mineração de textos. Em Rezende, S. O., editor, Sistemas Inteligentes: Fundamentos e Aplicações, capítulo 13, páginas 337-370. Manole, 1 edição. Citado na página 8.

Everitt, B. S., Landau, S., e Leese, M. (2001). Cluster Analysis. Arnold Publishers. Citado nas páginas 19 e 21.

Feldman, R. e Sanger, J. (2007). The Text Mining Handbook: Advanced Approaches in Analyzing Unstructured Data. Cambridge University Press. Citado nas páginas 5, 6, e 27.

Gantz, J. F. e Reinsel, D. (2009). As the economy contracts, the digital universe expands. External Publication of IDC (Analyse the Future) Information and Data, páginas 1-10. Citado na página 1.

Gantz, J. F., Reinsel, D., Chute, C., Schlichting, W., McArthur, J., Minton, S., Xheneti, I., Toncheva, A., e Manfrediz, A. (2007). The expanding digital universe. Relatório técnico, IDC. Disponível em: http://www.emc.com/leadership/digital-universe/expandingdigital-universe.htm. [15/07/2008]. Citado na página 1.

Gantz, J. F., Reinsel, D., Chute, C., Schlichting, W., Minton, S., Toncheva, A., e Manfrediz, A. (2008). The diverse and exploding digital universe. Relatório técnico, IDC. Disponível em: http://www.emc.com/leadership/digital-universe/expandingdigital-universe.htm. [15/07/2008]. Citado na página 1.

Glover, E. J., Pennock, D. M., Lawrence, S., e Krovetz, R. (2002). Inferring hierarchical descriptions. Em CIKM, páginas 507-514. ACM. Citado nas páginas 2, 28, 30, e 32.

Han, J., Cheng, H., Xin, D., e Yan, X. (2007). Frequent pattern mining: current status and future directions. Data Min. Knowl. Discov., 15(1):55-86. Citado na página 5. 
Han, J. e Kamber, M. (2001). Data mining concepts and techniques. San Diego, CA: Academic. Citado na página 1.

Hipp, J., Güntzer, U., e Nakhaeizadeh, G. (2002). data mining of association rules and the process of knowledge discovery in databases. Em Advances in Data Mining, páginas 15-36. Citado nas páginas 5 e 10.

Hofmann, T. (1999). The cluster-abstraction model: Unsupervised learning of topic hierarchies from text data. Em IJCAI, páginas 682-687. Citado nas páginas 29 e 32.

Houtsma, M. A. W. e Swami, A. N. (1995). Set-oriented mining for association rules in relational databases. Em ICDE '95: Proceedings of the Eleventh International Conference on Data Engineering, páginas 25-33, Washington, DC, USA. IEEE Computer Society. Citado na página 14.

Jain, A. K., Murty, M. N., e Flynn, P. J. (1999). Data clustering: a review. ACM Computing Surveys, 31(3):264-323. Citado na página 21.

Kantardzic, M. (2003). Data Mining: Concepts, Models, Methods, and Algorithms. John Wiley \& Sons, Piscataway, NJ, EUA. Citado na página 9.

Kashyap, V., Ramakrishnan, C., Thomas, C., e Sheth, A. (2005). Taxaminer: an experimentation framework for automated taxonomy bootstrapping. International Journal of Web and Grid Services, 1(2):240-266. Citado nas páginas 30 e 32.

Larsen, B. e Aone, C. (1999). Fast and effective text mining using linear-time document clustering. Em KDD '99: Proceedings of the fifth ACM SIGKDD international conference on Knowledge discovery and data mining, páginas 16-22, New York, NY, USA. ACM. Citado nas páginas 2, 28, 29, e 32.

Liu, G., Chang, E., e Han, S. (2005). Powerful tool to expand business intelligence: Text mining. World Academy of Science, Engineering and Technology, 8:334-337. Citado na página 5.

Lopes, A. A., Pinho, R., Paulovich, F. V., e Minghim, R. (2007). Visual text mining using association rules. Computers $\mathscr{6}$ Graphics, 31(3):316-326. Citado nas páginas 2, 31, 32, e 33 .

Mahgoub, H., Rösner, D., Ismail, N., e Torkey, F. (2008). A text mining technique using association rules extraction. International Journal of Computational Intelligence, páginas 21-28. Citado na página 31.

Manning, C. D., Raghavan, P., e Schütze, H. (2008). Introduction to Information Retrieval. Cambridge University Press, 1 edição. Citado nas páginas 19, 22, 23, 27, e 28.

Manning, C. D. e Schütze, H. (1999). Foundations of Statistical Natural Language Processing. MIT Press. Citado na página 8. 
Marcacini, R. M., Moura, M. F., e Rezende, S. O. (2007). Biblioteca digital do ifm: uma aplicação para a organização da informação por meio de agrupamentos hierárquicos. Em WDL'0\%: Proceeding of the Workshop on Digital Libraries, volume CD-ROM of WDL, páginas 1-16. Citado na página 5.

Martins, C. A. (2003). Uma abordagem para pré-processamento de dados textuais em algoritmos de aprendizado. Tese de Doutorado em Ciências da Computação e Matemática Computacional, Instituto de Ciências Matemáticas e de Computação - USP - São Carlos. Citado na página 8.

Melanda, E. A. (2004). Pós-processamento de Regras de Associação. Doutorado em ciências da computação e matemática computacional, USP - São Carlos, São Carlos, SP, Brasil. Citado na página 12.

Metz, J. (2006). Interpretação de clusters gerados por algoritmos de clustering hierárquico. Mestrado em ciências da computação e matemática computacional, USP - São Carlos, São Carlos, SP, Brasil. Citado nas páginas xiii, 24, e 25.

Miiller, A. e Dorre, J. (1999). The taxgen framework: Automating the generation of a taxonomy for a large document collection. Em HICSS '99: Proceedings of the ThirtySecond Annual Hawaii International Conference on System Sciences-Volume 2, página 2034, Washington, DC, USA. IEEE Computer Society. Citado na página 28.

Mitchell, T. M. (1997). Machine Learning. McGraw-Hill Science/Engineering/Math. Citado na página 9.

Monard, M. C. e Baranauskas, J. A. (2003). Conceitos sobre aprendizado de máquina. Em Rezende, S. O., editor, Sistemas Inteligentes: Fundamentos e Aplicações, capítulo 4, páginas 89-114. Manole, 1 edição. Citado na página 9.

Moura, M. F. (2009). Contribuições para a construção de taxonomias de tópicos em domínios restritos utilizando aprendizado estatístico. Citado nas páginas 7, 29, 33, 43, e 45 .

Moura, M. F., Nogueira, B. M., Conrado, M. S., dos Santos, F. F., e Rezende, S. O. (2008). Making good choices of non-redundant n-gram words. Em Library, I. X. D., editor, DMAI '08: Proceedings of I International Workshop on Data Mining and Artificial Intelligence - ICCIT '08: XI IEEE International Conference on Computer and Information Technology, páginas 64-71. Citado na página 54.

Moura, M. F. e Rezende, S. O. (2010). A simple method for labeling hierarchical document clusters. Em Proceedings of AIA 2010 - Artificial Intelligence and Applications, Innsbruck, Austria. Citado nas páginas 2, 27, 28, 31, 32, 39, 40, 41, 48, e 50.

Nogueira, B. M., da Silva Conrado, M., e Rezende, S. O. (2008). Avaliação de métodos não-supervisionados de seleção de atributos para mineração de. Em WTI '08 : Proceedings of I Workshop on Web and Text Intelligence - SBIA '08: XIX Simpósio Brasileiro de Inteligência Artificial, páginas 59-66. Citado na página 9. 
Park, J. S., syan Chen, M., e Yu, P. S. (1997). Using a hash-based method with transaction trimming for mining association rules. IEEE Transactions on Knowledge and Data Engineering, 9:813-825. Citado na página 14.

Pei, J., Han, J., e Mao, R. (2000). Closet: An efficient algorithm for mining frequent closed itemsets. Em ACM SIGMOD Workshop on Research Issues in Data Mining and Knowledge Discovery, páginas 21-30. Citado na página 14.

Ping-ping, M. e Qiu-ping, Z. (2002). Association rules applied to intrusion detection. Wuhan University Journal of Natural Sciences, 7(4):426-430. Citado na página 10.

Popescul, A. e Ungar, L. (2000). Automatic labeling of document clusters, unpublished manuscript. http://www.cis.upenn.edu/ popescul/Publications/popescul00labeling.pdf. Citado nas páginas 2, 28, 29, 30, 31, e 32 .

Porter, M. F. (1997). An algorithm for suffix stripping. Readings in Information Retrieval, páginas 313-316. Citado na página 41.

Rahmoun, A. e Elberrichi, Z. (2007). Experimenting n-grams in text categorization. The International Arab Journal of Information Technology, 4(4):377-385. Citado na página 8.

Rezende, S. O., Pugliesi, J. B., Melanda, E. A., e Paula, M. F. (2003). Mineração de dados. Em Rezende, S. O., editor, Sistemas Inteligentes: Fundamentos e Aplicações, capítulo 12, páginas 307-335. Manole, 1 edição. Citado nas páginas xiii, 6, e 7.

Salton, G. (1989). Automatic text processing: the transformation, analysis, and retrieval of information by computer. Addison-Wesley Longman Publishing Co., Inc., Boston, MA, USA. Citado nas páginas 7 e 9.

Salton, G. e Buckley, C. (1987). Term weighting approaches in automatic text retrieval. Relatório técnico, Ithaca, NY, USA. Citado na página 41.

Santos, F. F., de Carvalho, V. O., e Rezende, S. O. (2010). Selecting candidate labels for hierarchical document clusters using association rules. Em Springer-Verlag, editor, MICAI '10: Proceedings of 9th Mexican International Conference on Artificial Intelligence. Citado na página 54.

Santos, F. F. e Rezende, S. O. (2010). Selecionando candidatos a descritores para agrupamentos hierárquicos de documentos utilizando regras de associação. Em WTDIA '10: $V$ Workshop on MSc Dissertation and PhD Thesis in Artificial Intelligence. Citado na página 54 .

Searle, S. R. (1971). Linear models. J. Wiley, New York, NY. Citado na página 41.

Snedecor, G. W. e Cochran, W. G. (1967). Statistical methods, 6th ed. Iowa State University Press, Ames, IO. Citado na página 41. 
Souza, M. I. F., Santos, A. D., Moura, M. F., e Alves, M. D. R. (2006). Agência de informação embrapa: uma aplicação para a organização da informação e gestão do conhecimento. Em WDL'06: Proceeding of the Workshop de Bibliotecas Digitais, páginas 51-56, Florianópolis, SC. Sociedade Brasileira de Computação. Citado na página 5.

Steinbach, M., Karypis, G., e Kumar, V. (2000). A comparison of document clustering techniques. Em KDD workshop on text mining, volume 400, páginas 525-526. Citeseer. Citado nas páginas 22 e 24.

Tan, P.-N., Steinbach, M., e Kumar, V. (2005). Introduction to Data Mining. AddisonWesley. Citado na página 20.

Treeratpituk, P. e Callan, J. (2006). Automatically labeling hierarchical clusters. Em $d g . o$ '06: Proceedings of the 2006 international conference on Digital government research, páginas 167-176, New York, NY, USA. ACM. Citado nas páginas 2, 27, 28, 30, e 32.

Tseng, Y.-H. (2010). Generic title labeling for clustered documents. Expert Syst. Appl., 37(3):2247-2254. Citado nas páginas 2, 28, 31, e 32.

Webb, G. I. (1995). Opus: An efficient admissible algorithm for unordered search. Journal of Artificial Intelligence Research, páginas 431-465. Citado na página 14.

Weiss, S. M., Indurkhya, N., Zhang, T., e Damerau, F. J. (2005). Text Mining - Predictive Methods for Analizing Unstructured Information. Springer Science+Business Media, Inc. Citado na página 5 .

WordNet (2009). Wordnet: a lexical database for the english language. Citado na página 31.

Wu, X., Kumar, V., Ross Quinlan, J., Ghosh, J., Yang, Q., Motoda, H., McLachlan, G. J., Ng, A., Liu, B., Yu, P. S., Zhou, Z.-H., Steinbach, M., Hand, D. J., e Steinberg, D. (2007). Top 10 algorithms in data mining. Knowl. Inf. Syst., 14(1):1-37. Citado na página 21.

$\mathrm{Xu}$, R. e Wunsch, D. (2008). Clustering (IEEE Press Series on Computational Intelligence). Wiley-IEEE Press, illustrated edition edição. Citado na página 22.

Yang, Y. e Pedersen, J. O. (1997). A comparative study on feature selection in text categorization. Em Proceedings of the Fourteenth International Conference on Machine Learning (ICML 1997), páginas 412-420. Citado na página 9.

Zaki, m. e Hsio, c. (2002). CHARM: An Efficient Algorithm for Closed Itemset Mining. Em Proceedings of the 2nd SIAM International Conference on Data mining. Citado na página 14.

Zhang, C., Wang, H., Liu, Y., e Xu, H. (2009). Document clustering description extraction and its application. Em ICCPOL '09: Proceedings of the 22nd International Conference on Computer Processing of Oriental Languages. Language Technology for 
the Knowledge-based Economy, páginas 370-377, Berlin, Heidelberg. Springer-Verlag. Citado nas páginas 2 e 28.

Zhang, C. e Zhang, S. (2002). Association Rule Mining: Models and Algorithms, volume 2307 of Lecture Notes in Artificial Intelligence. Springer-Verlag New York, Inc. Citado nas páginas 11 e 14 .

Zhang, X. e Zhu, X. (2007). A new type of feature - loose n-gram feature in text categorization. Em IbPRIA'0\%: Proceeding of the Iberian Conference on Pattern Recognition and Image Analysis, páginas 378-385. Springer. Citado na página 8.

Zhao, Y., Karypis, G., e Fayyad, U. (2005). Hierarchical clustering algorithms for document datasets. Data Mining and Knowledge Discovery, 10(2):141-168. Citado nas páginas 21,23 , e 24 . 